Journal of Educational

and Psychological Sciences

Volume (5), Issue (50): 30 Dec 2021

P: 69 - 98

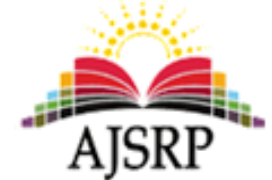

ISSN: 2522-3399
مجلة العلوم

التربوية والنفسية

المجلد (5)، العدد (50): 30 ديسمبر 2021 م

ص: 69 - 98

\title{
The views of students of the upper basic stage in public schools about distance learning via educational platforms during the Corona pandemic through: A case study based on graphics analysis
}

\author{
Fatima Mustafa Alimat \\ Ministry of Education || Jordan
}

\begin{abstract}
: this research aimed at studying the views of students of the upper basic stage in public schools about distance learning via educational platforms during the Corona pandemic through a case study based on graphics analysis. One of the qualitative research methods was used, which is the case study, the case study in this research was based on the analysis of graphics, and the research sample consisted of 8 students ( 7 females and one male) studying in the eighth, ninth and tenth grades from 3 public schools that include the upper basic stage in Mafraq Governorate. The research tools also included a case study through drawing to reveal the mental methods of individuals against facts and events, and the research reached three main conclusions. First: that students in the eighth, ninth, and tenth grades of upper basic schools rely to a large extent on laptops to use educational platforms during the Corona pandemic. Second: The method of educational platforms in presenting information does not answer the inquiries of some students, so it does not replace face-to-face learning. Third: The graphics showed that the frequent use of these technologies by the student and the teacher led to health problems for them, such as visual fatigue. Accordingly, the researcher made recommendations to those in charge of educational platforms represented in the need to simplify and facilitate the scientific concepts presented on educational platforms using interesting methods such as puppet theater and cartoon films that present the subject in a simplified manner, and the need to integrate face-to-face and distance education, and recommendations for school administrations represented by targeted awareness campaigns For parents to reduce their behaviors that led their children to neglect and dependence on parents during the distance learning period, and recommendations to parents about the need to instill a sense of security in the hearts of their children, and increase the care and love provided to them, especially in this critical age stage (adolescence), and the presence of an individual with patience and positivity In the family and has a close relationship with the student, he helps him review the book's information after attending lessons on educational platforms and other knowledge channels.
\end{abstract} Keywords: distance learning; educational platforms; Corona pandemic; graphics analysis; face-to-face learning; Blended learning.
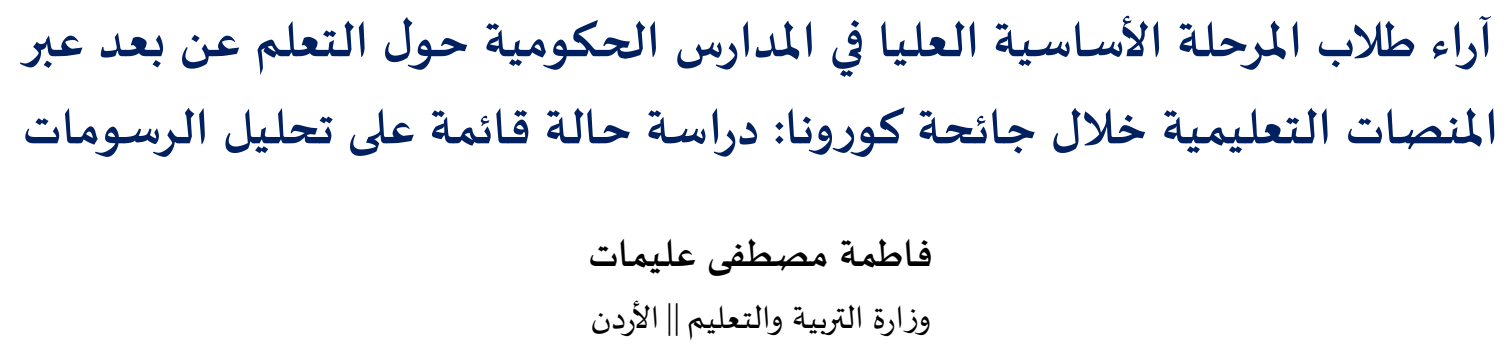
المستخلص: هدف البحث الحالي إلى دراسة آراء طلاب المرحلة الأساسية العليا في المدارس الحكومية حول التعلم عن بعد عبات المنائهات

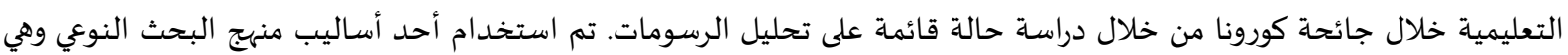

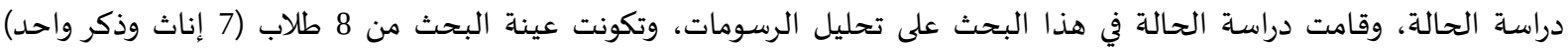

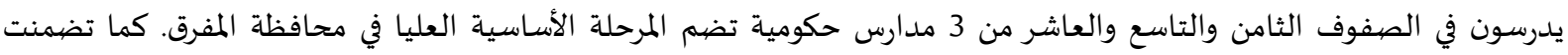

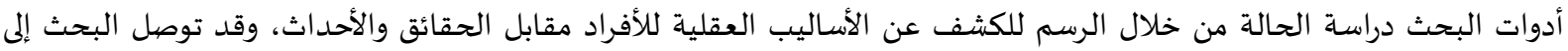

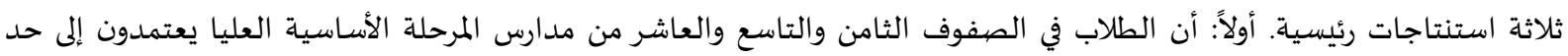

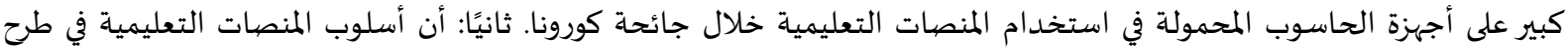

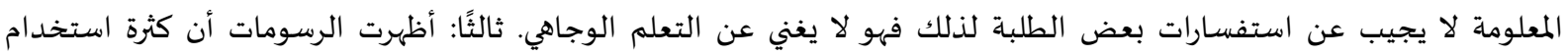

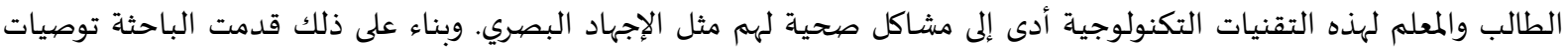

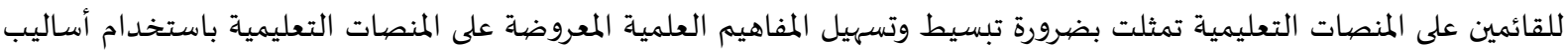

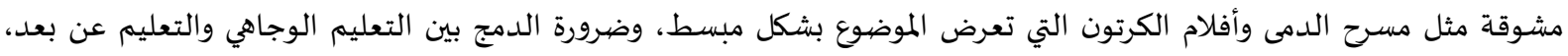

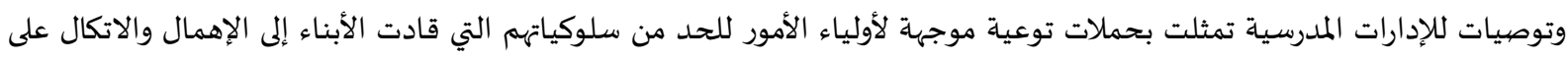

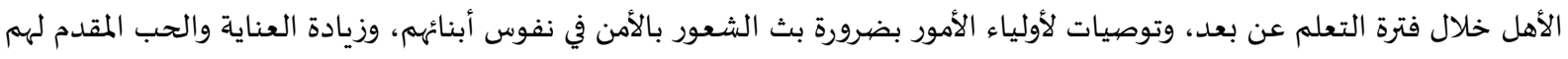

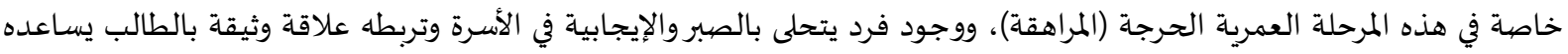
في مراجعة معلومات الكتاب بعد حضور الدروس على المنصات التعليمية وقنوات المعرفة الأخرى. الكلمات المفتاحية: التعلم عن بعد؛ المنصات التعليمية؛ جائحة كورونا؛ تحليل الرسومات؛ التعلم الوجاهي؛ التعلم المدمج.

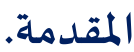

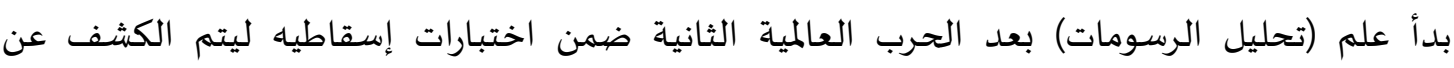

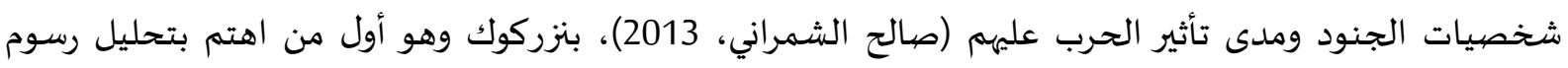

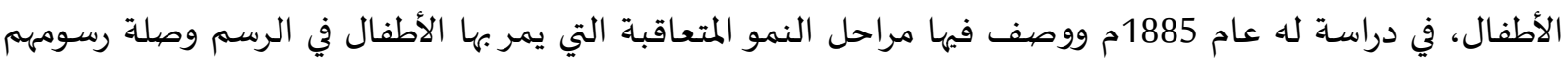

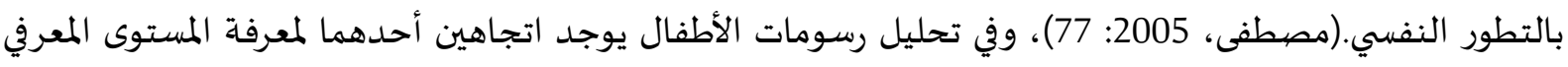

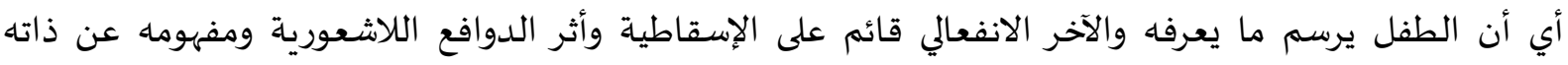

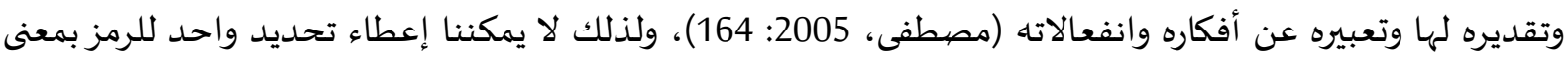

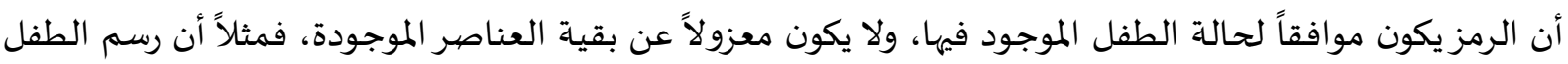

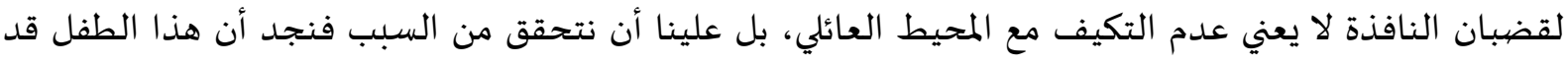

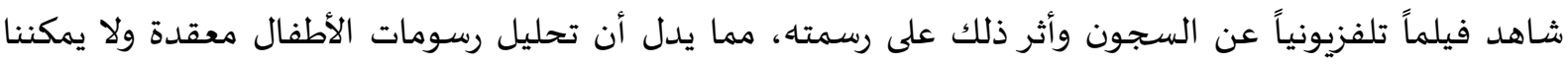

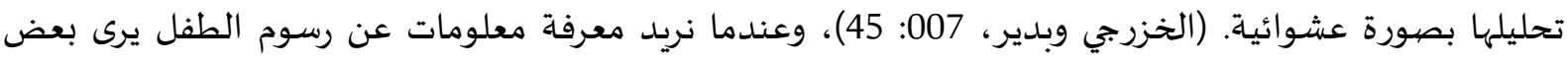

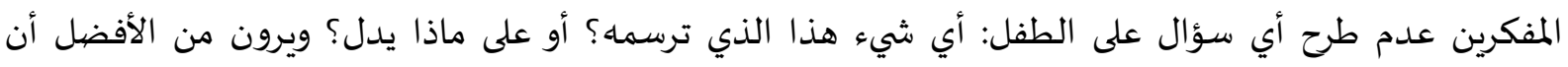

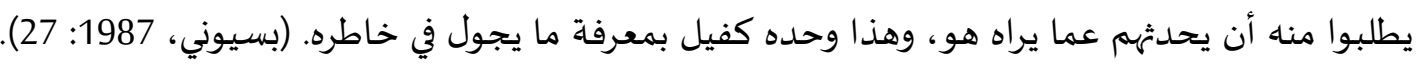

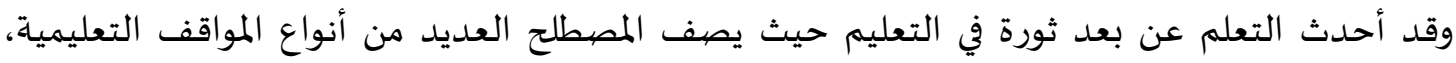

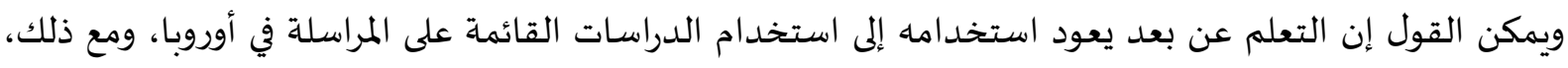

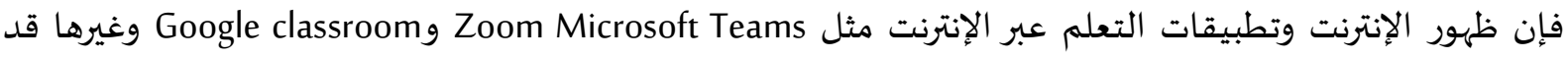
أحدث ثورة في بروتوكولات التعلم عن بعد في التدريس عبر الإنترنت باستخدام الإنترنت. أدت جائحة

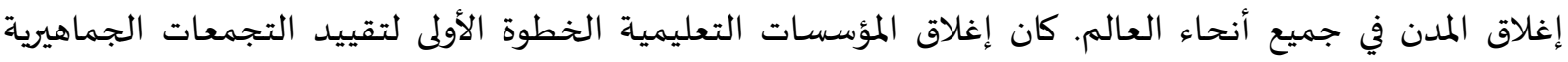

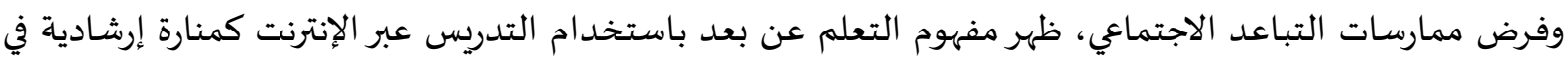
هذا الموقف المضطرب. (Qazi et al., 2021). 
تم تطوير أساليب ومهارات للتعلم والتدريس لحث المتعلم على اكتساب المعلومات؛ بتوفير المواد التعليمية

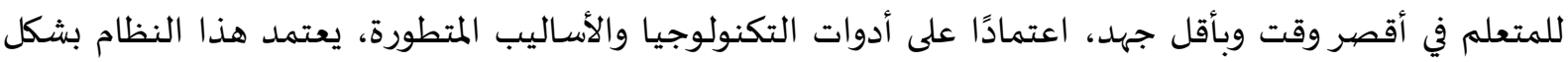

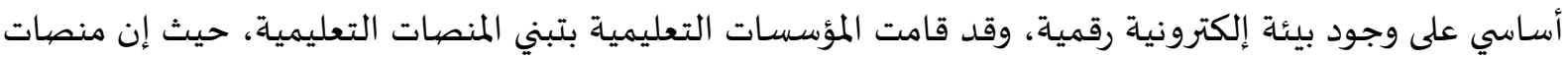

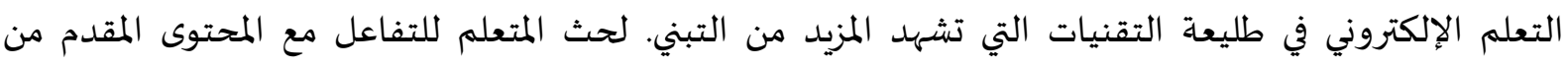

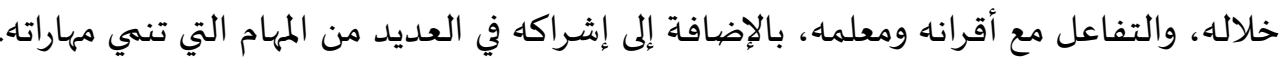

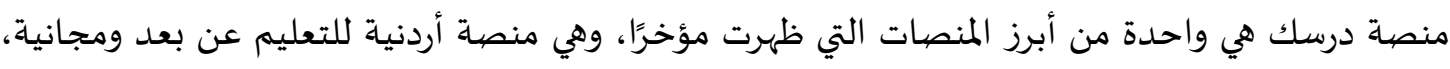

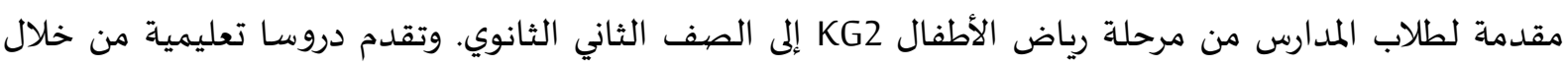
مقاطع فيديو مرتبة حسب منهج التعليم الأردني، يقدمها معلمون ومعلمات ليسهل على الطاضلاب مواصلة معلة تعلمههم

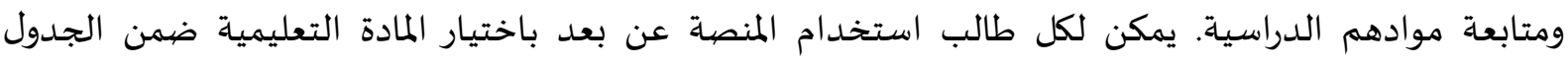

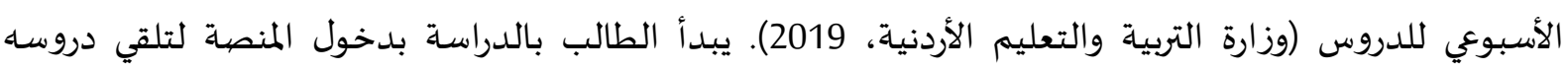

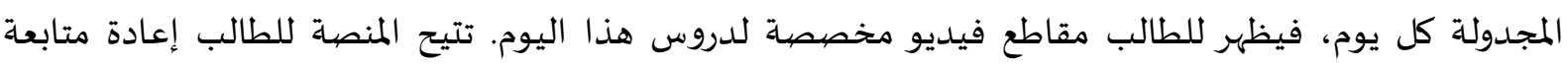

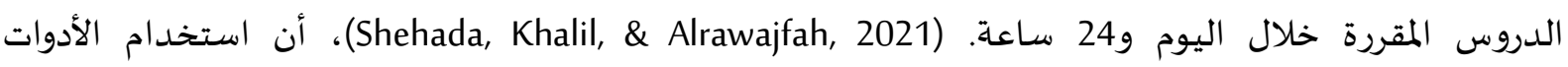

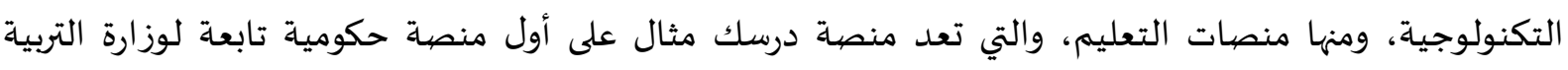

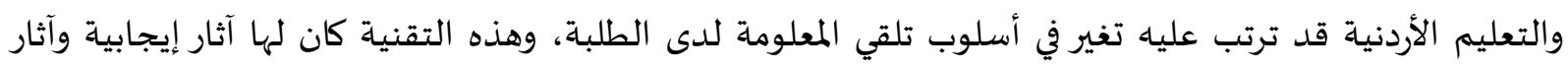
سلبية على الطلبة. وتوجد مكونات التعلم الإلكتروني في العديد من منصات التعلم الرقمية المتاحة اليوم وتقوم على الماتى

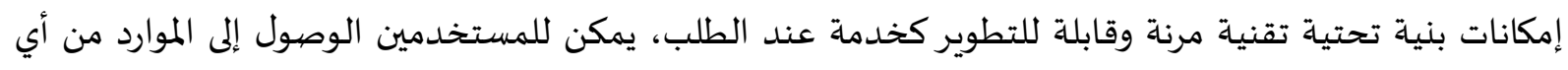

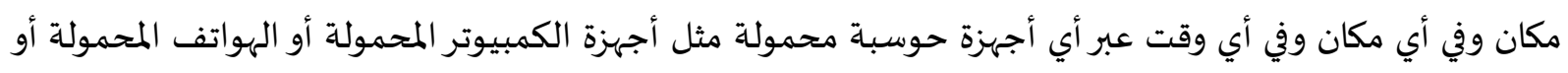

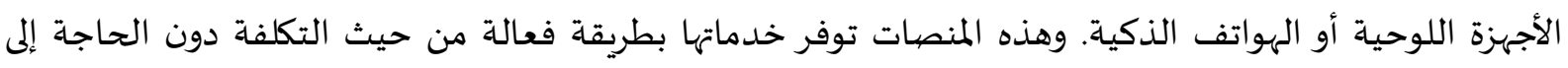

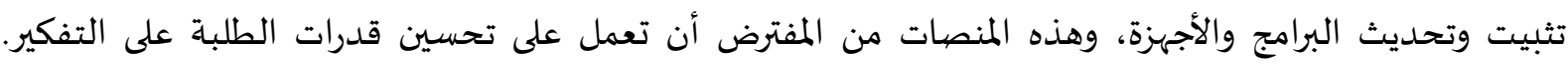

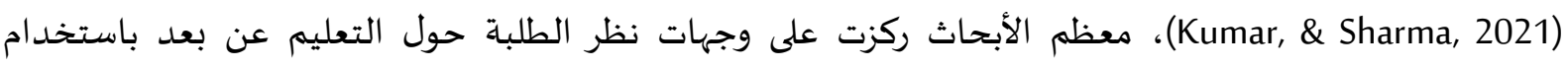

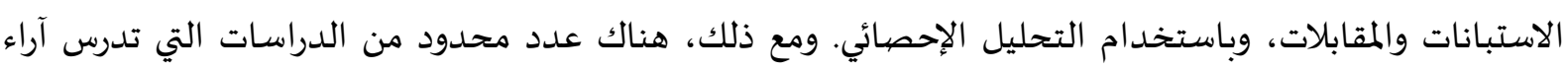

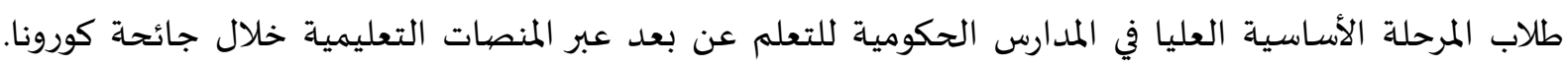

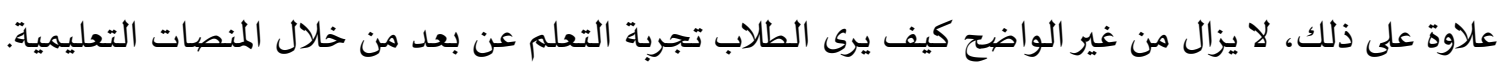

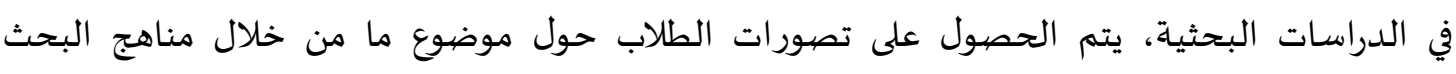

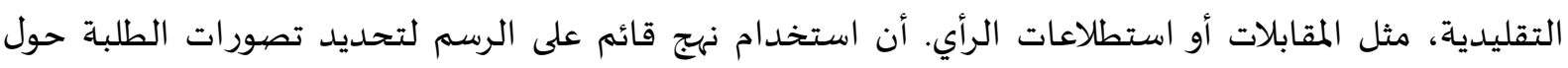

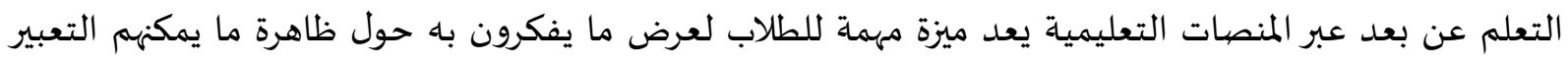

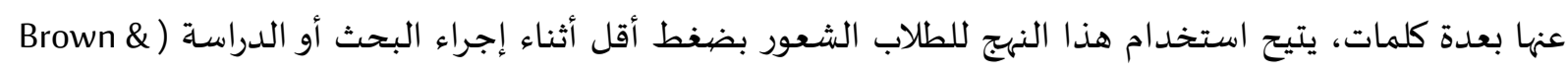

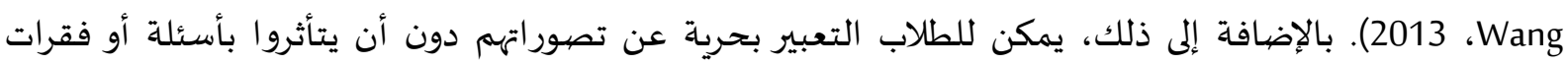

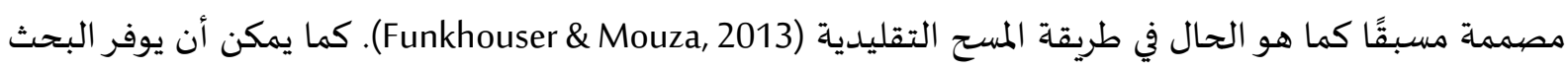
القائم على الرسم ميزة كبيرة من حيث فحص تصهور الطلاب للتعليم عن بعد عبر المنصات التعليمية، أن تحليل

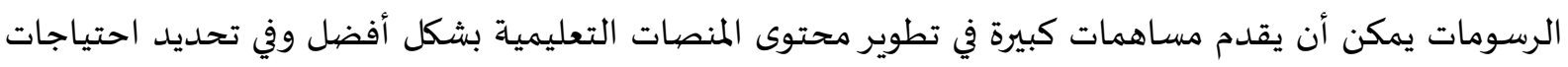

التعلم للطلاب. (ilhan, Kaba, \& Sin, 2021). 
مشكلة الدراسة:

تتمثل مشكلة البحث في استكشاف آراء ووجهات نظر طلبة المرحلة الأساسية العليا في تجربة التعلم عن بعد من خلال المنصات التعليمية خلال جائحة كورونا، من خلال تحليل دلالات رسوماتهم عن هذا الموضوع.

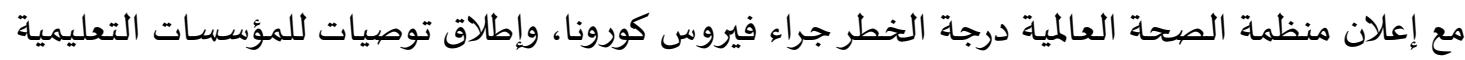

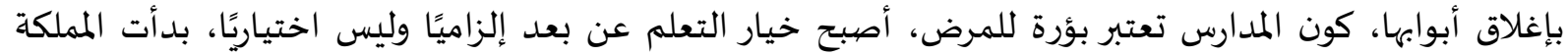

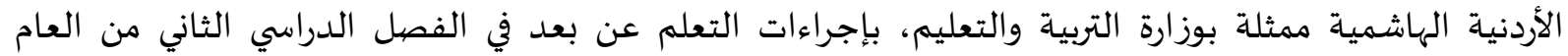
الدراسي 2019 / 2020، عن طريق إطلاق قناتين تلفزيونيتين وهما (درسك1، درسك2) الأول لطلبة المرحلة الأساسية والثانية لطلبة المرحلة الثانوية، يقوم فيها عدد من المعلمين والمعلمات بتخصصيات متنوعة، بشرح الدروس على التلفاز، وكانت منصة نور سبيس التي كانت موجودة من قبل تستخدم لإرسال واستقبال الواجبات، وإنشاء

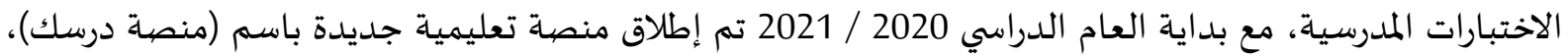
حيث يتم بث الدروس عليها مع إمكانية إعادتها متى أراد الطالب ذلك، ويمكن من خلالها أيضًا إرسال واستقبال

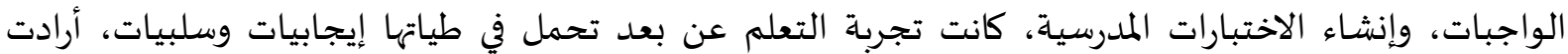

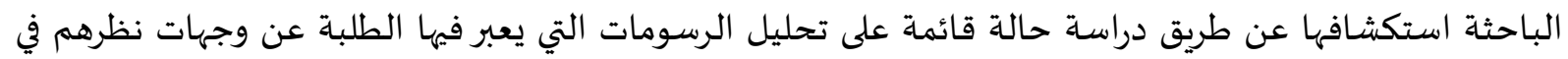
عملية التعلم عن بعد من خلال المنصات التعليمية.

أسئلة الدراسـة:

ولذلك يمكن تحديد مشكلة البحث في سؤال الدراسة الرئيس الآتي: ما وجهات النظر المتعددة التي ظهرت

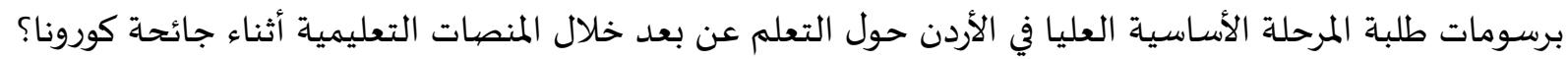
ويمكن صياغة أسئلة الدراسة الحالية على النحو التالي: 1- ما الظواهر العامة التي ظهرت مصاحبة للتعلم عن بعد من خلال المنصات التعليمية والتي ظهرت في في التهولئ

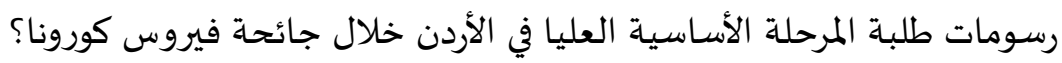

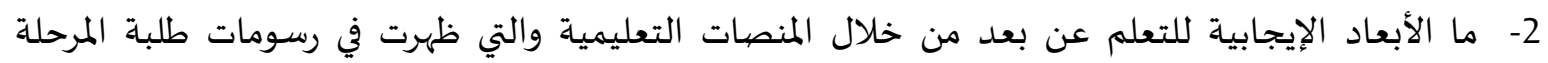

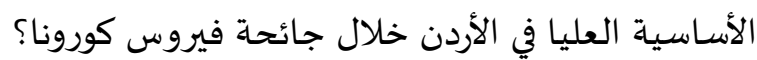

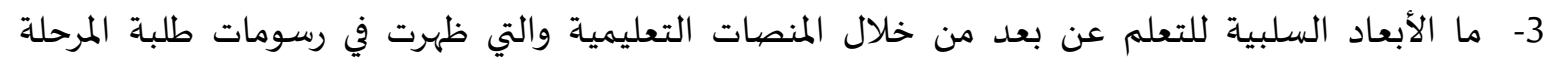

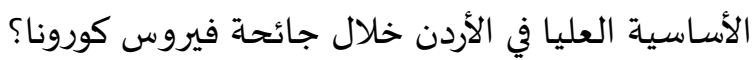

أهداف الدراسة: تهدف الدّراسة الحالية إلى استكشاف آراء طلاب المرحلة الأساسية العليا في المدارس الحكومية حول التعلم

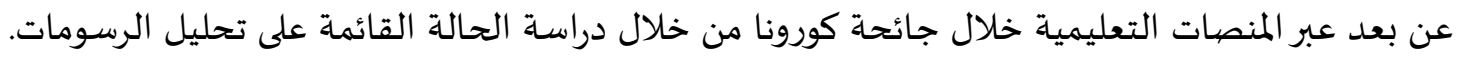

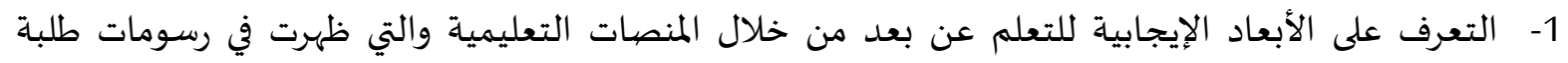
المرحلة الأساسية العليا في الأردن خلال جائحة الإبها لانعلم فيروس كورونا.

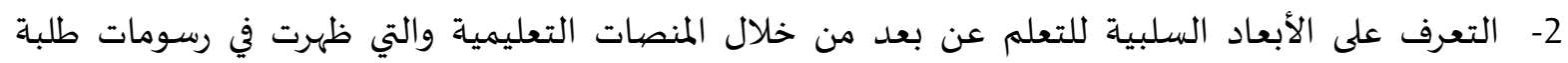

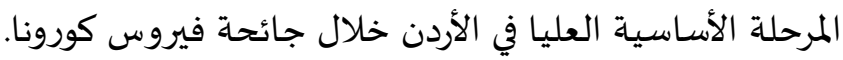
3- الكشف عن وجهات النظر المتعددة التي ظهرت مصاحبة للتعلم عن بعد من خلال المنصات الماتهات التعليمية خلال جائحة كورونا في رسومات طلبة المرحلة الأساسية العليا في الأردن. 
أهمية الدّراسة ومبرراتها:

تكتسب هذه الدّراسة أهميتها من أهمية الموضوع الذي تطرحه للدّراسة، وهو التعلم عن بعد من خلال

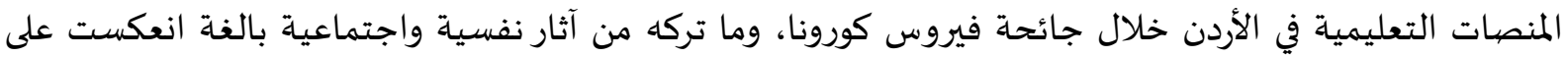
كافة جوانب حياة الطلبة بشكل عام واسرهم بشكل خاص، وذلك من خلال التعرف على تحليل رسومات الطئل الطلبة الذين تلقوا التعليم عن بعد من خلال المنصات الالكترونية خلال الجائحة، وبحسب علم الباحث تعتبر هذه الدراسة الأولى في الأردن التي تتناول هذا الموضيوع وهذه المتغيرات، ويمكن توضيح أهمية الدراسة من خلال مالمات يأتي:

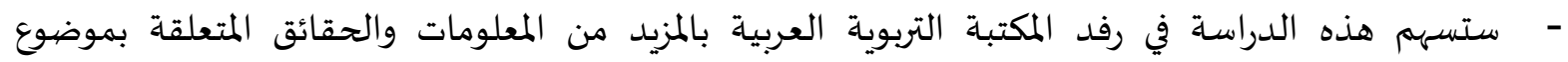

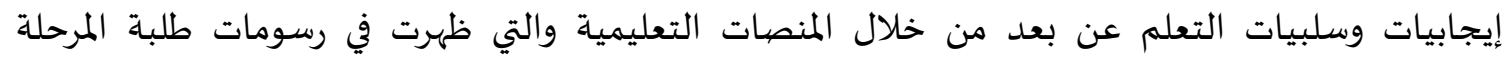
الأساسية العليا في الأردن خلال جائحة فيروس كورونات - يُنتظر من الدراسة الحالية إضافة علمية جديدة، حيث لا توجد دراسة مباشرة في - حلدود علم الباحث- التي

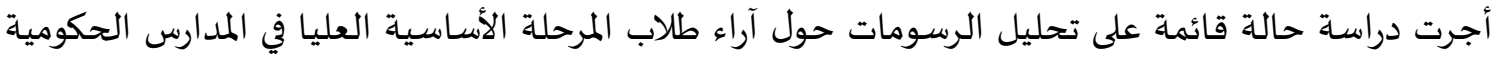
حول التعلم عن بعد عبر المنصات التعليمية خلال جائحة كورونا.

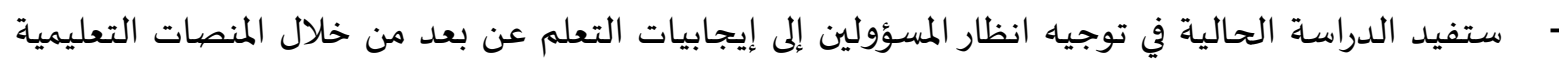
واعتبارها نقاط قوة، وسلبيات التعلم عن بعد واعتبارها نقاط ضعف وعمل اللازم لإيجاد حلول لهذه السلبيات لتحسين تجربة التعلم عن بعد من خلال المنصات التعليمية. - ستفيد نتائج الدراسة المهتمين بمجال تصميم البرمجيات التعليمية في التعرف إلى اهتمامات الطلبة وتلبيتها لجذب انتباههم إلى المحتوى التعليمي.

حدود الدراسة:

سيقوم الباحث بإجراء هذه الدّراسة ضمن حدود متنوعة وهي:

الحدود الموضوعية: آراء طلاب حول التعلم عن بعد عبر المنصاء المدات التعليمية خلال جائحة كورونا

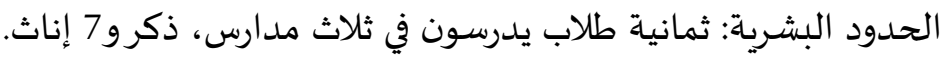

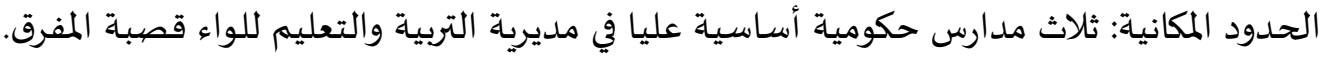
الحدود الزمانية: تشمل عملية جمع البيانات الفصل الدراسي الثاني من العام الدراسي 2020 / 2021 البيانات تم الحصول عليها على أساس طريقة الرسم. تقنية تمثيل الأشياء والأحداث والأفكار.

\section{مصطلحات الدراسة:}

- التعلم عن بعد: "تعريف التعلم عن بعد اصطلاحيًا: هو عمليّة الفصل بين المتعلّم والمعلّم في بيئة التعليم، ونقل

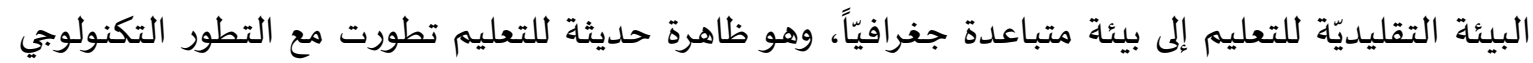

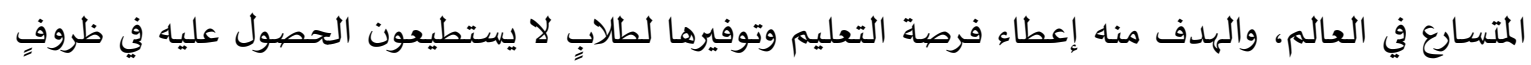

$$
\text { تقليدية ودوامٍ شباه يومي". (عوضها \& سارة، 2021) }
$$

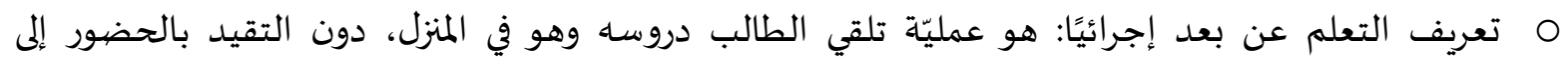
المدرسة، عن طريق المنصات التعليمية التي أطلقتها وزارة التربية والتعليم وأهمها (منصية درسك) تلكيك. 
- المنصات التعليمية: "بيئة تعليمية تفاعلية توظف تقنية الويب وتجمع بين مميزات أنظمة إدارة المحتوى

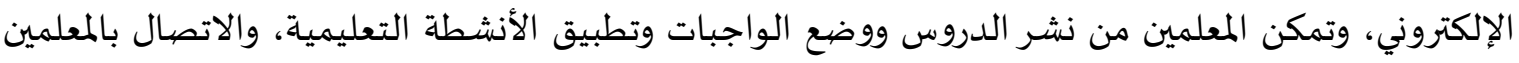

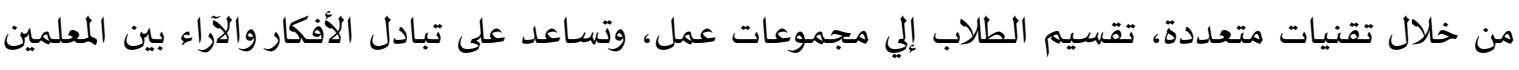

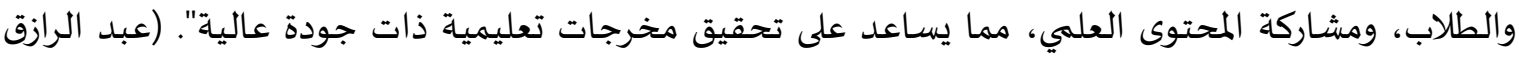

( \& عزام، 2021).

O ت تعريف المنصات التعليمية إجرائيًا: هي مواقع تعليمية مزودة بقواعد بيانات تحتوي على معلومات مستخدميها

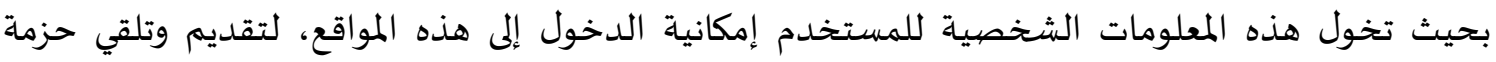
خدمات تعليمية تناسب وظيفة المستخدم (مدير، معلم، طالب). تحليل الرسومات: يعرف تحليل الرسومات اصطلاحيًا بأنه: "مفتاح فهم انعكاس شخصية الطية الطفل في اعتدالها وانحرافها على الرسومات، وفي حالاتها الشعورية واللاشعورية، والكشف عن أغوسية أغوارها". (القريطي، 2001)

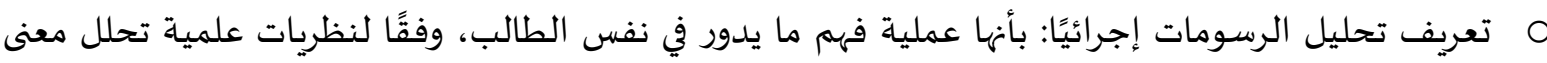

$$
\text { اللون والفراغ وعناصر الصورة. }
$$

2. الإطار النظري والدراسـات السابقة.

\section{التعلم عن بعد باستخدام المنصيات التعليمية}

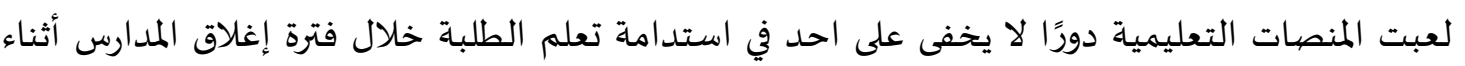

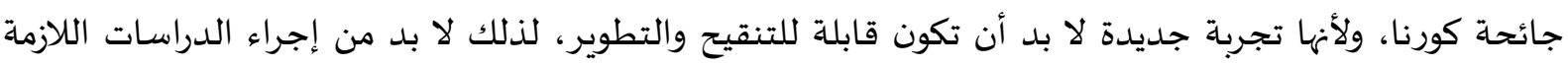

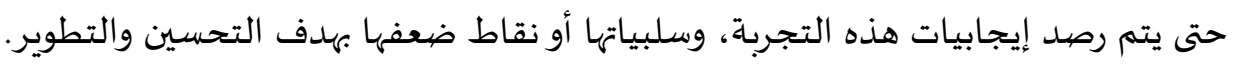

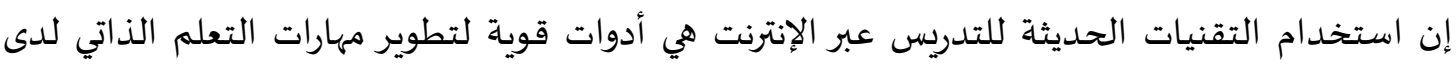

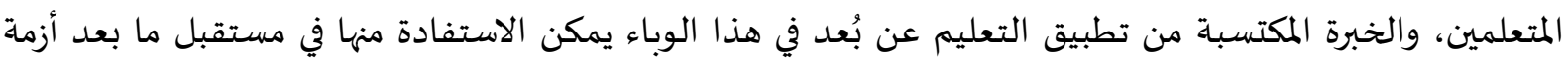

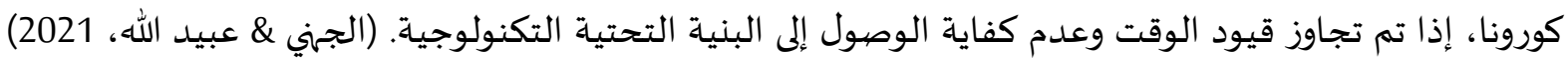

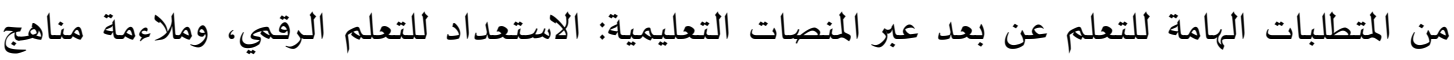

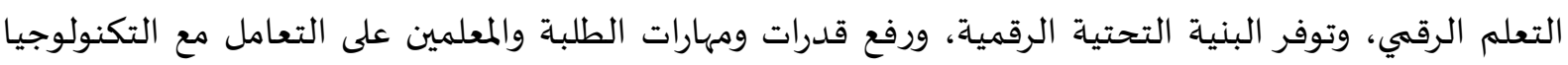

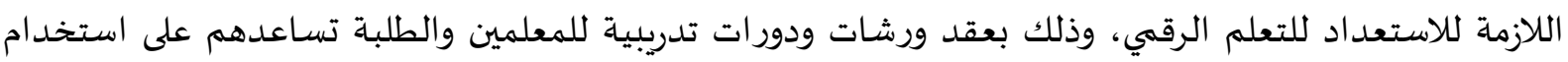

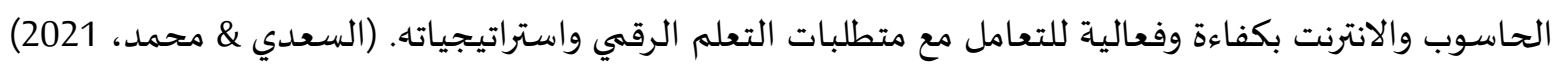

الدراسـات السابقة: - n قام الباحث بالاطلاع على الدراسـات المتعلقة بموضوع الدراسة ومتغيراته، بشكل مباشر أو غير مباشر، وذلك

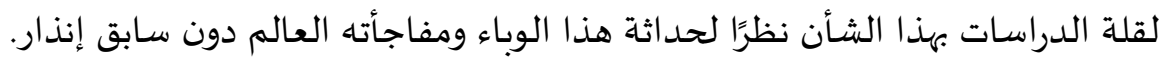
ومن هذه الدراسـات:

- دراسة Alabdulkarim, et al. , بعنوان: رسومات أطفال ما قبل المدرسة: انعكاس لاحتياجات الأطفال

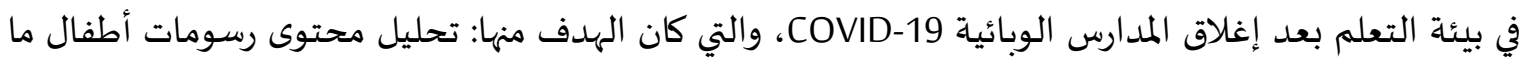
قبل المدرسة عندما يفكرون في جوانب بيئتهم في مرحلة ما قبل المدرسة التي فاتههم أكثر من غيرها أثناء إنهاء إغلاق المداق

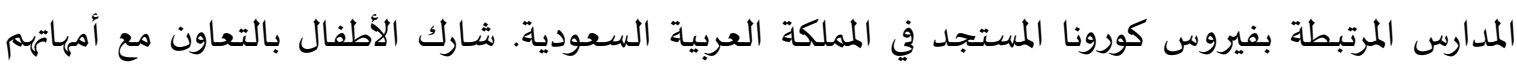
اللواتي أخرجن وجمعن رسوماتهن. تكونت عينة البحث من 41 طفلاً تتراوح أعمارهم بين 3-7 سنوات. وكشفيطت 


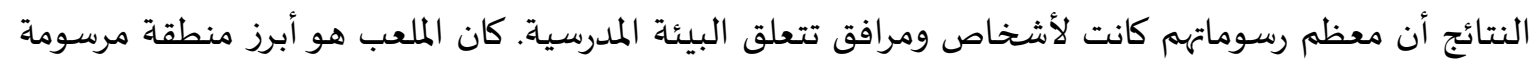

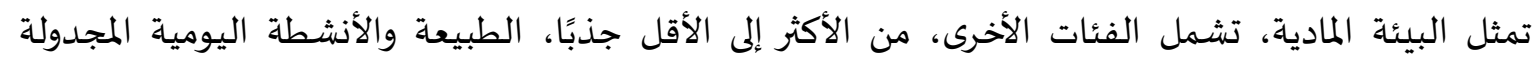

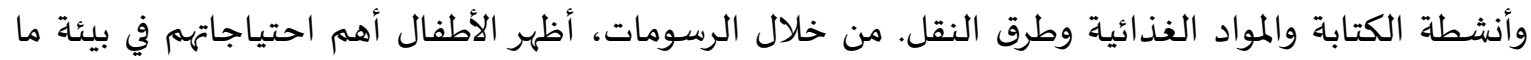

قبل المدرسة، مما يوفر بعض الأفكار حول ما يجب على المعلمين التخطيط لله عند عودة الأطفال إلى المدرسة.

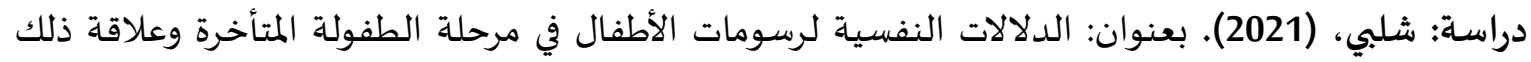
بالمُناخ الأسري والتوافق النفس واجتماعي لديهم في محافظة جنين، والتي كان الهيدف منها: التعرّف إلى لئل

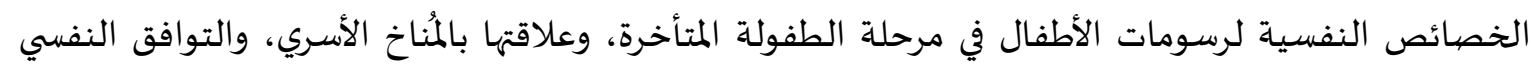

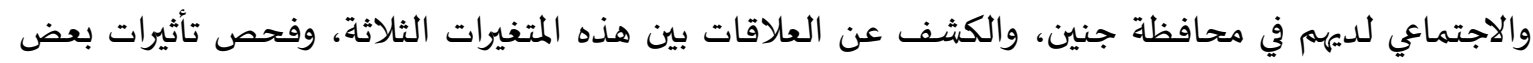

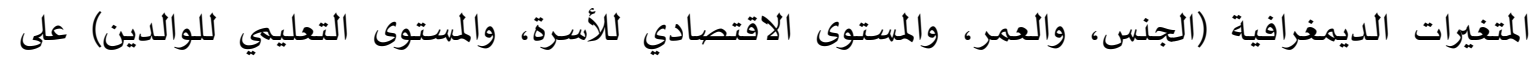

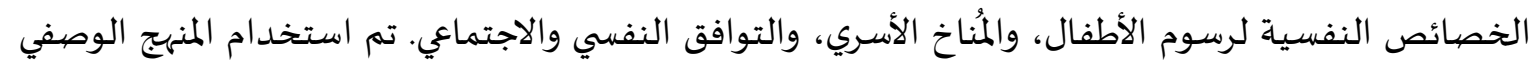

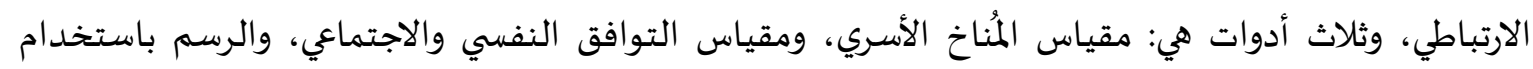

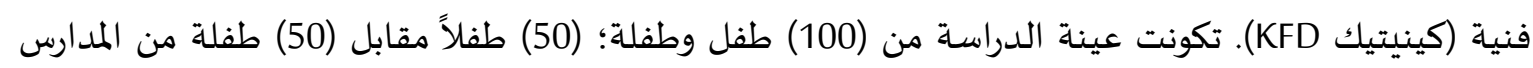

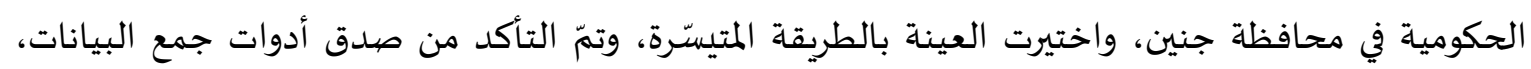

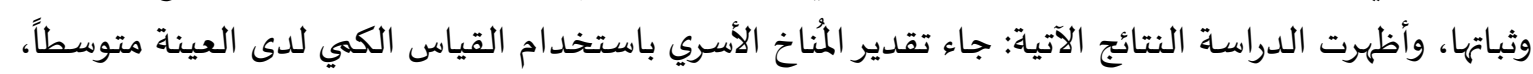

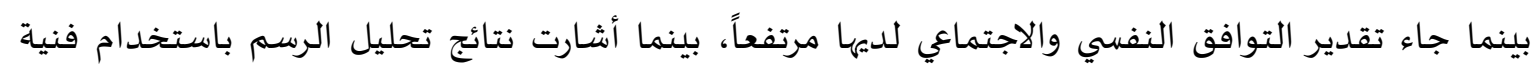

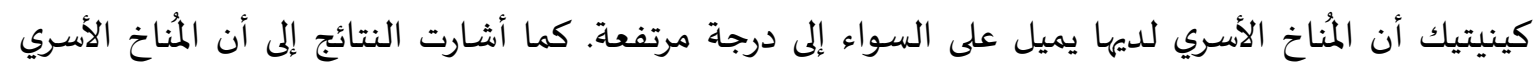

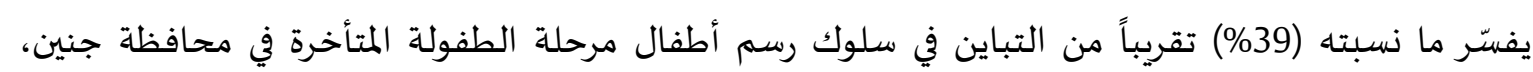

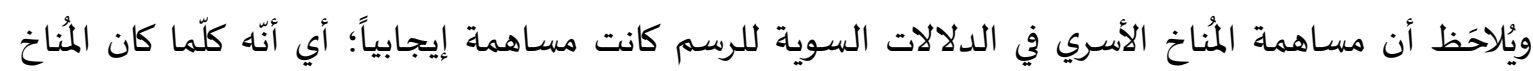

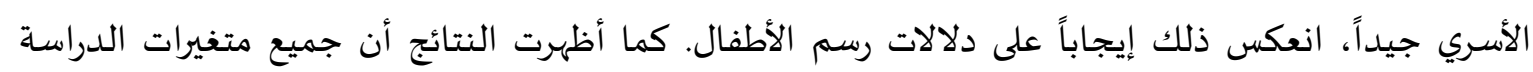

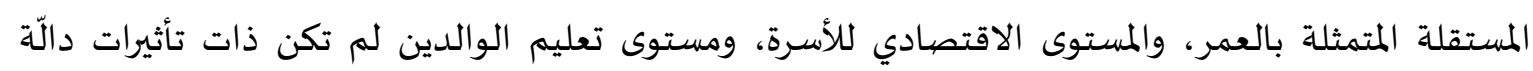

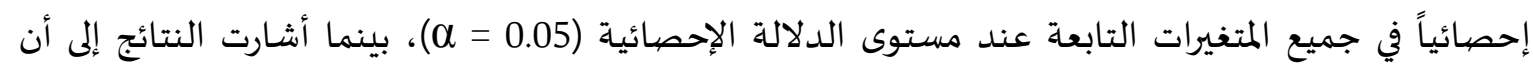

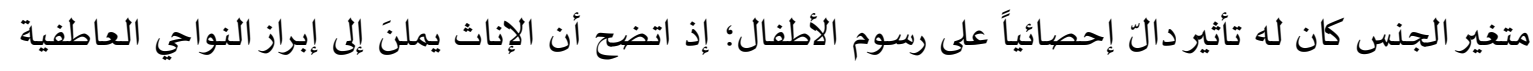

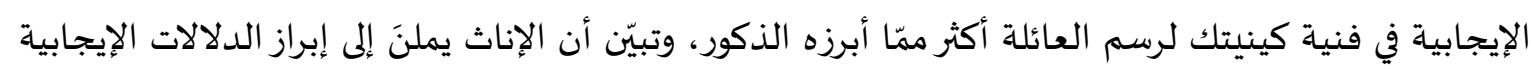
في اختبار فنية كينيتيك أكثر ممّا فعله الذكور. دراسة (2020) Inaltekin, بعنوان: فحص تصورات طلاب المرحلة الثانوية للتعلم المعتمد على التكنولوجيا والتدريس في مقررات العلوم، والذي كان يهدف إلى: دراسة تصورات التعلم القائم على التكنولوجيا والتدريس

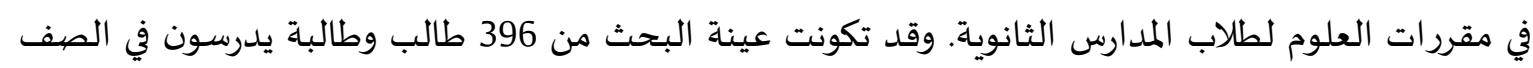
الثامن من سبع مدارس ثانوية في مركز كارس بتركيا. تم استخدام تصميم دراسة الحالة. كأداة لجمع البيانات،

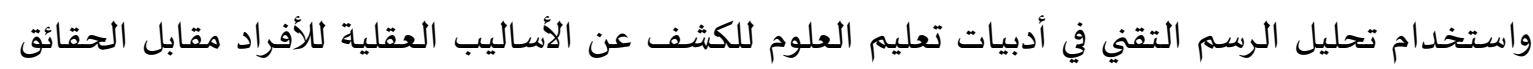

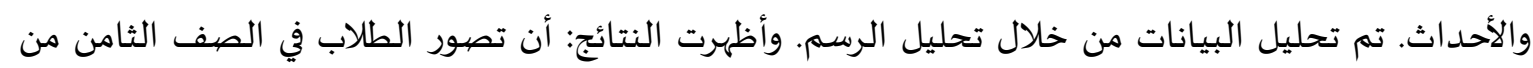

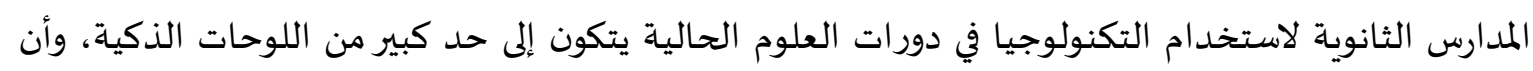

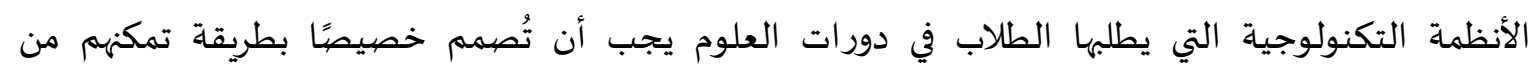

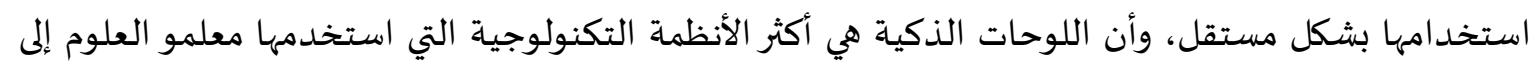

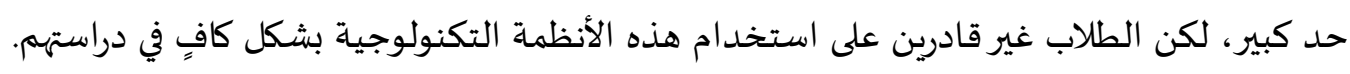


في دراسة (2020) Kuzle, \& Gracin, بعنوان: تحليل مشاعر الطلبة حول تعلم الهندسة من خلال عدسة

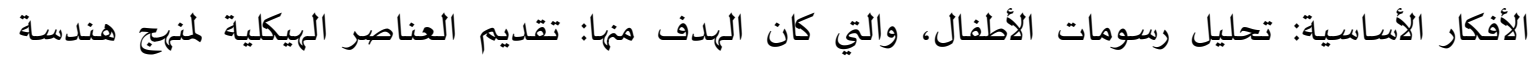

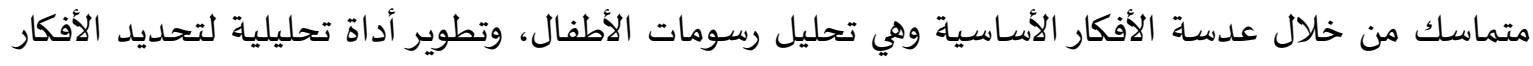

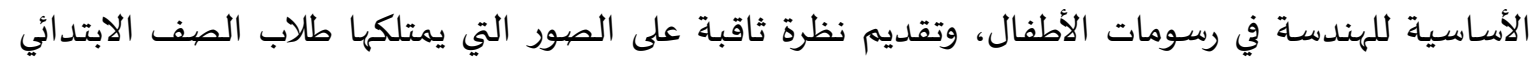

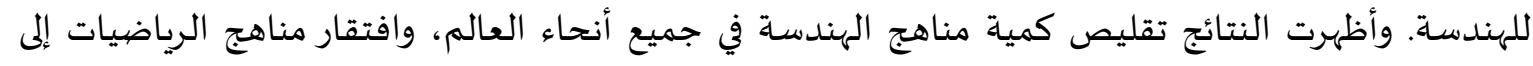

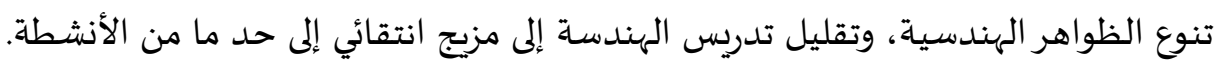

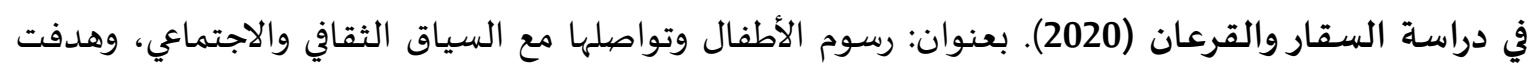

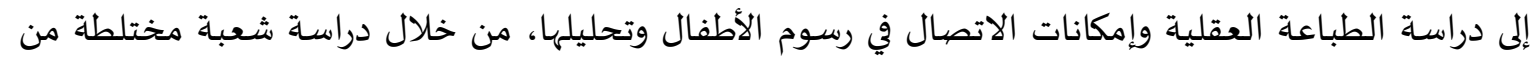

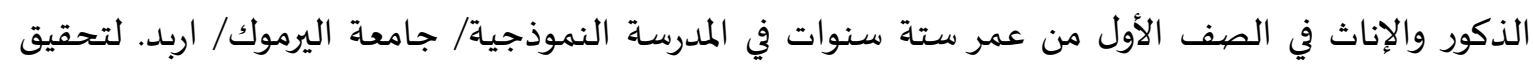

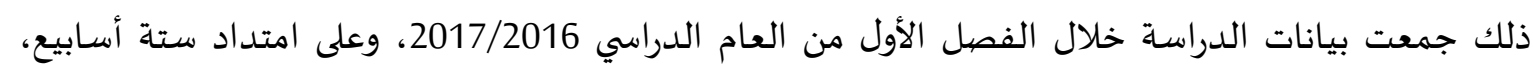
حيث أعطي التلاميذ دفترين ليرسموا عليها في المدرسة والبيت، وتكونت عينة التلاميذ من ثلاثين طفلاً وطفلة. بعد ذلك نوقشت الرسومات مرة كل أسبوع في محادثات بحثية فردية مسجلة صوتيا وبشكل فردي، كمات كما تم

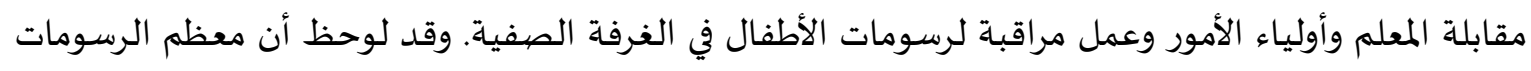

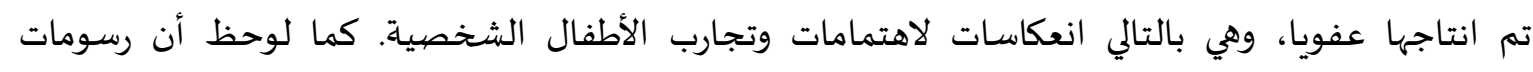

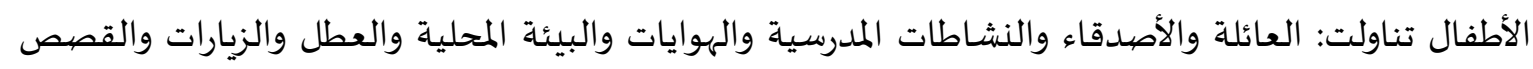

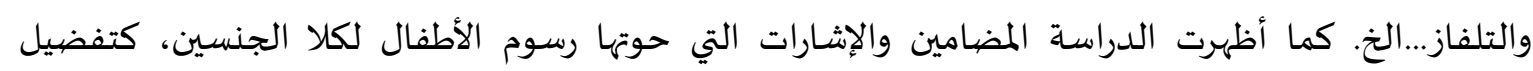

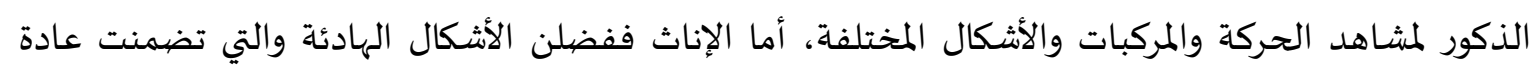

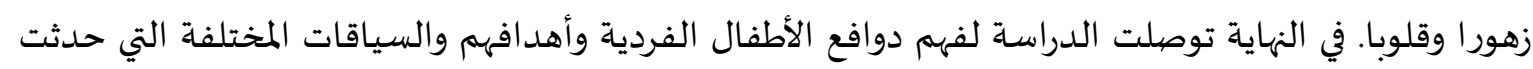
أثناء ممارستهم للرسم. في دراسة فلفلان، (2020). بعنوان: التلفزيون وتأثيره على رسوم الأطفال في مرحلة الطفولة المتأخرة (من 9 إلى

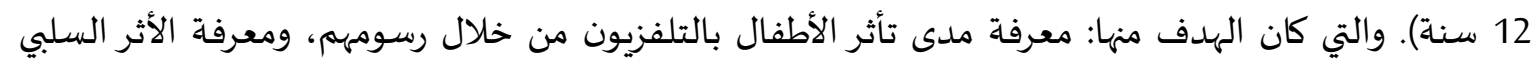

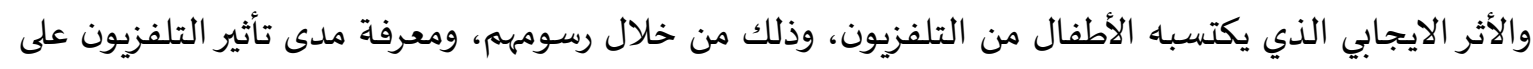

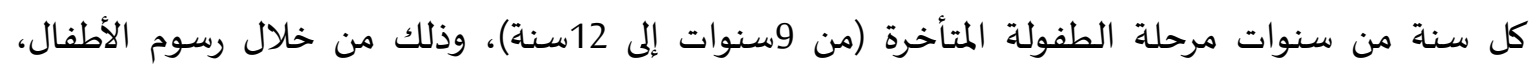

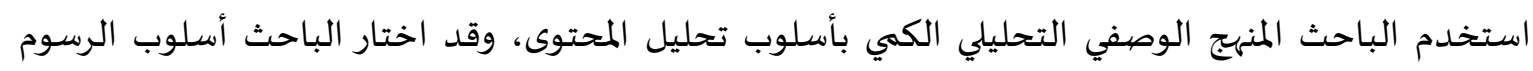

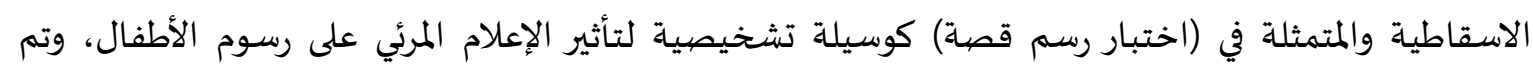

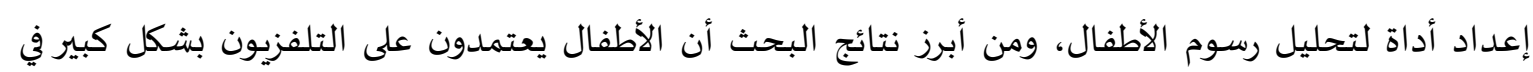

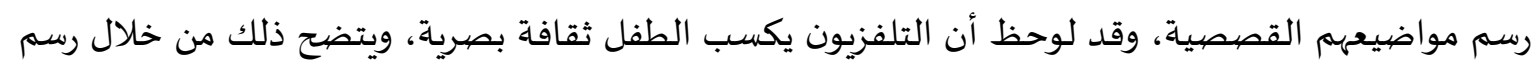
العناصر غير الموجودة في البيئة المحيطة وكذلك رسم موجزات شكلية من بيئات مختلفة، ويكمن التأثير السلبي

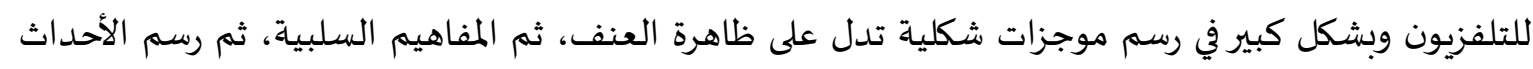
المأساوية، يظهر التأثير الايجابي للتلفزيون في كتابة المفردات اللغوية بالعربية الفصحى وبنسبة كبيرة جدا، ولئ وتليها رسم الموجزات الشكلية التي تدل على اللعب والمرح والرياضية. في دراسة (2019) Deguara, بعنوان: رسومات الأطفال الصغار: أداة منهجية لتحليل البيانات، والتي كان

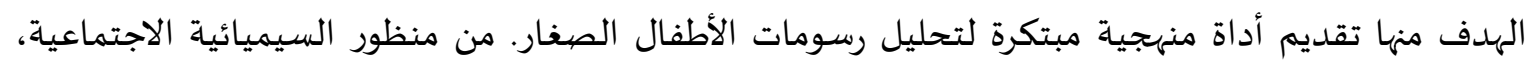
بحيث يكون الهدف من هذه الأداة ليس استبدال التحليل السردي بل استكماله. تكونت عينة الدراسـة من ثلاثثة

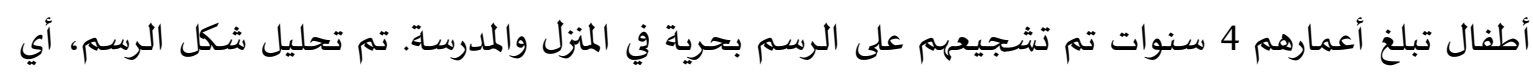


نوع وكمية الأنماط التي استخدمها الأطفال؛ تبع ذلك تحليل المحتوى، أي نوع وكمية المواضيع التي رسمها

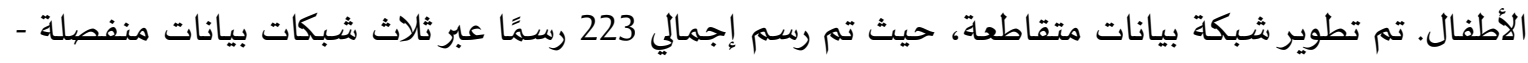

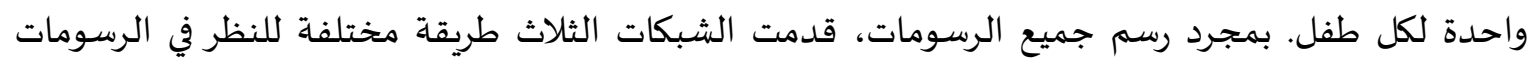

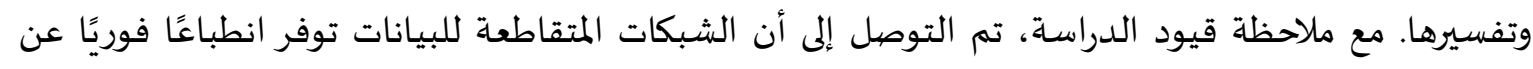

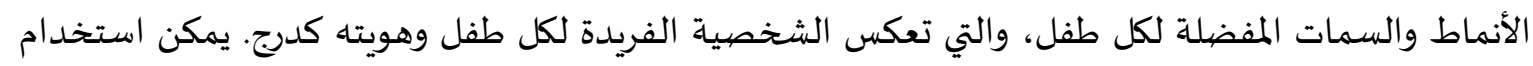
هذه الأداة من قبل الممارسين والباحثين لفهم طرق الرسم المفضلة للأطفال، ويمكن تكييفها وتعديلها لتحليل

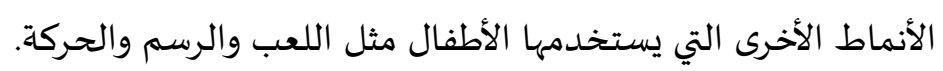

دراسة (حسن وفراج ومحمد، 2019) بعنوان: دراسة سيكولوجية رسوم الأطفال في ضوء تحليل الأنماط

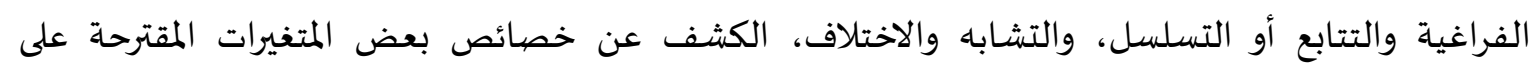
خصائص رسوم الأطفال وسمات شخصيتهم، واستخدم الباحث المنهج الوصفي الترابطي، وقد اظهرت الطهات النتائج

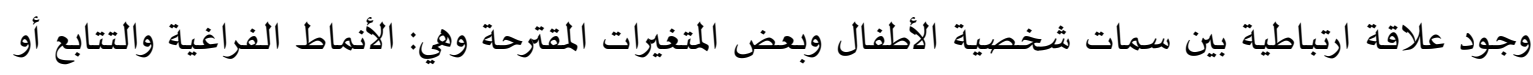

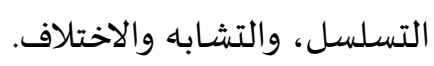
دراسة (2018) Caymaz, et al. , بعنوان: تحليل رسومات الأطفال في سن المدرسة الابتدائية حول منطقة

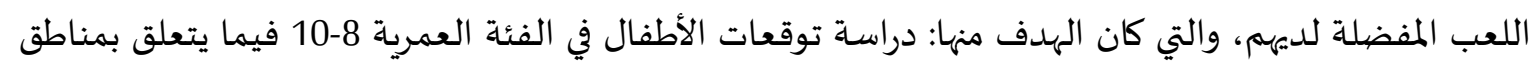

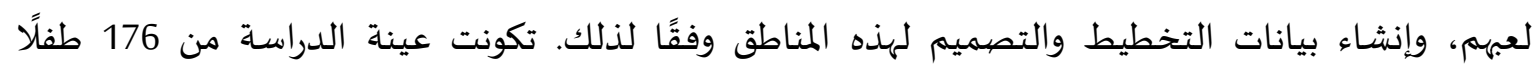

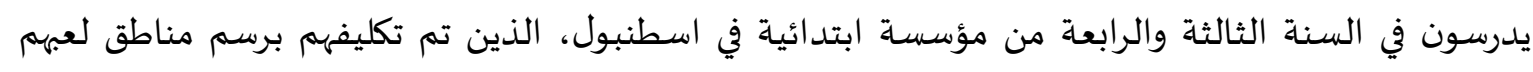
الخيالية. في تحليل رسوماتهم، تم تحديد تفضيلات الأطفال في ثلاث فئات رئيسية: البيئة الطبيعية، والبئية البئة البئة

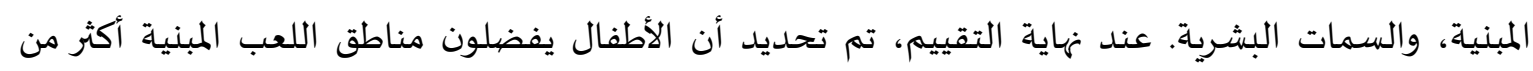
البيئة الطبيعية. دراسة الشطي، وبن جمعة، (2017). بعنوان: واقع الطفل الكويتي مع بيئتها من خلال التعبيرات الفنية، والتي

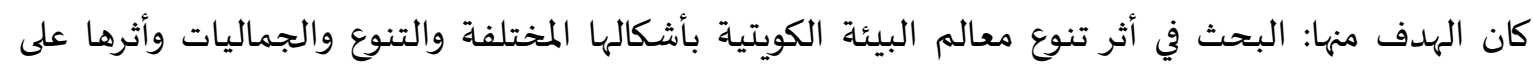

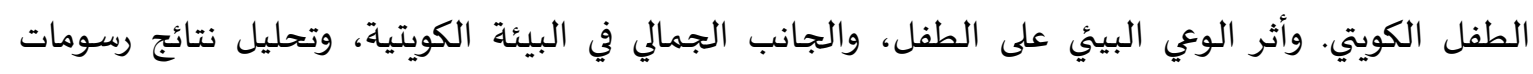

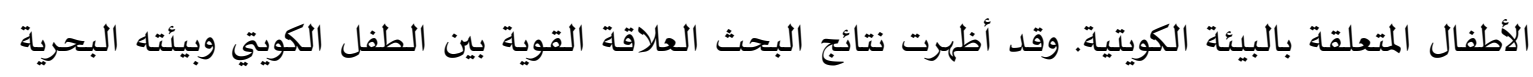

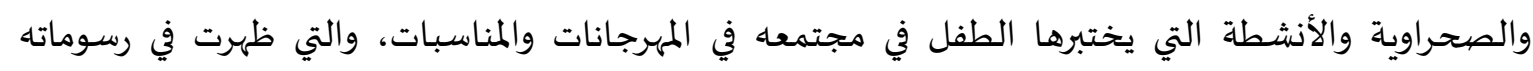
وتعبيراته الفنية. دراسة (الشهري، 2016) بعنوان: اثر البيئة على رسوم الأطفال في منطقة عسير (دراسة مقارنة)، والتي كان الهدف منها التعرف على عناصر بيئة منطقة عسير والتي تظهر في تعبيرات الأطفال الفنية في مرحلة محاولة التئة

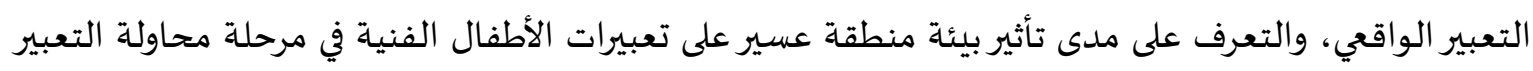

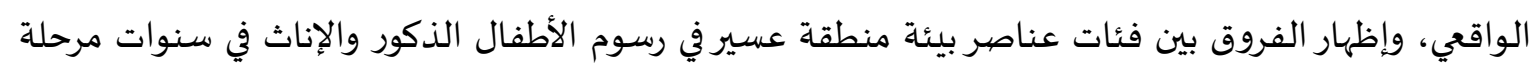

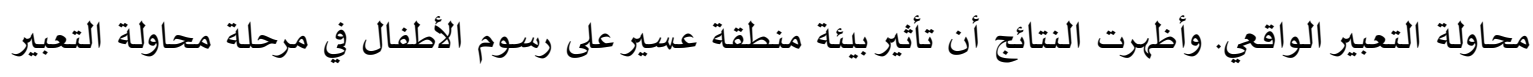

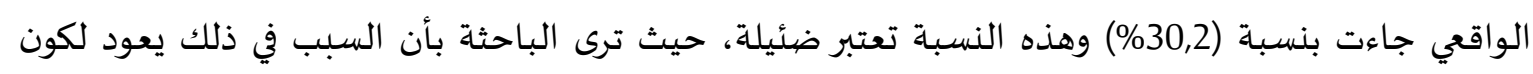

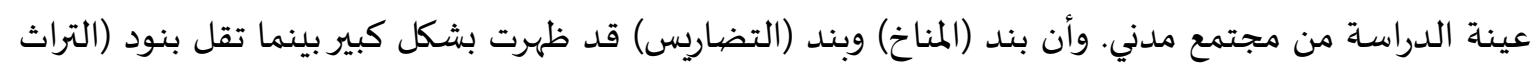

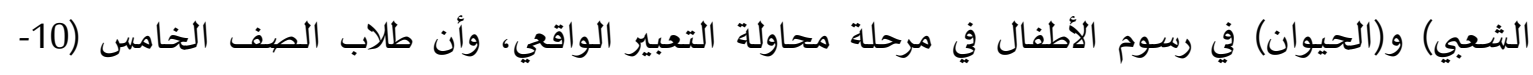

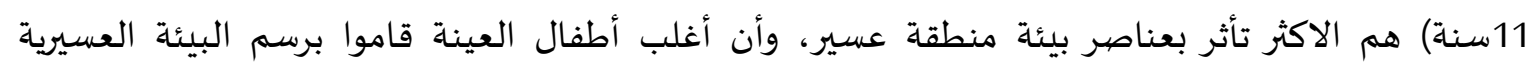

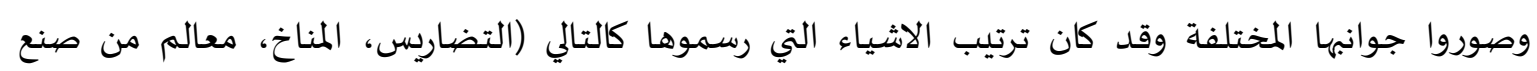


الانسان، النبات، التراث الشعبي، الحيوان)، كما لاحظت الباحثة تفوقا واضحاً للإناث حيث إن رسومهن مليئة

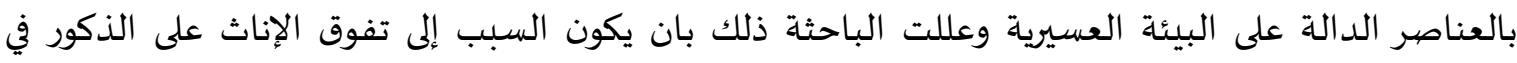
قدرتهن على التعبير، وتصويرهن للجوانب المختلفة للطبيعة.

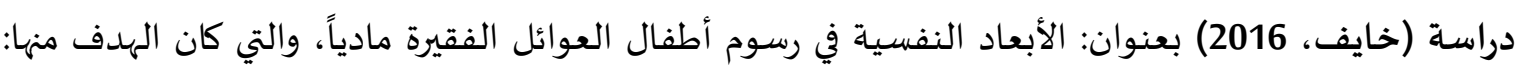

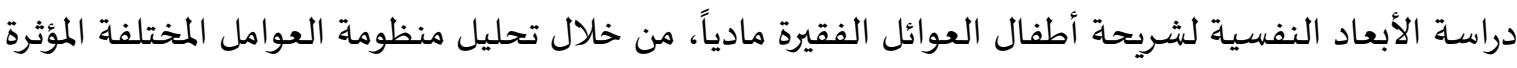

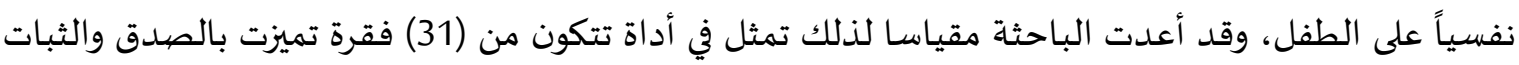

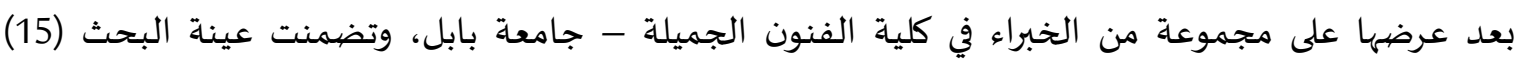

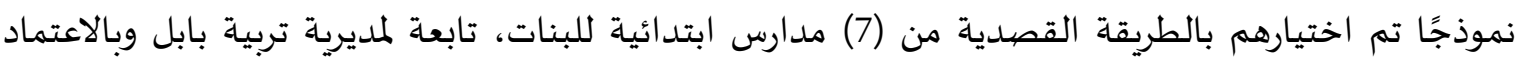

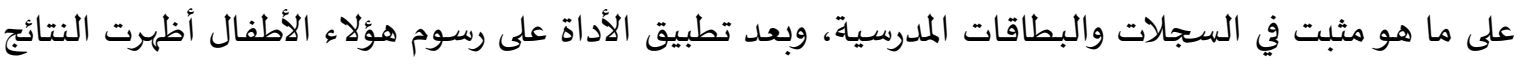

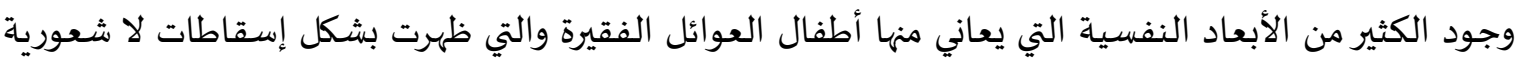

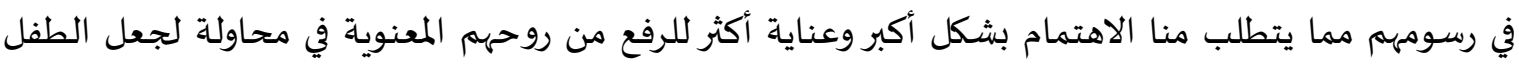
فردًا ناجحًا في المجتمع لا يشعر بأي نوع من النقص أو الاختلاف عن أقرانها في المدرسـة.

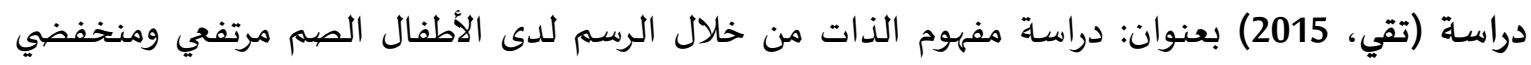

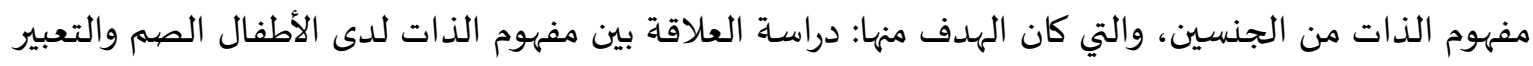

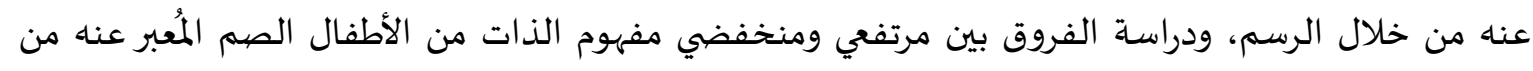

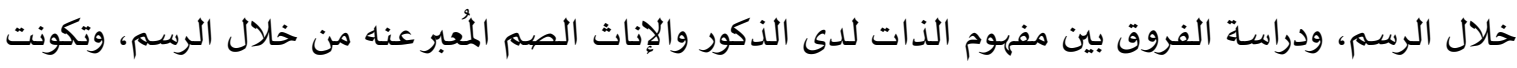

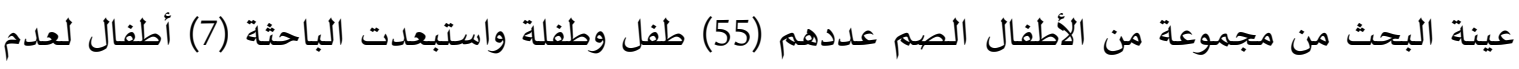

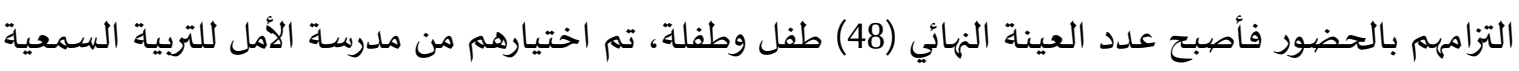

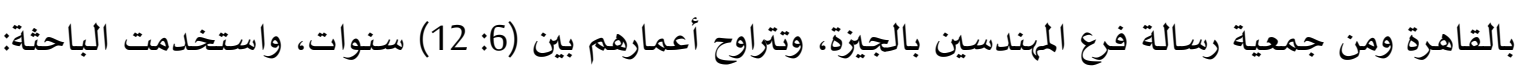

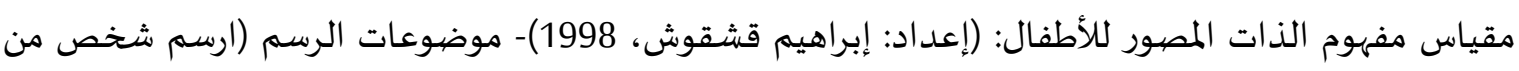

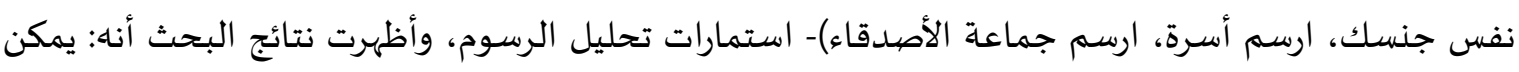

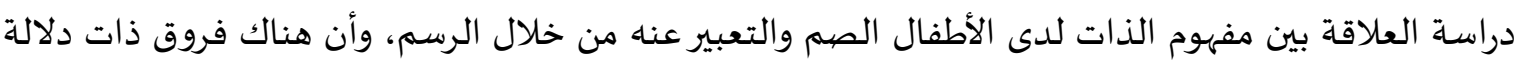

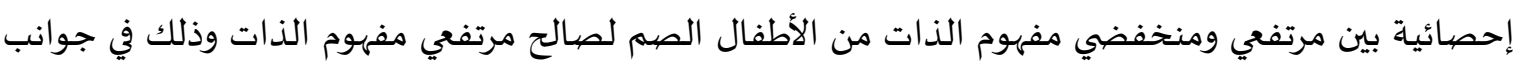

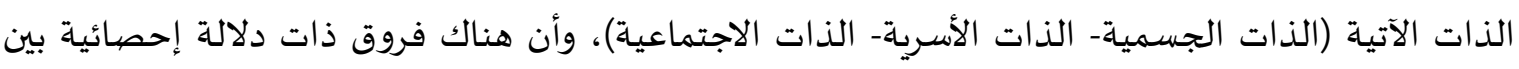

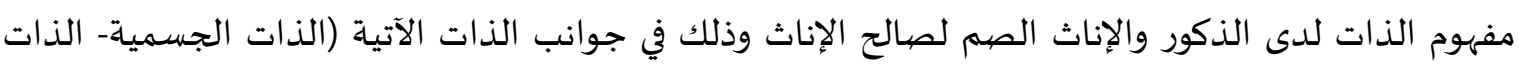
الأسرية).

دراسة (زيدان، 2015) بعنوان: الفروق بين التعبيرات الجرافيتية لثوار25 يناير، وثوار30 يونيو، والتي كان

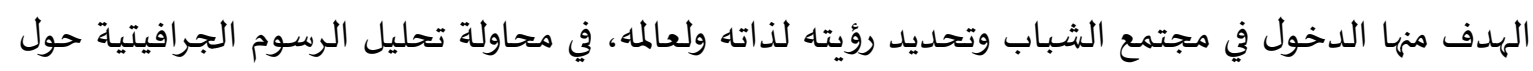

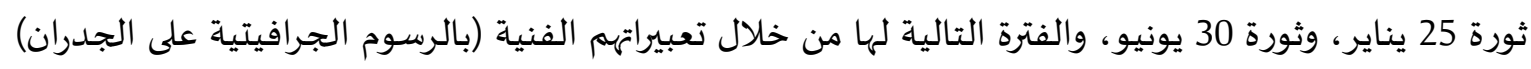

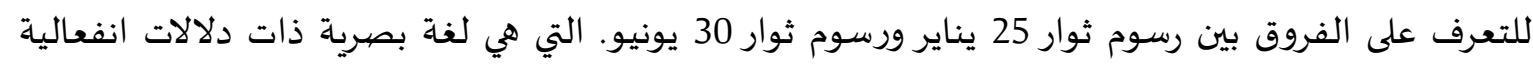

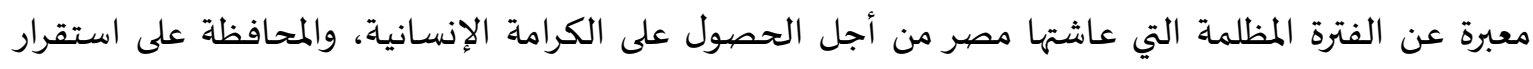

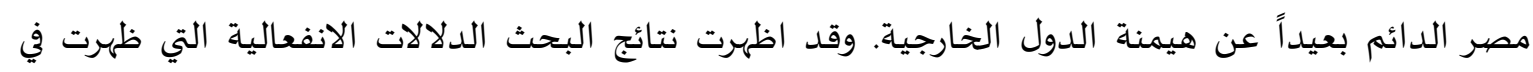

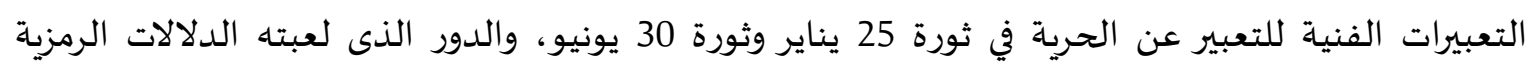

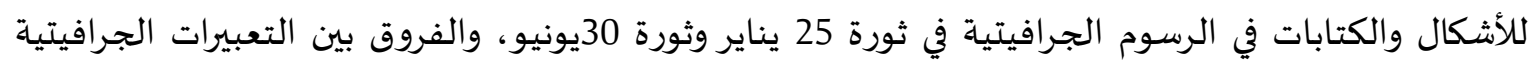
لثورة 25 يناير وثورة 30 يونيو. 
دراسة (سعدون، 2013) بعنوان: تحليل رسوم الأطفال المعتَدَى عليهم جنسيًا بمملكة البحرين دراسة وصفية

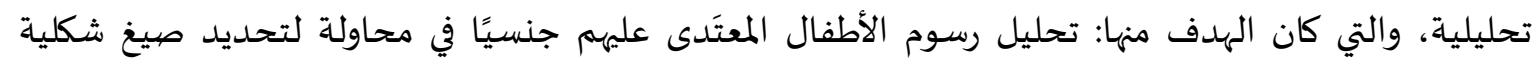

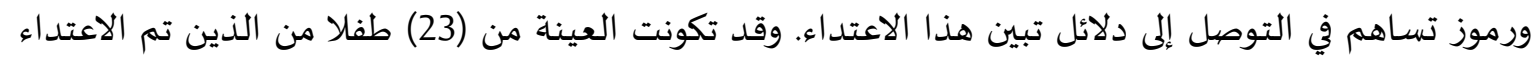

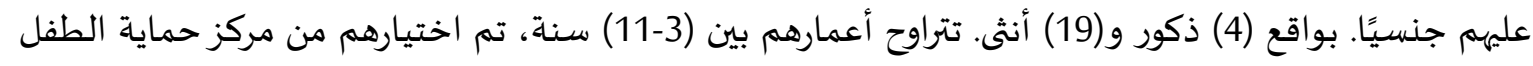

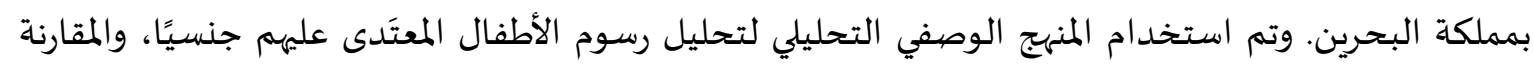

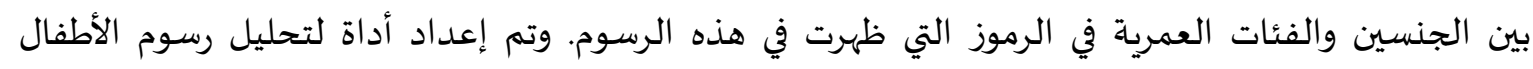

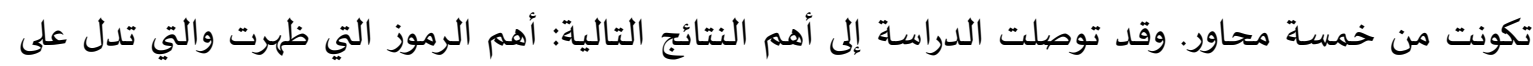

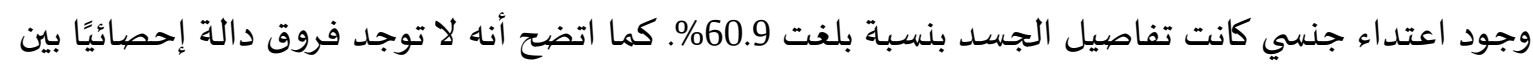

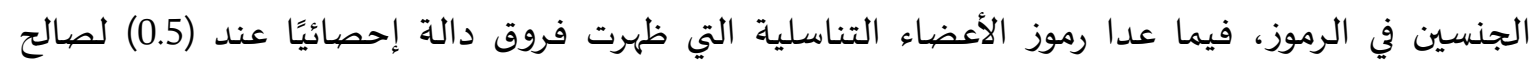

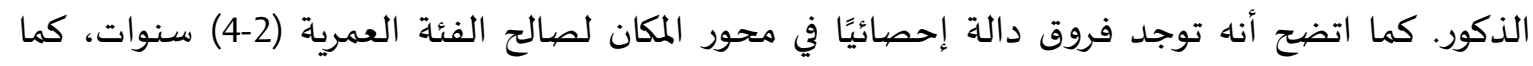

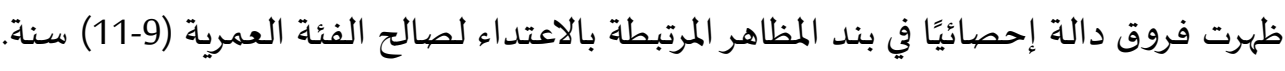

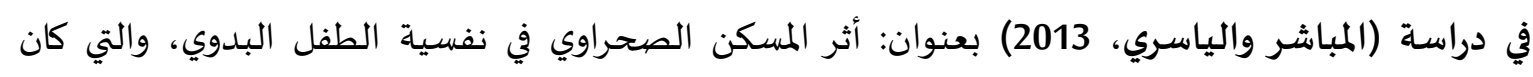

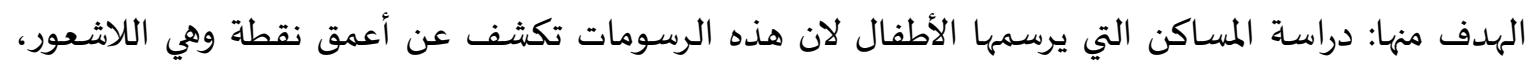

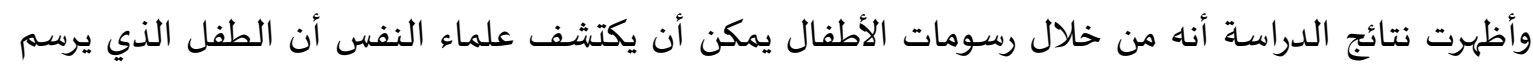

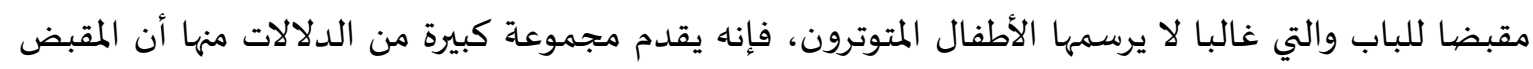

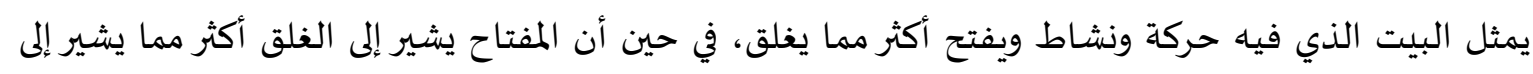

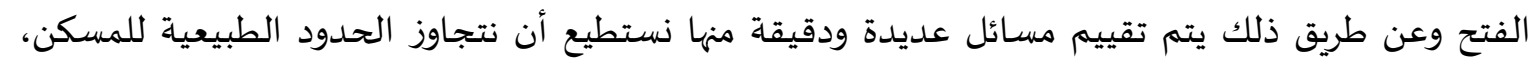

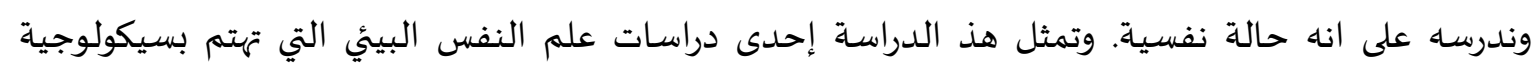
المكان الفيزيقي (البيئة الطبيعية). دراسة (كريمة، 2012) بعنوان: محاولة تقنين اختبار رسم العائلة باستخدام تقنية رسم العائلة المتخيلة

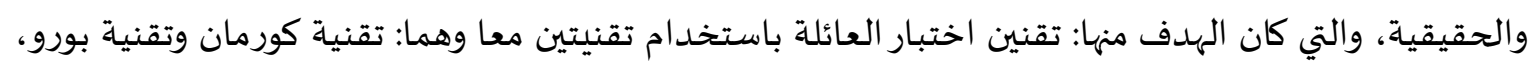

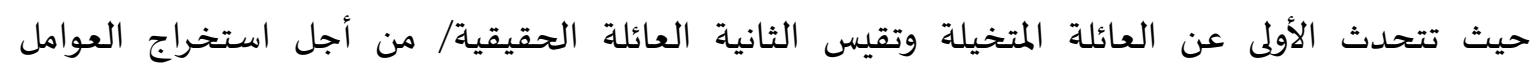

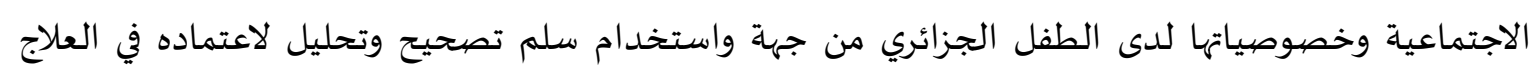
النفسي للطفل الجزائري، من خلال تحليل رسومات الأطفال.

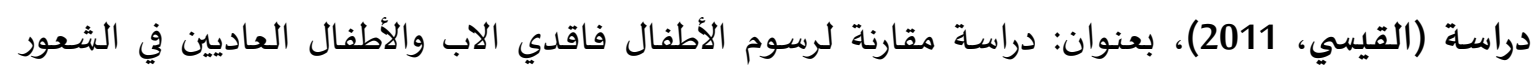

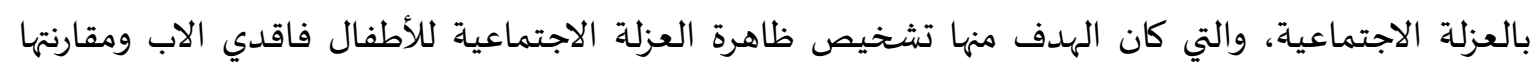

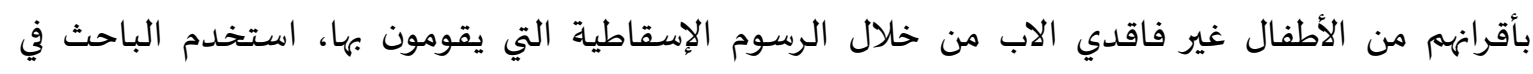
الدراسة منهج تحليل المحتوى لملائمته لهدف البحث، وتكونت العينة من (160) طالبًا وطالبة تم البهابة اختيارهم

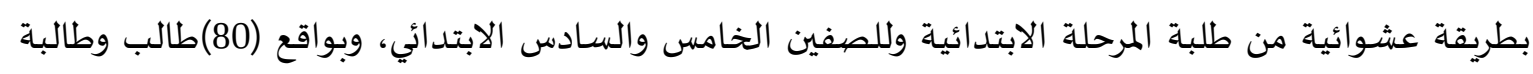

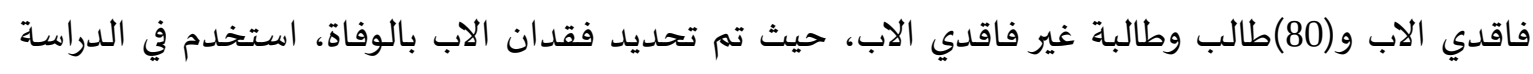

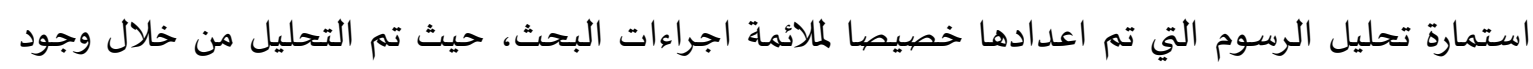

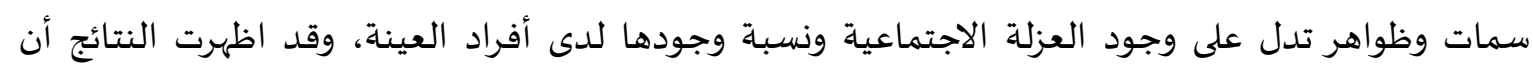

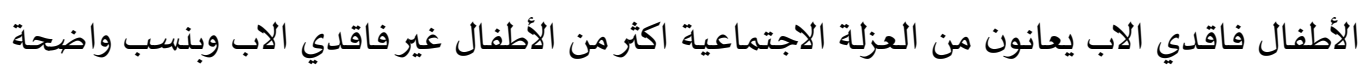

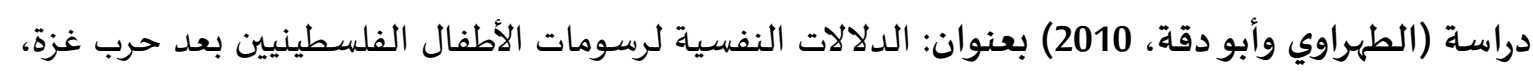

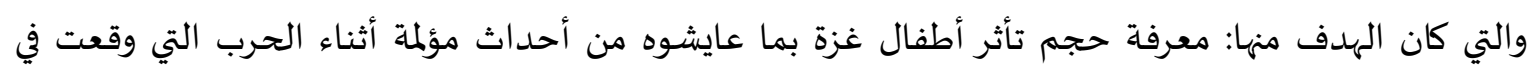


الفترة ما بين 27-12-2008 إلى 18-12009، من خلال تحليل رسوماتهم، مع استجلاء الفروق في الرسومات في

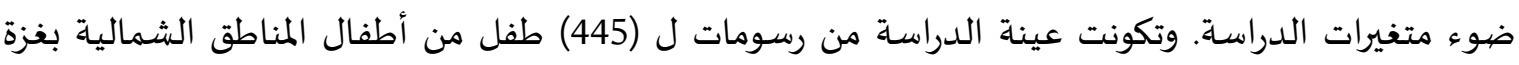

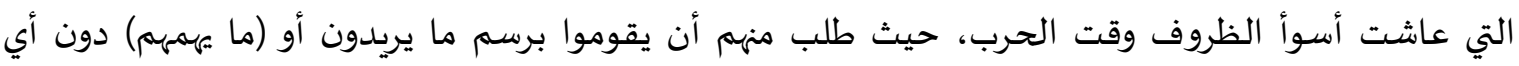

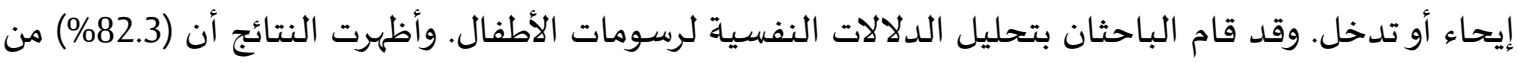

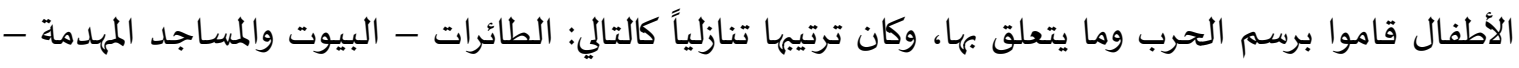

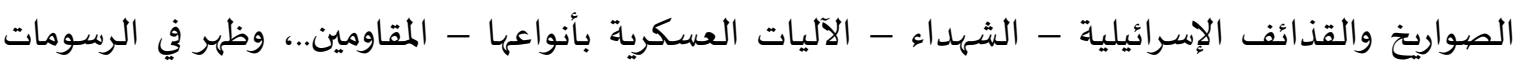

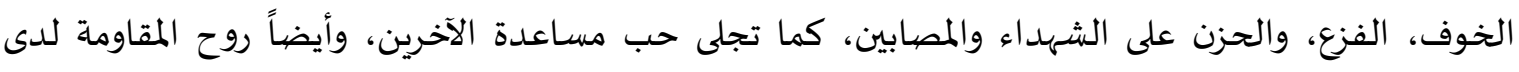

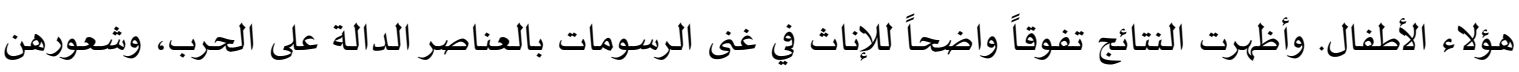

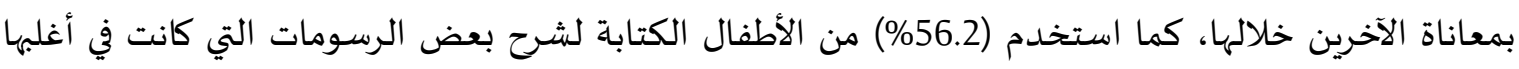

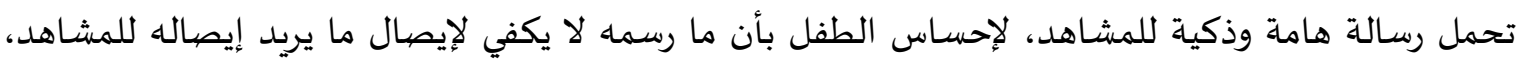

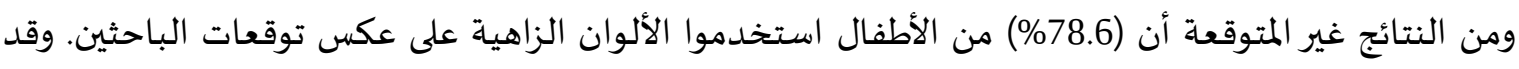

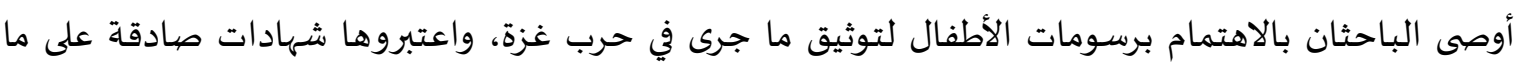

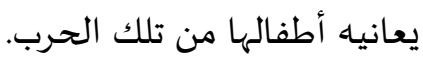

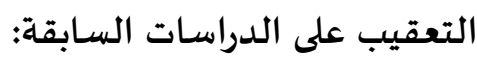
بعد استعراض الدراسات السابقة لاحظت الباحثة التنوع في عناوين واهداف الدراسات وتباينًا في مجتمع

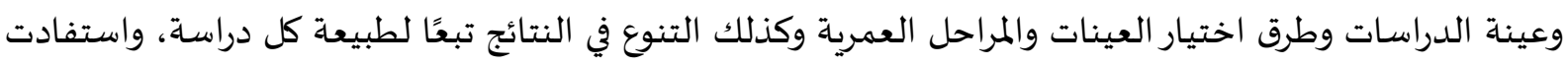

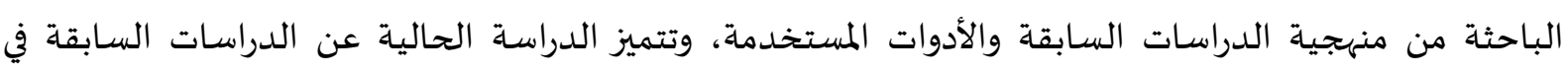

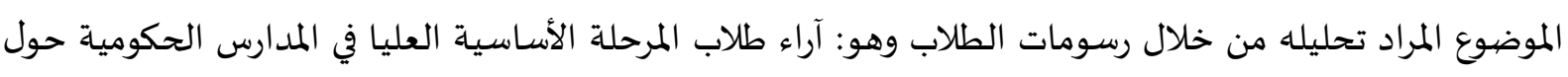

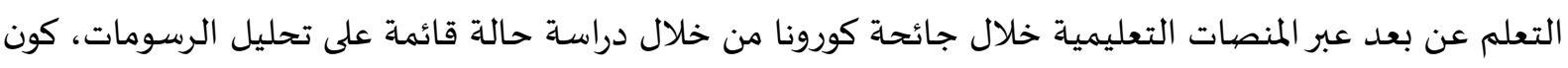

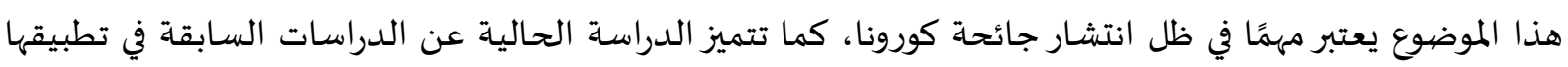
في الأردن، بالإضافة إلى اختيارها طلبة المرحلة الأساسية العليا كعينة للدراسة.

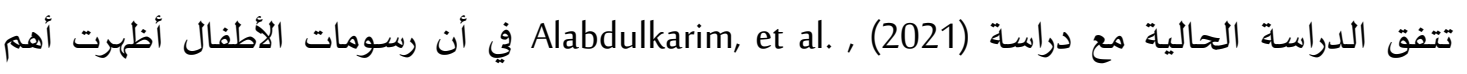

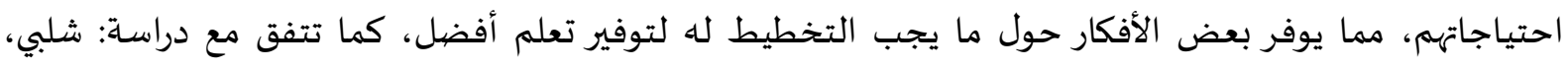

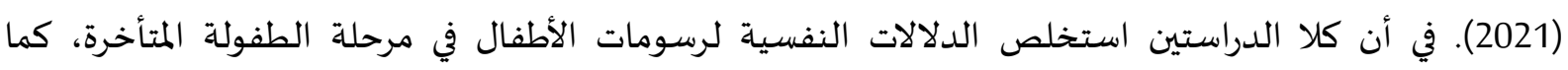

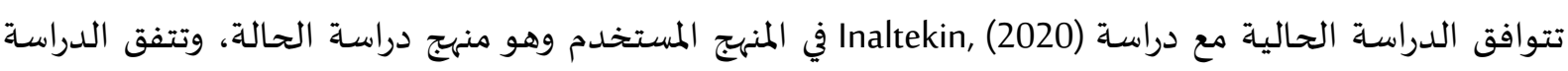
الحالية مع دراسة (2020) Kuzle, \& Gracin, وكذلك دراسة السقار والقرعان (2020). في الأداة المستخدمة

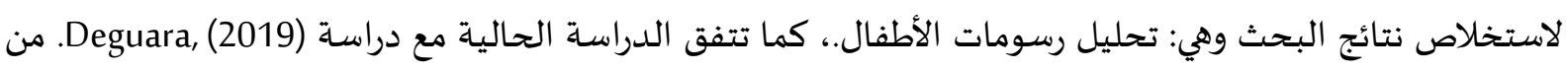

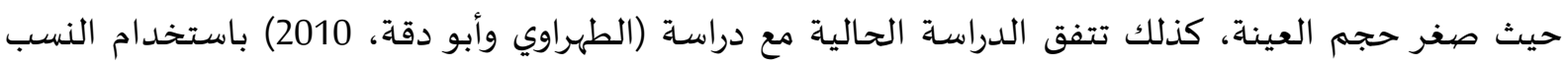
المئوية الدالة على نسبة تكرار الظاهرة التي تم تحليلها في الرسومات.

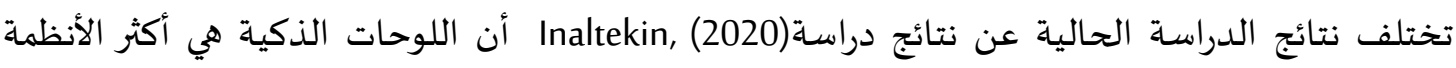

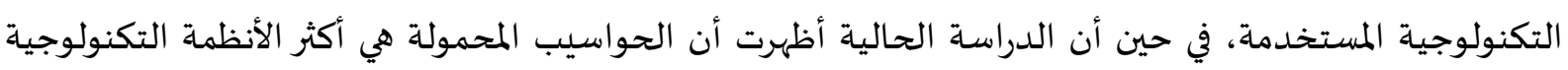

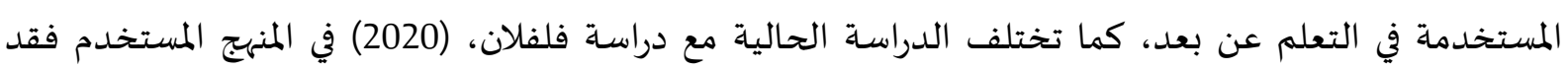

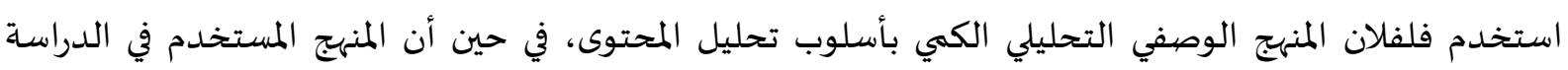

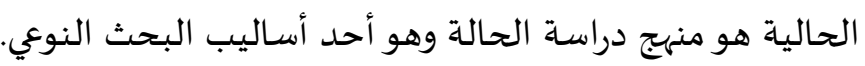


3. منهجية الدراسة وإجراءاتها.

منهجية الدراسـة:

هذا البحث عبارة عن دراسة حالة تم إنشاؤها لمعرفة آراء طلاب المرحلة الأسـاسية العليا في المدارس الحكومية حول التعلم عن بعد عبر المنصات التعليمية خلال جائحة كورونا في الصفوف (الثامن والتاسع والعاشر)

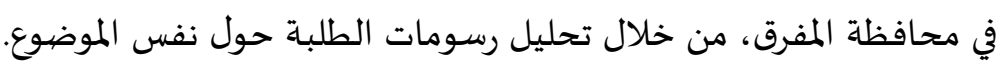

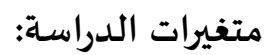

متغير مستقل: (التعلم عن بعد عبر المنصات التعليمية).

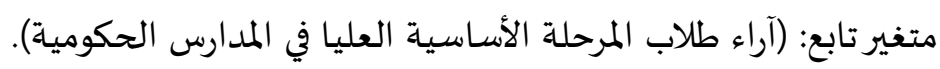
المتغير الوسيط: (جائحة كورونا).

مجتمع الدراسة: سوف يتكون مجتمع الدراسة من طلاب المرحلة الأساسية العليا في المدارس الحكومية الذين تلقوا التعلم

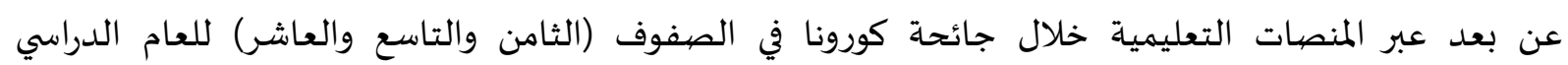
.2021/2020

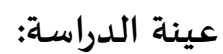
تم أخذ العينات بطريقة العينة القصدية، حيث تم إرسال رسائل لأولياء أمور الطلبة على تطبيق الواتساب

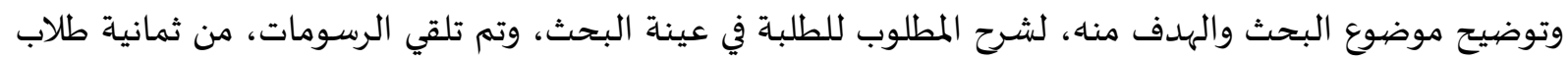

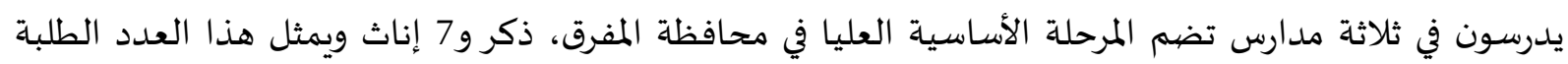

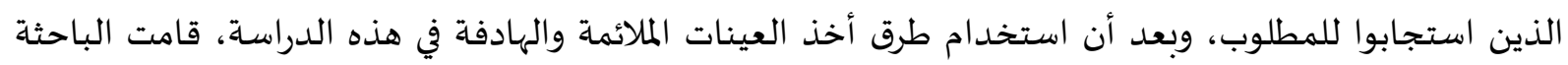

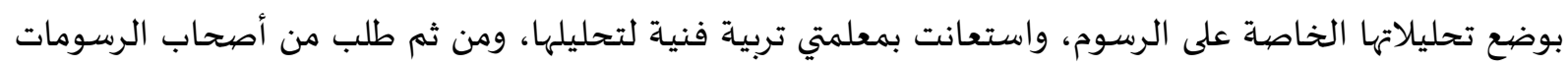
إرسال مقاطع صوتية عما يعنونه بهذه الرسومات.

أداة الدراسة:

تم جمع المفاهيم باستخدام الرسومات أو الخطوط أو الرموز أو الملصقات أو النصوص، لأن التعبير عن

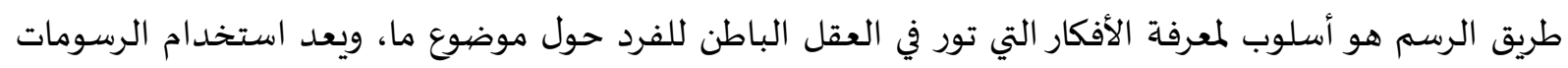

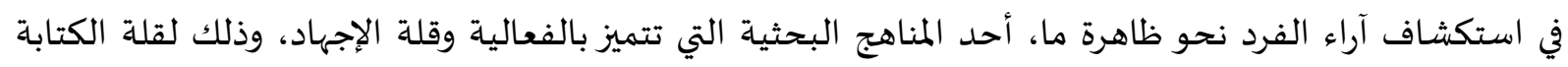

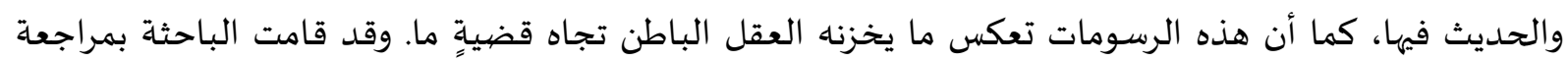

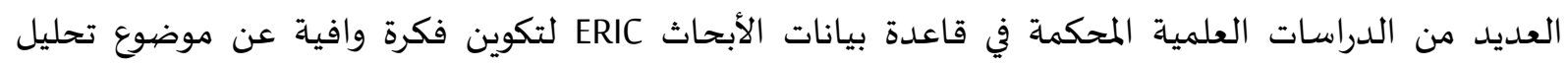

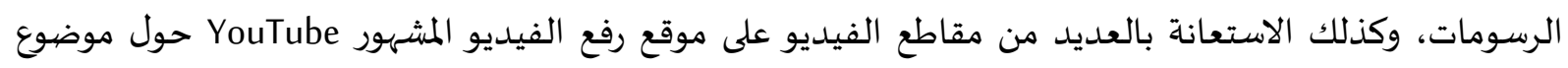
تحليل الرسومات، لتكوين فكرة واضحة عن تقنية البحث القائمة على الرسم، ودلالات الألوان في الرسم، مفرك، أثناء

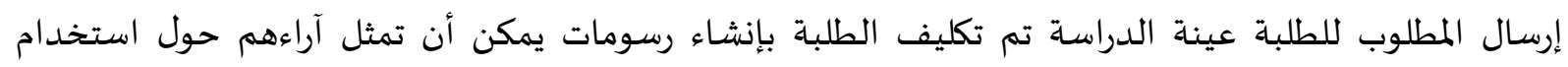
المنصات التعليمية أثناء فترة التعلم عن بعد، واستغرق الحصيول على بيانات هذا البحث أسبوعين تتضمن تسليم

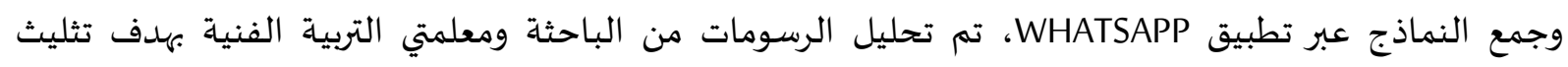


المعلومة وهو مبدأ هام من مبادئ البحوث النوعية، كما تم الطلب من الطلاب والطالبات الذين رسموا هذه الرسومات إرسال مقاطع صوتية توضح كل جزئية في رسوماتهم بهدف ضبط الصددق والثبات ومنع تحيز الباحث هن والمحللتين لرأهيما الشخصي، وتم ذلك بعد الانتهاء من التحليل حتى لا يتأثر تحليل الباحث بأقوال الطفل، ووُجِد أن هناك تطابق في جزء كبير من التحليل. استغرقت الباحثة يومين في تحليل الرسومات، واستغرقت كل معلمة تربية فنية ثلاث أيام في تحليل البيانات، واستغرق جمع التسجيلات الصيوتية من الطلبة يوم واحد، وتم تفريغها في يوم

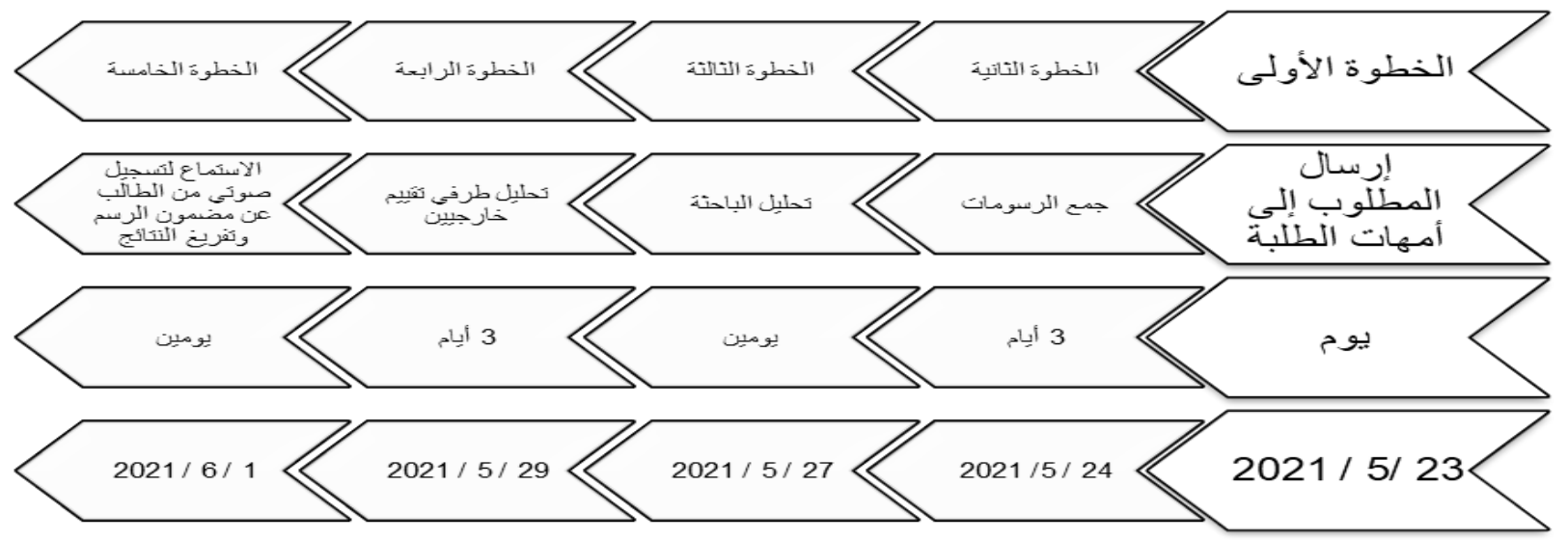

\section{الشكل (1): خطوات عملية جمع البيانات}

تحليل البيانات

تستخدم طريقة تحليل المستندات لتحليل البيانات التي تم الحصول عليها من البحث. في هذا السياق، يتم

تحليل رسومات الطلاب باستخدام تقنيات التحليل النوعي باستخدام تقنيات التحليل الوصفي والمحتوى. تم وصف بيانات البحث باستخدام النسبة المئوية وتم تقديمها من خلال تحويلها إلى رسم بياني. تم تحديد ثلاثة محاور رئيسية لتحليل البيانات.

1- الظواهر العامة المرتبطة بالتعلم عن بعد عبر المنصات التعليمية. 2- الظواهر الإيجابية المرتبطة بالتعلم عن بعد عبر المنصات التعليمية.

3- الظواهر السلبية المرتبطة بالتعلم عن بعد عبر المنصيات التعليمية.

يحتوي الموضوع الأول وهو الظواهر العامة المرتبطة بالتعلم عن بعد عبر المبهر المنصات التعليمية على على ما مجموعاه

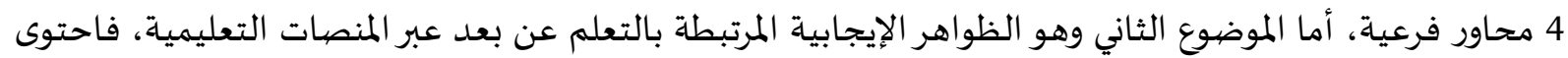

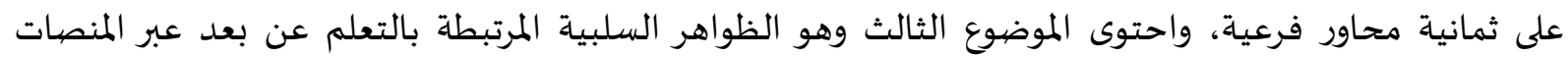

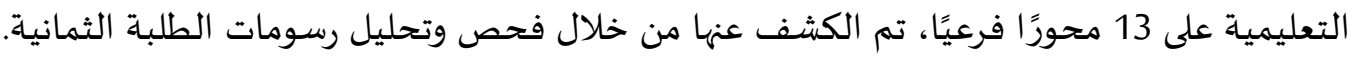




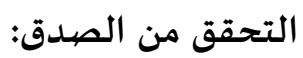

تم استخدام منهج البحث النوعي، وبالتحديد (دراسة الحالة)، وهذا المنهج له نوعين من الصيدق:

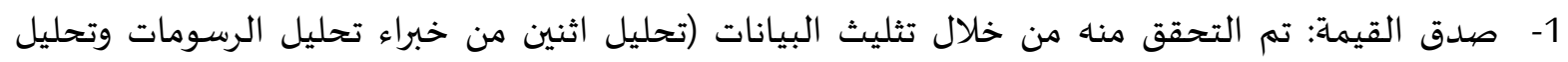

الباحثة بعد دراستها للموضيوع مطولاً).

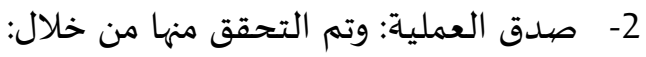

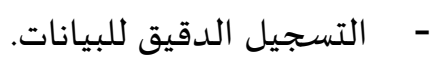

- - ماستخلاص المعلومات من المشاركين.

- - مليل الانطباعات السلبية.

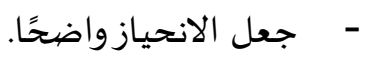

التحقق من الثبات:

ظهر الثبات واضحًا في هذه الدراسة النوعية، من خلال تقاطع آراء خبراء التحليل والباحثة.

تصيميم الدراسـة وتحليل النتائج: الدراسة الحالية هي دراسة نوعية تهدف للتعرف على آراء طلبة المرحلة الأساسية العليا بالتعلم عن بعد عن

طريق المنصات التعليمية خلال جائحة كورونا: دراسة حالة قائمة على تحليل الرسومات.

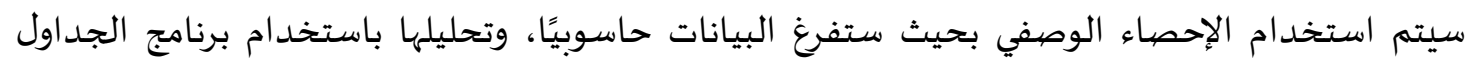

الالكترونية MS-EXCEL، وستتمثل فيما يلي:

$$
\begin{aligned}
& \text { 1- عدد مرات تكرار الفكرة في رسومات الطلبة، حسب رسبة رأي خبراء التحليل. } \\
& \text { 2- حساب النسبة المئوية لتكرار الفكرة في الرسومات الثمانية. } \\
& \text { 3- عمل رسومات بيانية توضح مدى تكرار الفكرة. } \\
& \text { 4- تفسير النتائج وصياغة التوصيات بناءً على النتائج. }
\end{aligned}
$$

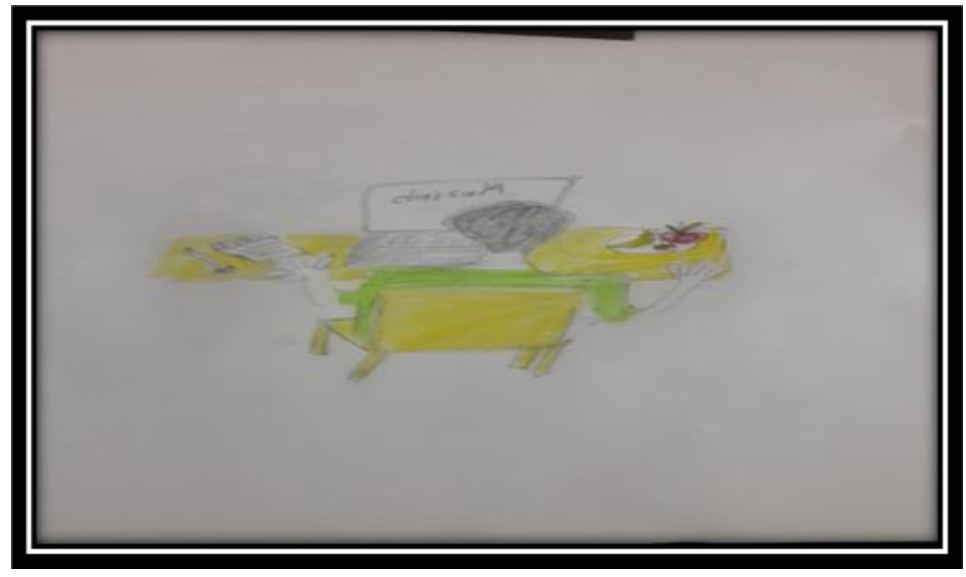

(1) (1) (1) (1) (1) (1) (1)

يتضح أن الرسمة تتحدث عن كيفية تلقي الدرس (التعليم عن بعد) والشخصية والرموز فيها تواجه الرائي

وهو بذلك يعطينا معلومات يظن الطفل انها تغيب عنا.

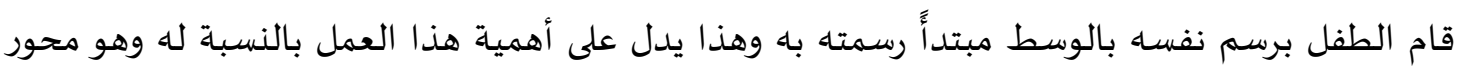

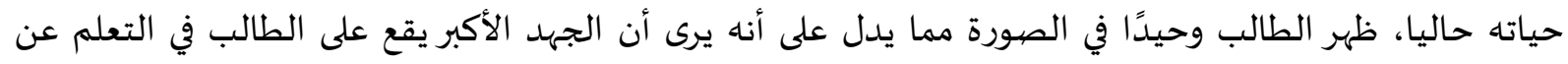


بعد، واهتم بإظهار بعض التفاصيل من شعر وأدوات دراسة من مكتب وكرسي ولابتوب (جهاز حاسوب) الذي هو أساس العملية التعليمة في الوقت الراهن إنه بذلك يعطي قيمة وأهمية للعمل المراد القيام باه، ولكن التعليم التهاتيم الوجاهي (التعليم في المدرسة) وهو بذلك يفتقده بشكل كبير ومما يدلل على ذلك استخدام نظام لوني واحد والذية والذي

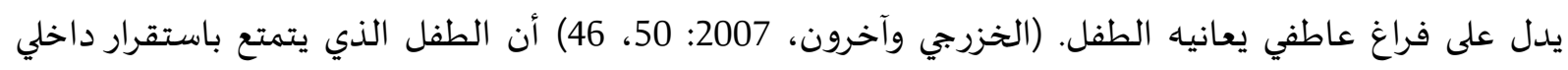
وتكيف اجتماعي يستعمل من 4-6 ألوان في الرسمة.

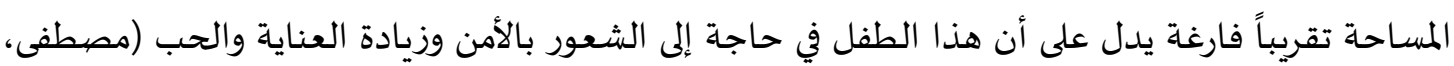

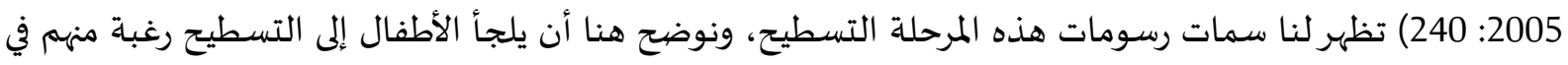

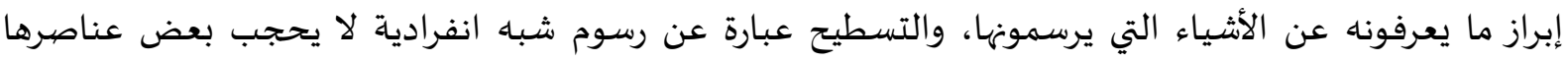

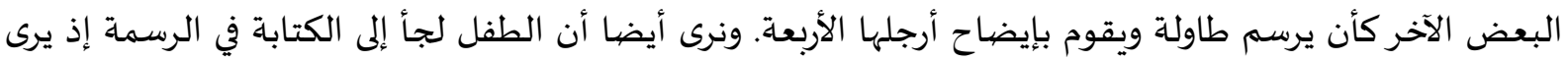

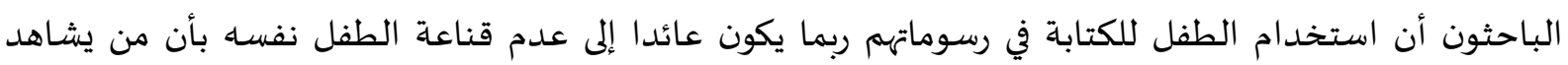
رسمته سوف يفهم ما يقصده. كما تظهر الرسمة أن الحاسوب هو أداة التعلم عن بعد التي تلبي حاجات الطفات الطفل

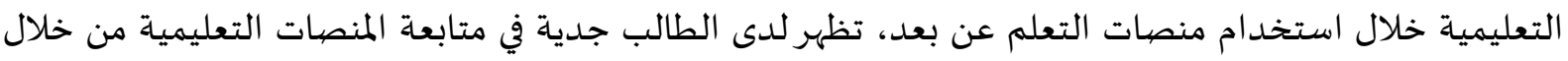

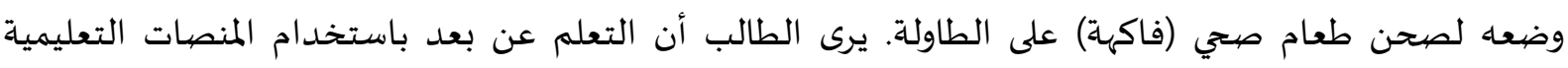

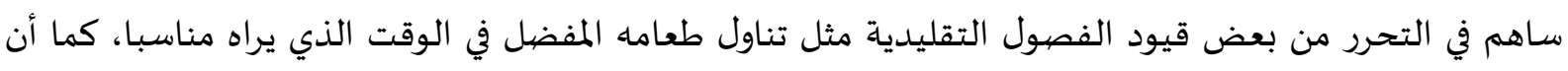
الطفل يستخدم قلم ودفتر لتدوين ملاحظاته مما يدل على وجود مضميمون تعليمي يستحق التدوين في المنصة.

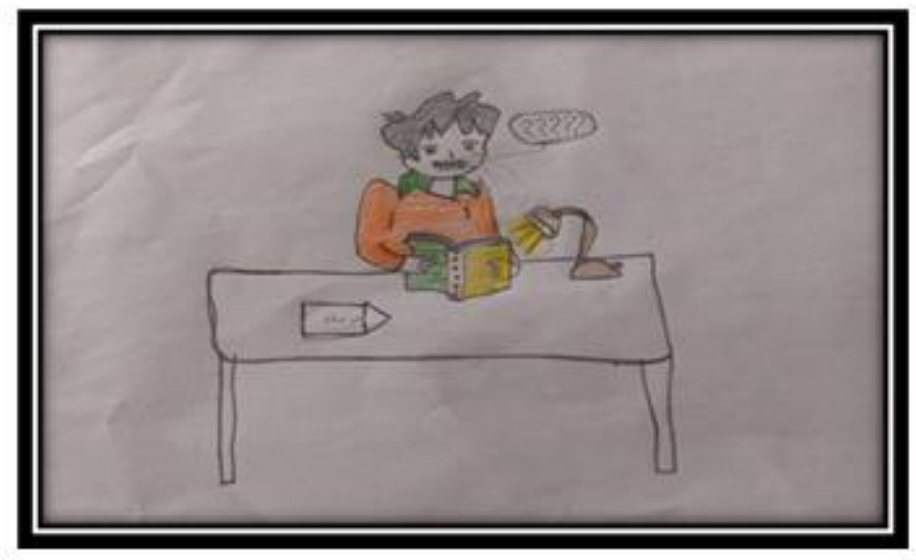

الشكل رقم (2) (2)

يتضح لنا الاتزان في العمل هنا من حيث اختيار نوع الدراسة بين التعليم الوجاهي والتعليم عن بعد وتخبرنا

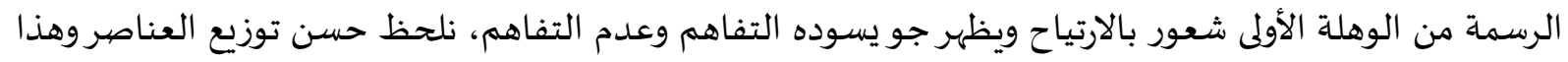

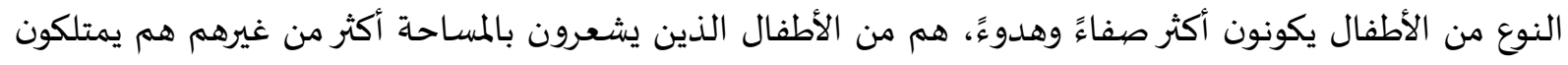
القدرة الفضلى على مستوى الإدراك (الخزرجي وآخرون، 2007: 64، 62، 34) تم استخدام الكناء الكتابة بعبارتين الأولى

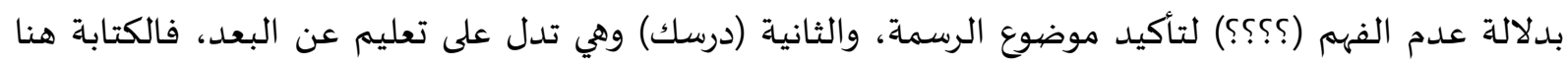
قصدت لذاتها، فهي تثير معاني ليس من السهل التعبير عنها بالرسم لأنها معاني ذهنية وعاطفية وشياعرية التهية (بسيوني،

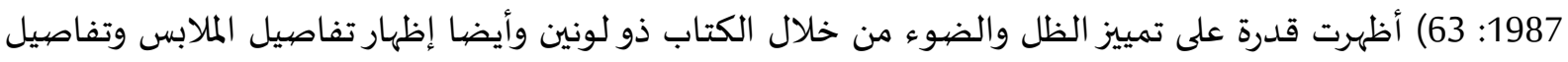

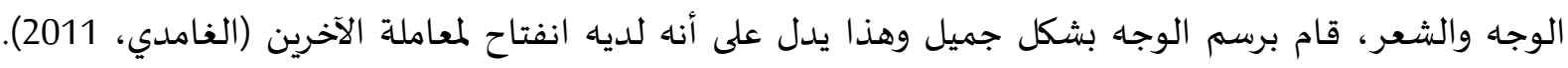

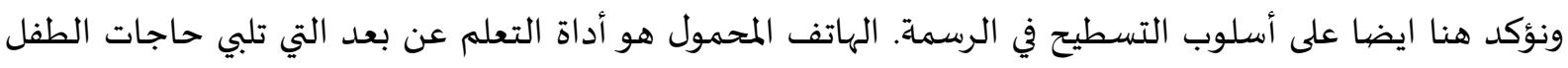

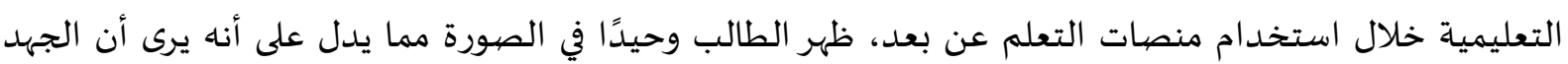


الأكبر يقع على الطالب في التعلم عن بعد. الطفل أنهى تصفح المنصة وتوجه لمراجعة المعلومات في الكتاب مما يدل على وجود معلومات قد توصل الطالب لفهمها من الشرح المعروض على لمعلى المنصية.

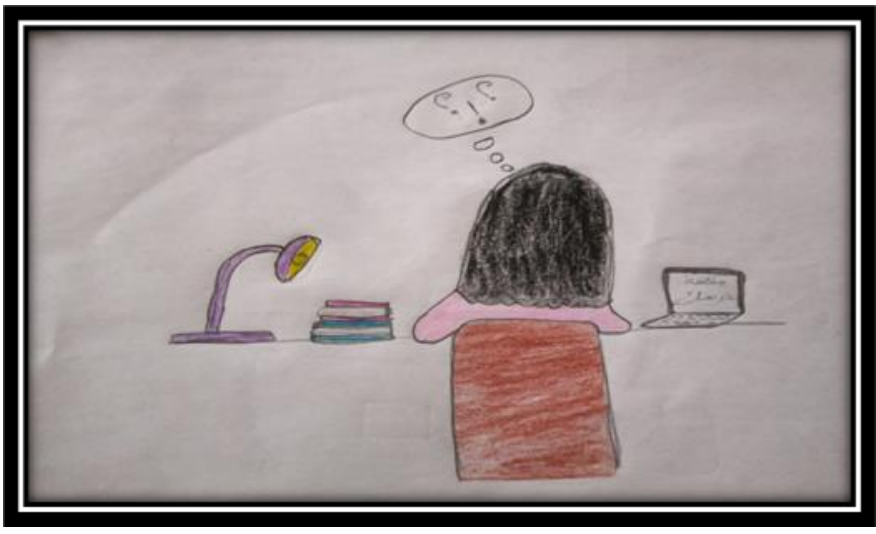

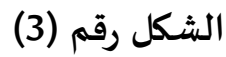

رسمت الرسمة متوسطة المكان ويظهر فيها الجمع بين أساليب التعليم مختلفة بوجود جهاز الحاسوب (منصة درسك) على يمين اللوحة وبين الكتب في جهة الشمالية للوحة الطفل، ودعم هذه الفكرة محاول رسم التفاصيل وعلى شكل مجموعات وبألوان مختلفة كما نلاحظ في اللوحة، قام الطفل برسم الكتب والحاسوب بمكان

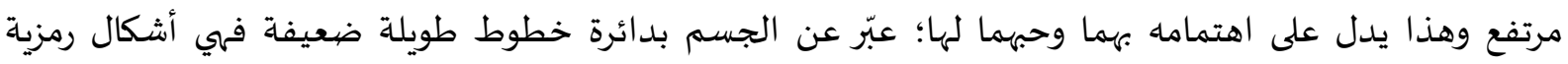

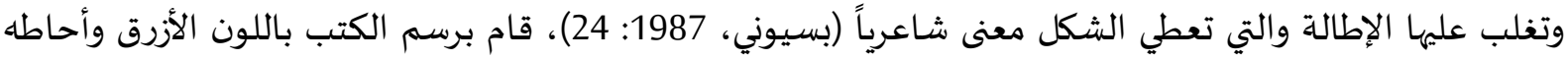
باللون الزهري الذي يؤكد فيه قلقه من الدراسة، يتضح وجود جهاز الحاسوب على يمين الرسمة وهو خال من

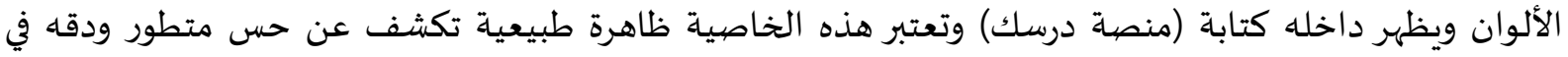
الملاحظة (الخزرجي وآخرون، 2007: 26)، يظهر التكرر بشكل واضح في معظم عناصر الرسمة من حيث الإشكال

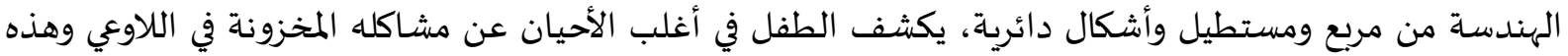
الأشياء اللاواعية يمكن أن تحمل معاني كثيرة وتعبر عن مشاكل الطفل العاطفية والاجتماعية فمثلاً في رسمة الجسم

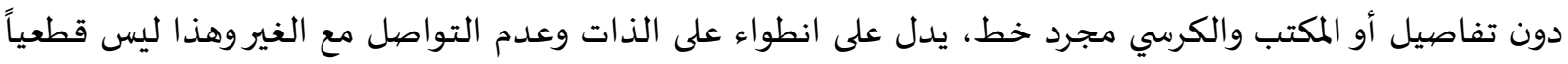

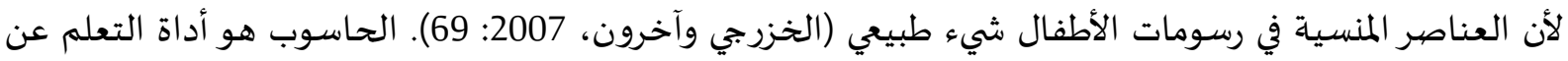

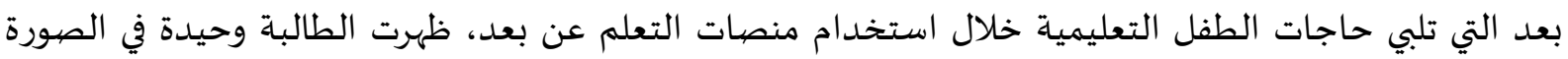

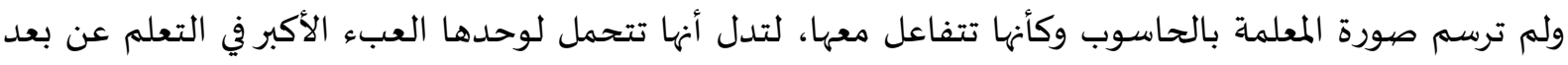

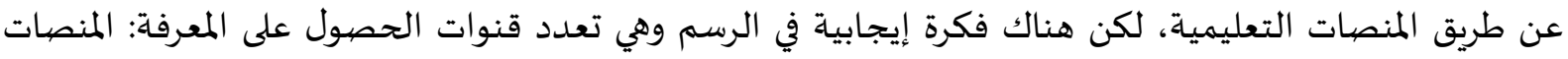
التعليمية، الكتب على الطاولة... 


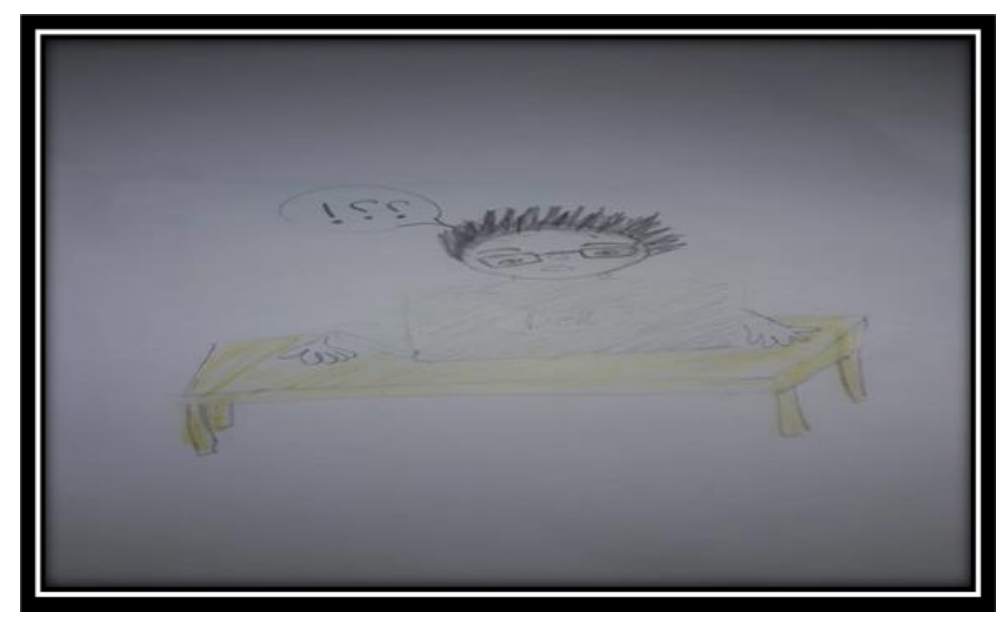

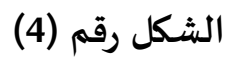

تظهر الكثير من التفاصيل واهتمام بها وهو بذلك طفل تفصيلي (شركس، 2011) يغلب عليها النمط

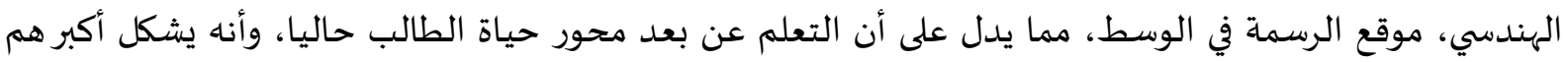

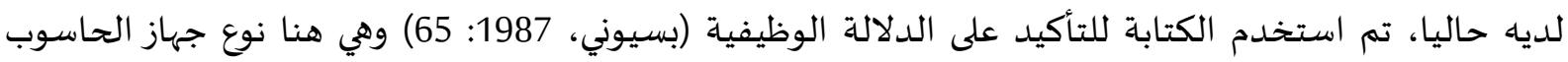
(DELL) (؟؟؟؟)، نلحظ تفصيل الرأس وملامح الوجه بصيغة عامة عن الحاجات الاجتماعية ويعتبر الوجه علامة التوافق الاجتماعي، ونذكر هنا أن الرأس أول جزء في جسم يرسمه الطفل وأيضا يغلب أن يرسم بتفاصيل ومهارة وحذر.

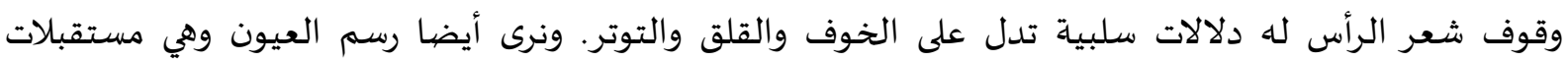

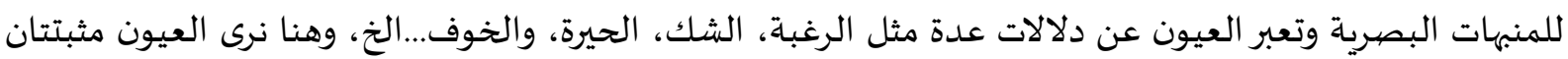

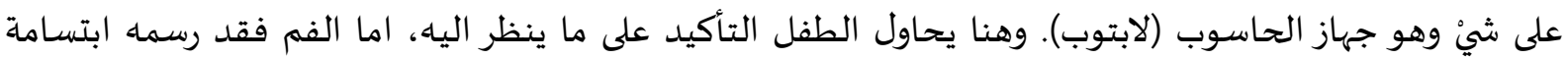
منحنية واضحة تعبيرا عن الموقف الذي المهاز الم باه.

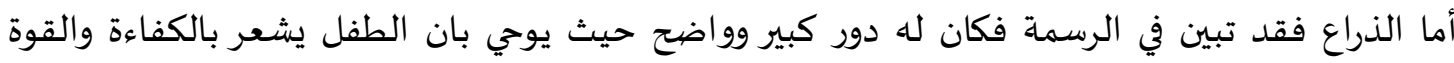

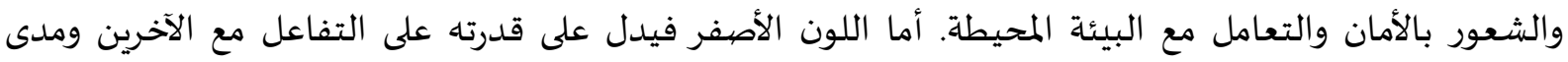

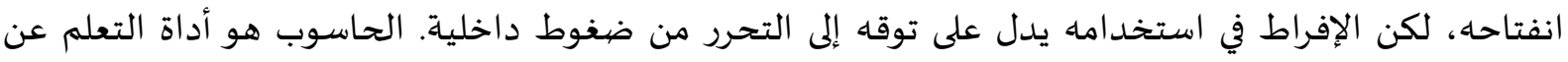

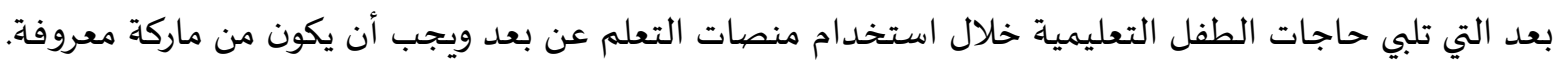

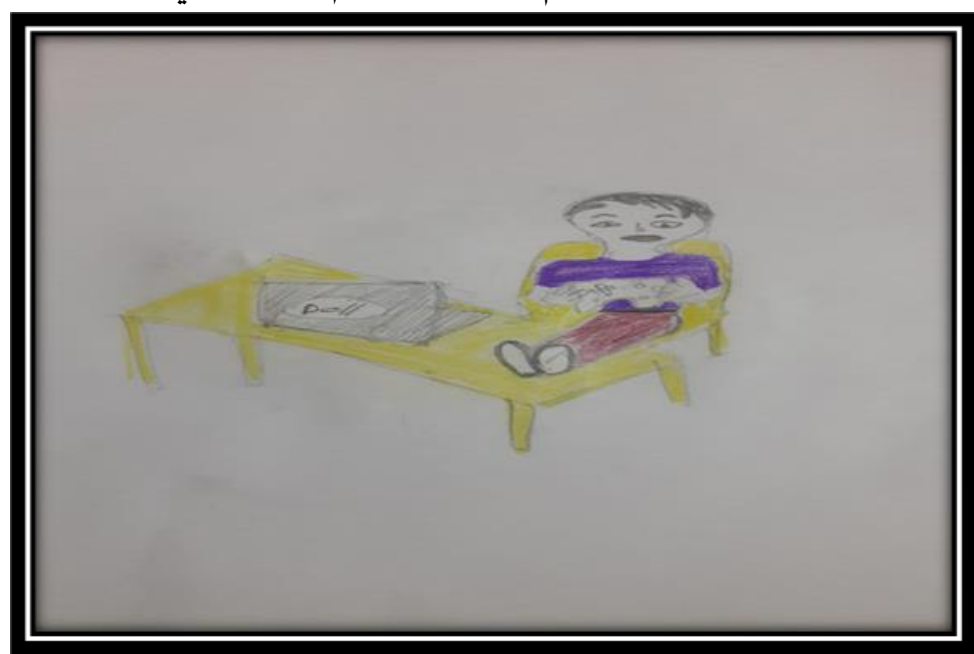

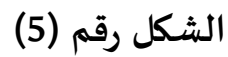


الرسم في وسط الورقة، تدلّ على أنّه طفل اجتماعي يحب الرفقة والاختلاط مع الناس، كما تدل على أنّه

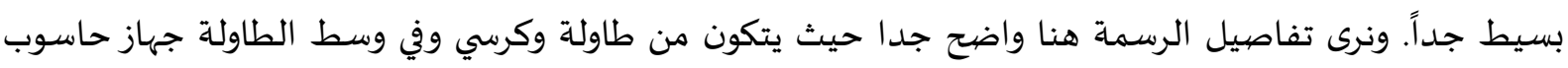

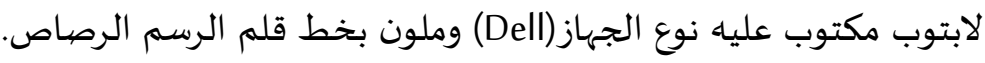

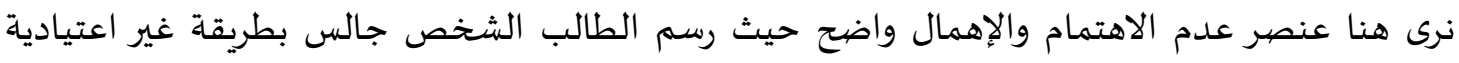

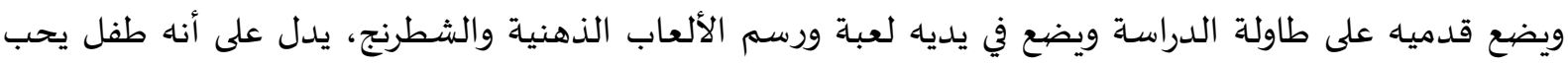

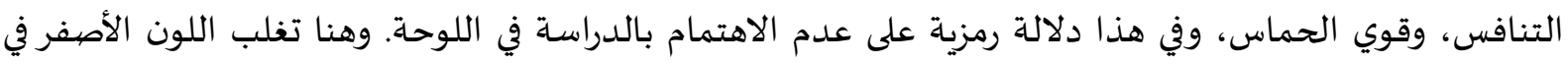

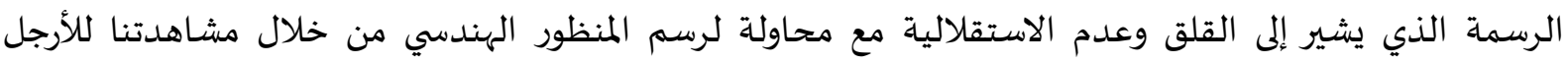

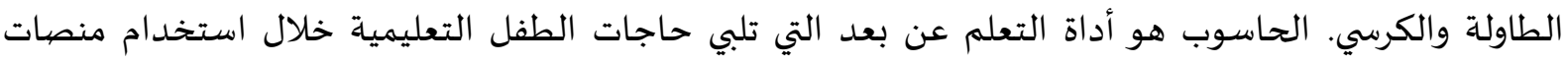

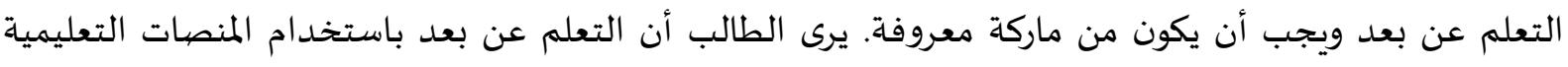

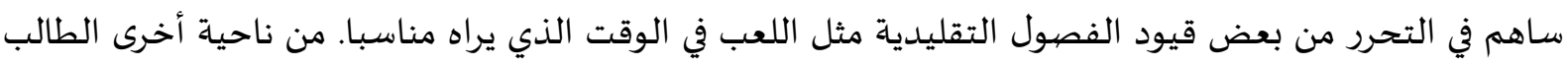

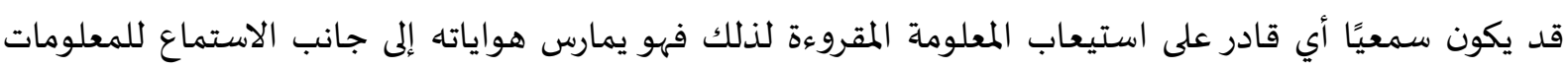
المطروحة على المنصة (نظرية الذكاءات المتعددة).

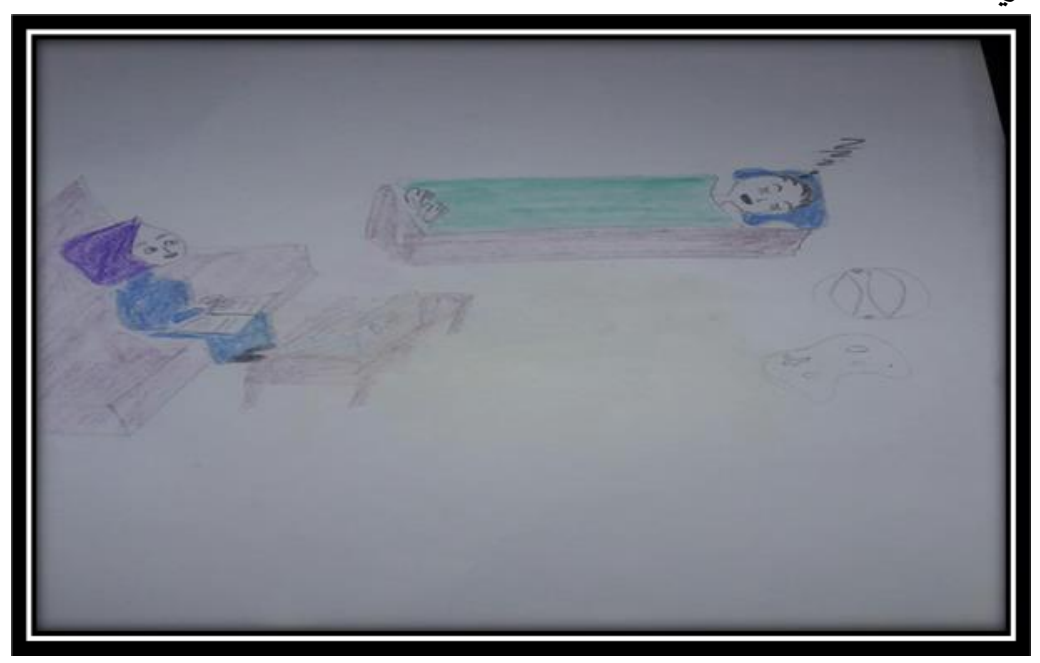

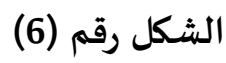

أول ما يلفت الانتباه فيما قام باه الطالب هو ذلك السرير الكبير الذي يتوسط الرسمة، ، تظهر الرسمة

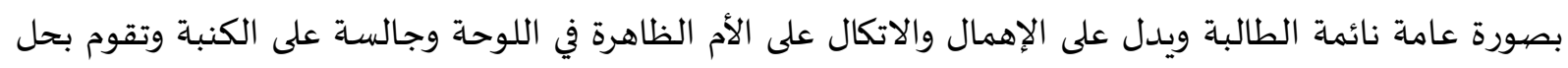

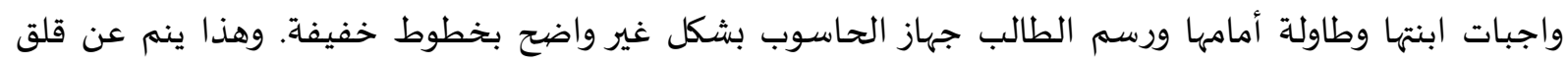
وتوتر.

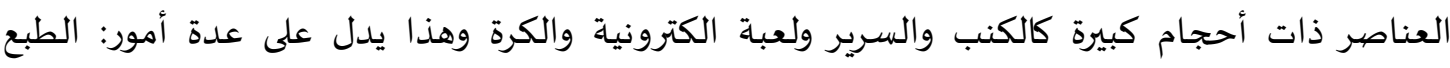

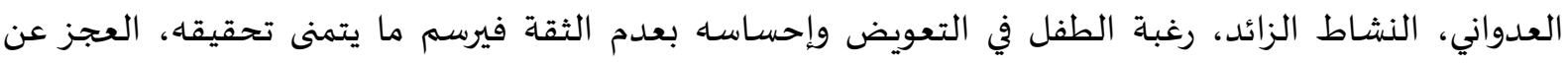

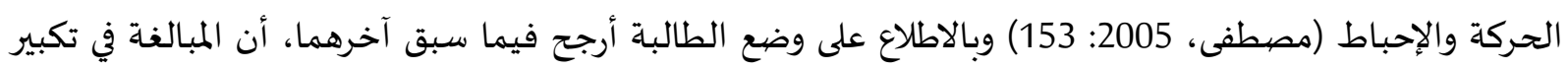

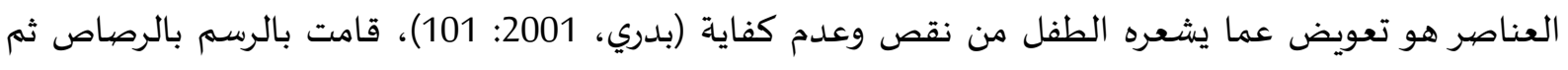

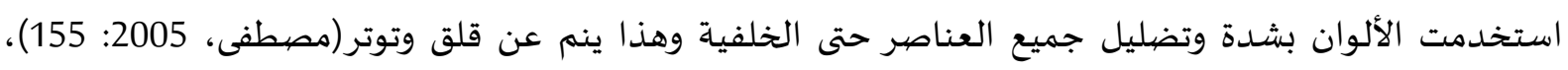

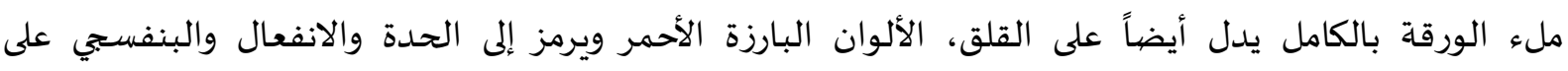

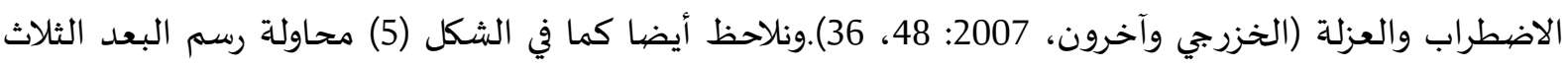

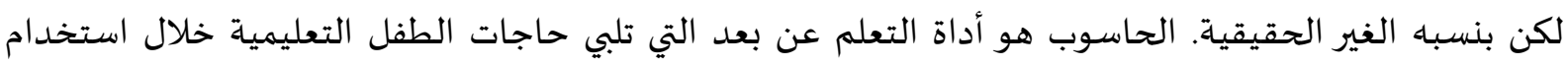
منصات التعلم عن بعد. 
يرى الطالب أن التعلم عن بعد باستخدام المنصات التعليمية ساهم في التحرر من بعض قيود الفصول التقليدية من خلال نوماه في الوقت الذي يراه مناسبا.

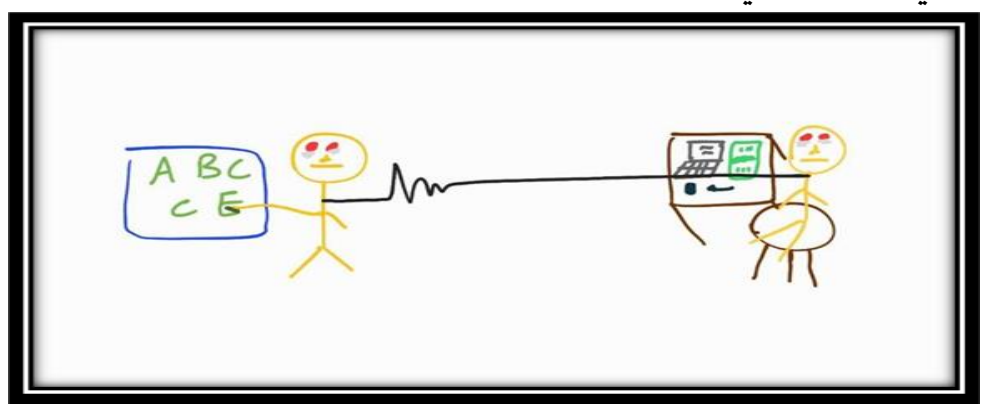

(7) (7) الشكل رقم (con)

موضهوع الرسمة يظهر بأن الطالب بين موضوع التعليم عن بعد بشكل واضح ومميز كما أكدت على موضهوع

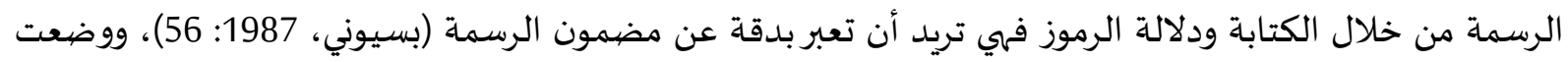

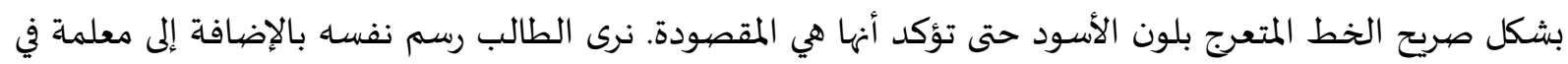

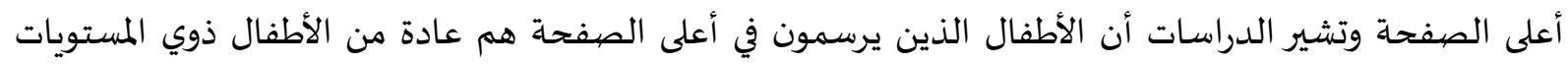

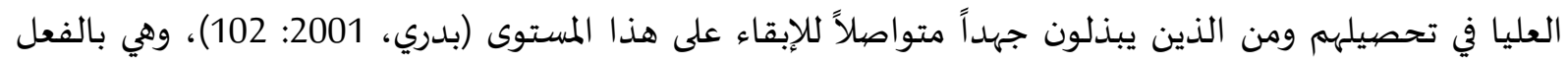
متميزة دراسياً. رسمت الطالبة نفسها مع المعلمة وهذا ينم عن تمتعها باتزان نفسي، وثقة بالنفس (الخزرجي وآخرون،

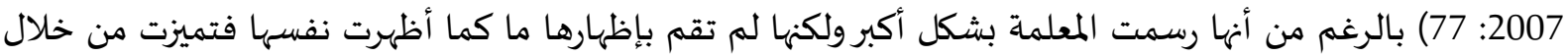

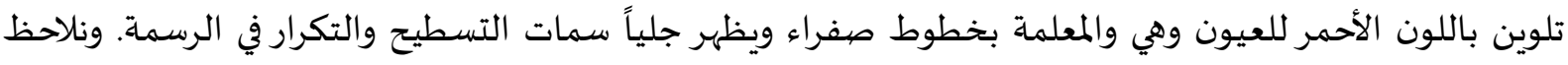

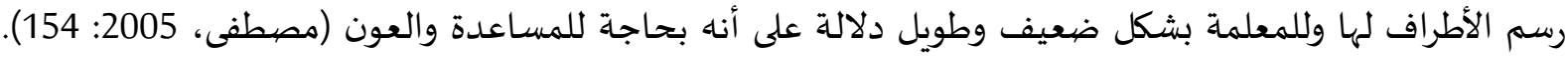

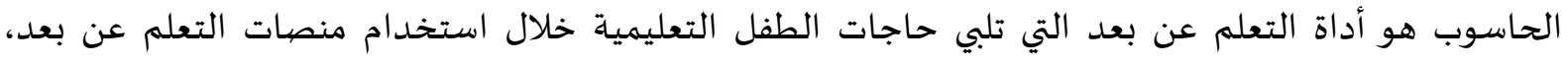
واللوح الذكي SMART Board عند المعلم يلبي حاجات المعلم. يرى الطالب أن التعلم عن بعد باستخدام المنصات التعليمية ساهم في التحرر من بعض قيود الفصول

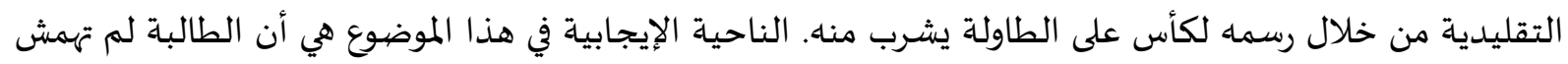
دور المعلمة وأنها لا زالت على تواصله رسهل معها لفهم دروسيا.

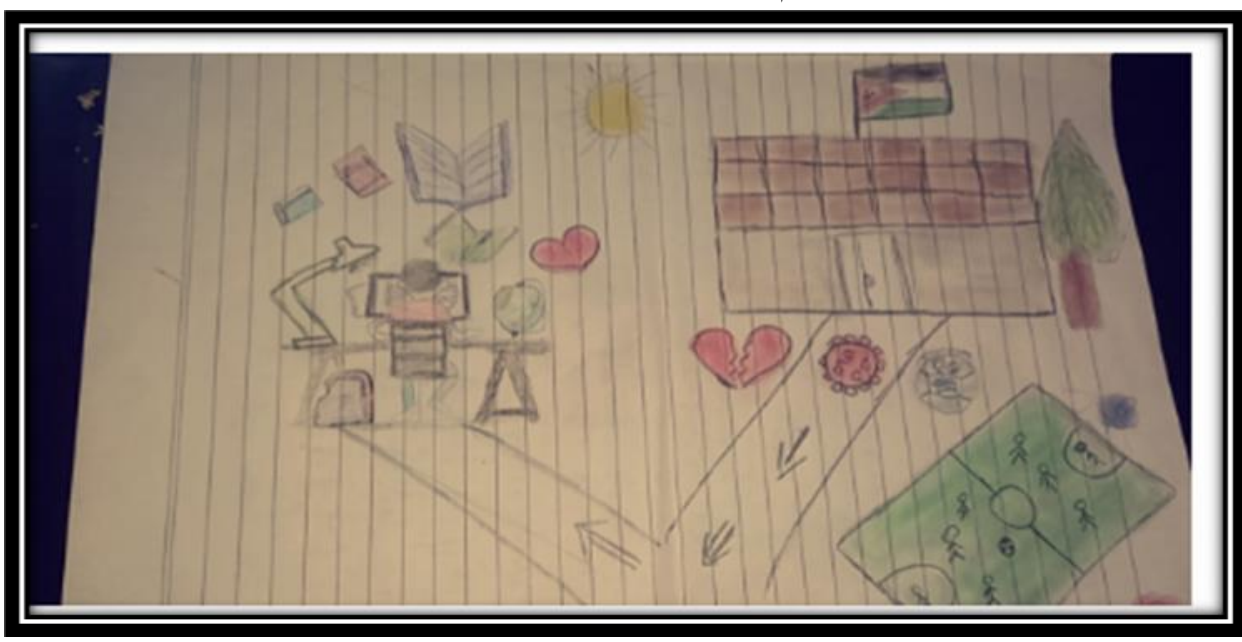

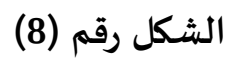


التعلم عن بعد محور حياة الطالب حاليا بدليل انه اختزل كل حياته في مكتب وحاسوب وأدوات دراسة،

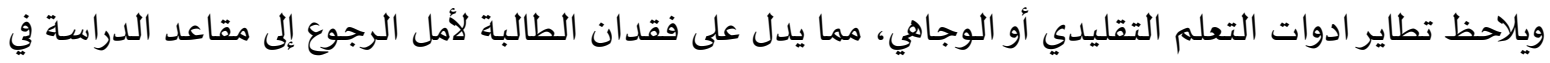

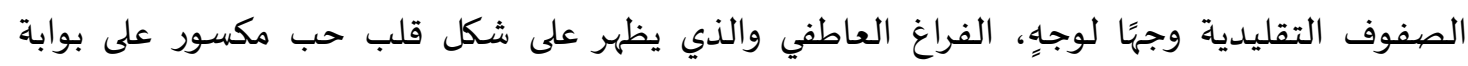

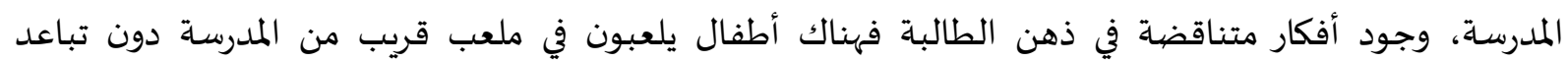

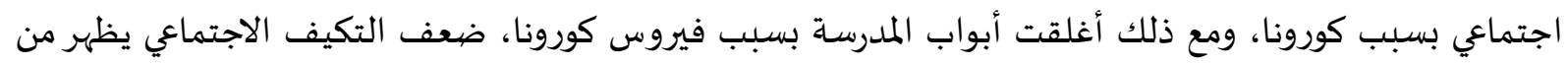

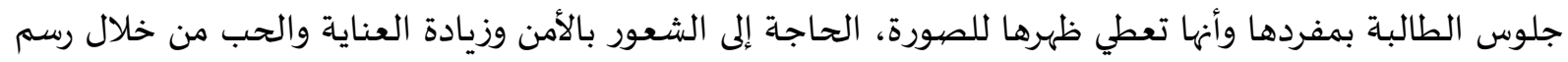

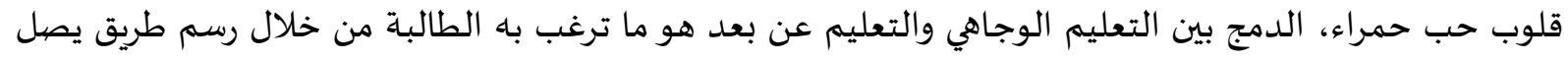

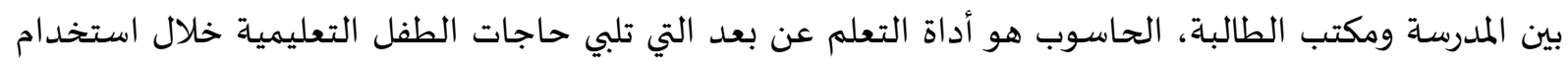

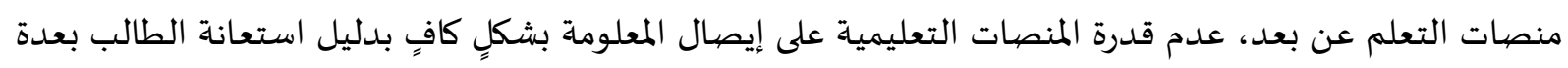

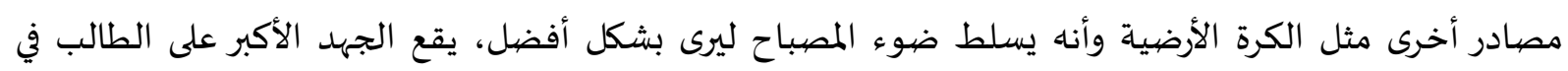
التعلم عن بعد في هذه الصيورة أمور إيجابية وهي إدراك الطالب أن التحول عن بعد كان لغايات لحفاظ على صحته من

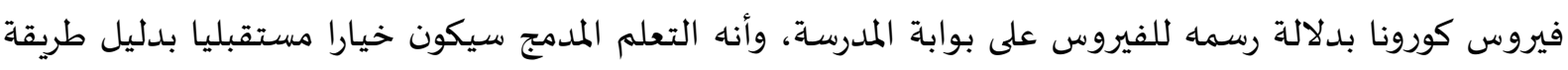

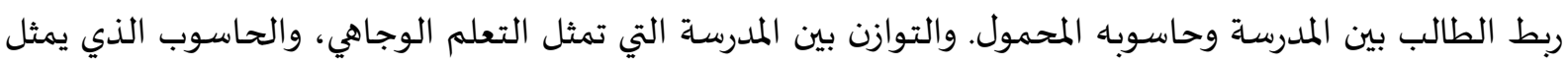

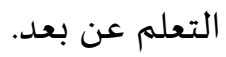

نتائج تحليل البيانات:

\begin{tabular}{|c|c|c|c|c|c|c|c|c|c|}
\hline & $\frac{\overline{3}}{\sqrt[3]{3}}$ & $\frac{\overline{3}}{13}$ & $\frac{\overline{3}}{3}$ & $\frac{\overline{3}}{3}$ & $\frac{\overline{3}}{3}$ & $\frac{\overline{3}}{3}$ & $\frac{\overline{3}}{3}$ & $\frac{\overline{3}}{3}$ & ظواهر عامة مرتبطة بالتعلم عن بعد عن طريق المنصيات \\
\hline $\begin{array}{l}63 \\
\%\end{array}$ & $\sqrt{ }$ & & & & $\sqrt{ }$ & $\sqrt{ }$ & $\sqrt{ }$ & $\sqrt{ }$ & التعلم عن بعد محور حياة الطالب حاليا \\
\hline $\begin{array}{l}50 \\
\%\end{array}$ & $\sqrt{ }$ & & & & & $\sqrt{ }$ & $\sqrt{ }$ & $\sqrt{ }$ & الرغبة بالدمج بين التعليم الوجاهي والتعليم عن بعد \\
\hline $\begin{array}{l}88 \\
\%\end{array}$ & $\sqrt{ }$ & $\sqrt{ }$ & $\sqrt{ }$ & $\sqrt{ }$ & $\sqrt{ }$ & $\sqrt{ }$ & & $\sqrt{ }$ & الحاسوب هو أداة التعلم عن بعد التي تلبي حاجات الطفل \\
\hline $\begin{array}{l}13 \\
\%\end{array}$ & & & & & & & $\sqrt{ }$ & & الهاتف المحمول هو أداة التعلم عن بعد التي تلبي حاجات \\
\hline & \multicolumn{9}{|c|}{ ظواهر سلبية مرتبطة بالتعلم عن بعد عن طريق المنصيات التعليمية } \\
\hline $\begin{array}{l}50 \\
\%\end{array}$ & $\sqrt{ }$ & & & & & $\sqrt{ }$ & $\sqrt{ }$ & $\sqrt{ }$ & الفراغ العاطفي \\
\hline $\begin{array}{l}50 \\
\%\end{array}$ & $\sqrt{ }$ & & & & & $\sqrt{ }$ & $\sqrt{ }$ & $\sqrt{ }$ & ضعف الاستقرار الداخلي \\
\hline $\begin{array}{l}63 \\
\%\end{array}$ & $\sqrt{ }$ & & $\sqrt{ }$ & & & $\sqrt{ }$ & $\sqrt{ }$ & $\sqrt{ }$ & ضعف التكيف الاجتماعي والشعور بالعزلة \\
\hline $\begin{array}{l}50 \\
\%\end{array}$ & $\sqrt{ }$ & & & & & $\sqrt{ }$ & $\sqrt{ }$ & $\sqrt{ }$ & الحاجة إلى الشعور بالأمن وزيادة العناية والحب \\
\hline
\end{tabular}




\begin{tabular}{|c|c|c|c|c|c|c|c|c|c|}
\hline & $\underset{\infty}{3}$ & $\frac{\overline{3}}{n}$ & $\frac{\overline{3}}{6}$ & in & $\frac{\pi}{3}$ & $\frac{\bar{s}}{m^{3}}$ & $\frac{\overline{3}}{2}$ & $\frac{\overline{3}}{5}$ & ظواهر عامة مرتبطة بالتعلم عن بعد عن طريق المنصيات \\
\hline $\begin{array}{l}13 \\
\%\end{array}$ & & & & & & $\sqrt{ }$ & & & القلق من الدراسة على الكتاب بعد حضور الدروس على المنعية \\
\hline $\begin{array}{l}38 \\
\%\end{array}$ & $\sqrt{ }$ & $\sqrt{ }$ & & & $\sqrt{ }$ & & & & عدم قدرة المنصهات التعليمية على إيصال المعلومة بشكلٍ كافٍ \\
\hline $\begin{array}{l}25 \\
\%\end{array}$ & $\sqrt{ }$ & $\sqrt{ }$ & & & & & & & الطالب يبذل جهدًا كبيرًا ليبقى متميزًا باستخدام منصهات \\
\hline 13 & & $\sqrt{ }$ & & & & & & & المشكلات الصحية التي سبيها التقنيات والأجهزة مثل الإجهاد \\
\hline $\begin{array}{l}38 \\
\%\end{array}$ & $\sqrt{ }$ & $\sqrt{ }$ & & & $\sqrt{ }$ & & & & 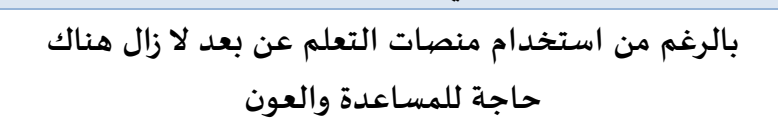 \\
\hline $\begin{array}{l}75 \\
\%\end{array}$ & $\sqrt{ }$ & $\sqrt{ }$ & & & $\sqrt{ }$ & $\sqrt{ }$ & $\sqrt{ }$ & $\sqrt{ }$ & يقع الجهد الأكبر على الطالب في التعلم عن بعد \\
\hline $\begin{array}{l}13 \\
\%\end{array}$ & & & $\sqrt{ }$ & & & & & & سلوكيات بعض أولياء الأمور خاصلة الأمهات التي قادت الأبناء \\
\hline $\begin{array}{l}38 \\
\%\end{array}$ & & & $\sqrt{ }$ & $\sqrt{ }$ & $\sqrt{ }$ & & & & 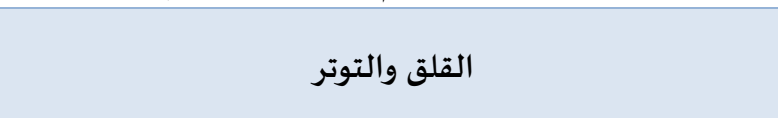 \\
\hline $\begin{array}{l}25 \\
\%\end{array}$ & & & $\sqrt{ }$ & $\sqrt{ }$ & & & & & 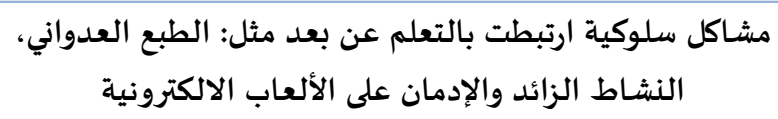 \\
\hline & \multicolumn{9}{|c|}{ ظواهر إيجابية مرتبطة بالتعلم عن بعد عن طريق المنصيات التعليمية } \\
\hline $\begin{array}{l}13 \\
\%\end{array}$ & $\sqrt{ }$ & & & & & & & & التحول للتعلم عن بعد ساهم في الحفاظ على صحة الطلبة مع \\
\hline $\begin{array}{l}38 \\
\%\end{array}$ & & $\sqrt{ }$ & $\sqrt{ }$ & & & & & $\sqrt{ }$ & التعلم عن بعد باستخدام المنصات التعليمية ساهم في التحرر \\
\hline $\begin{array}{l}13 \\
\%\end{array}$ & & & & & & & & $\sqrt{ }$ & وجود مضمون تعليمي يستحق التدوين في المنصهة. \\
\hline $\begin{array}{l}13 \\
\%\end{array}$ & & & & & & & $\sqrt{ }$ & & وجود معلومات قد توصل الطالب لفهمها من الشرح المعروض على المنصية. \\
\hline $\begin{array}{l}75 \\
\%\end{array}$ & $\sqrt{ }$ & $\sqrt{ }$ & & & $\sqrt{ }$ & $\sqrt{ }$ & $\sqrt{ }$ & $\sqrt{ }$ & تعدد قنوات الحصول على المعرفة: المنصهات التعليمية، \\
\hline $\begin{array}{l}13 \\
\%\end{array}$ & & & & $\sqrt{ }$ & & & & & دعم الذكاءات المتعددة \\
\hline $\begin{array}{l}13 \\
\%\end{array}$ & & $\sqrt{ }$ & & & & & & & 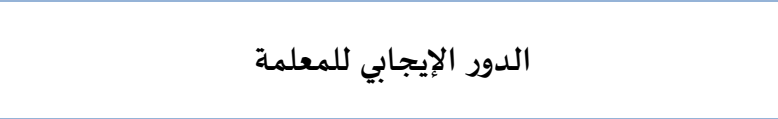 \\
\hline $\begin{array}{l}13 \\
\%\end{array}$ & $\sqrt{ }$ & & & & & & & & التوزان بين التعلم الوجاهي والتعلم عن بعد \\
\hline
\end{tabular}


النتائج على شكل رسومات بيانية: ولتسهيل قراءة النتائج تم تفريخ هذه الجداول على برنامج الجداول الالكترونية MS-EXCEL وتئة وتحويلها إلى

\begin{tabular}{|c|c|c|c|c|}
\hline & & & & $100 \%$ \\
\hline & & & & $80 \%$ \\
\hline & & & & $70 \%$ \\
\hline & & 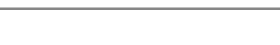 & . & $60 \%$ \\
\hline & & & & $40 \%$ \\
\hline & & & & $30 \%$ \\
\hline & & 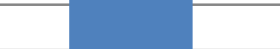 & 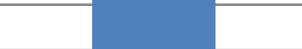 & $20 \%$ \\
\hline \multirow{2}{*}{\multicolumn{5}{|c|}{ الحاسوب هو أداة التعلم عن الهاتف الدحمول هو أداة }} \\
\hline & & & & \\
\hline \multicolumn{5}{|c|}{ 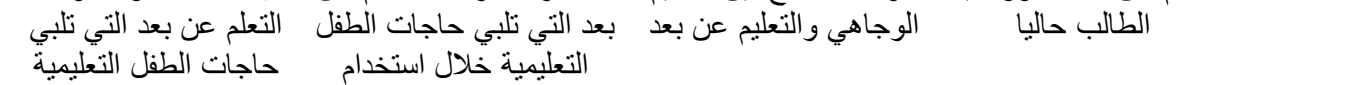 } \\
\hline \multicolumn{5}{|c|}{ منصات التعلم عن بعد خلال استخدام منصات التعلم } \\
\hline \multicolumn{5}{|c|}{ عن بعد } \\
\hline
\end{tabular}

الرسم البياني 1: ظواهر عامة مرتبطة بالتعلم عن بعد عن طريق المنصيات التعليمية

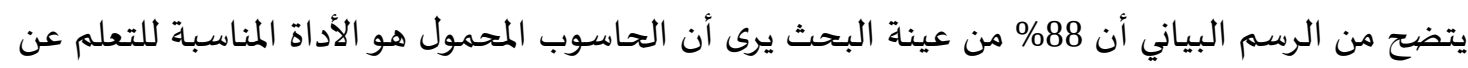

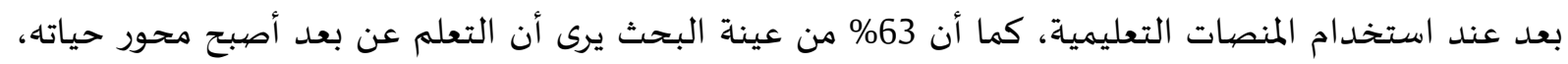

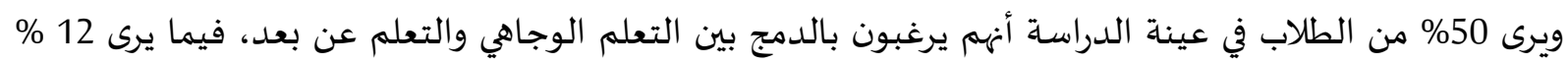

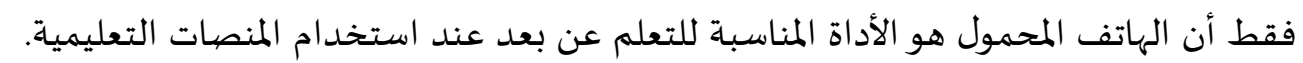

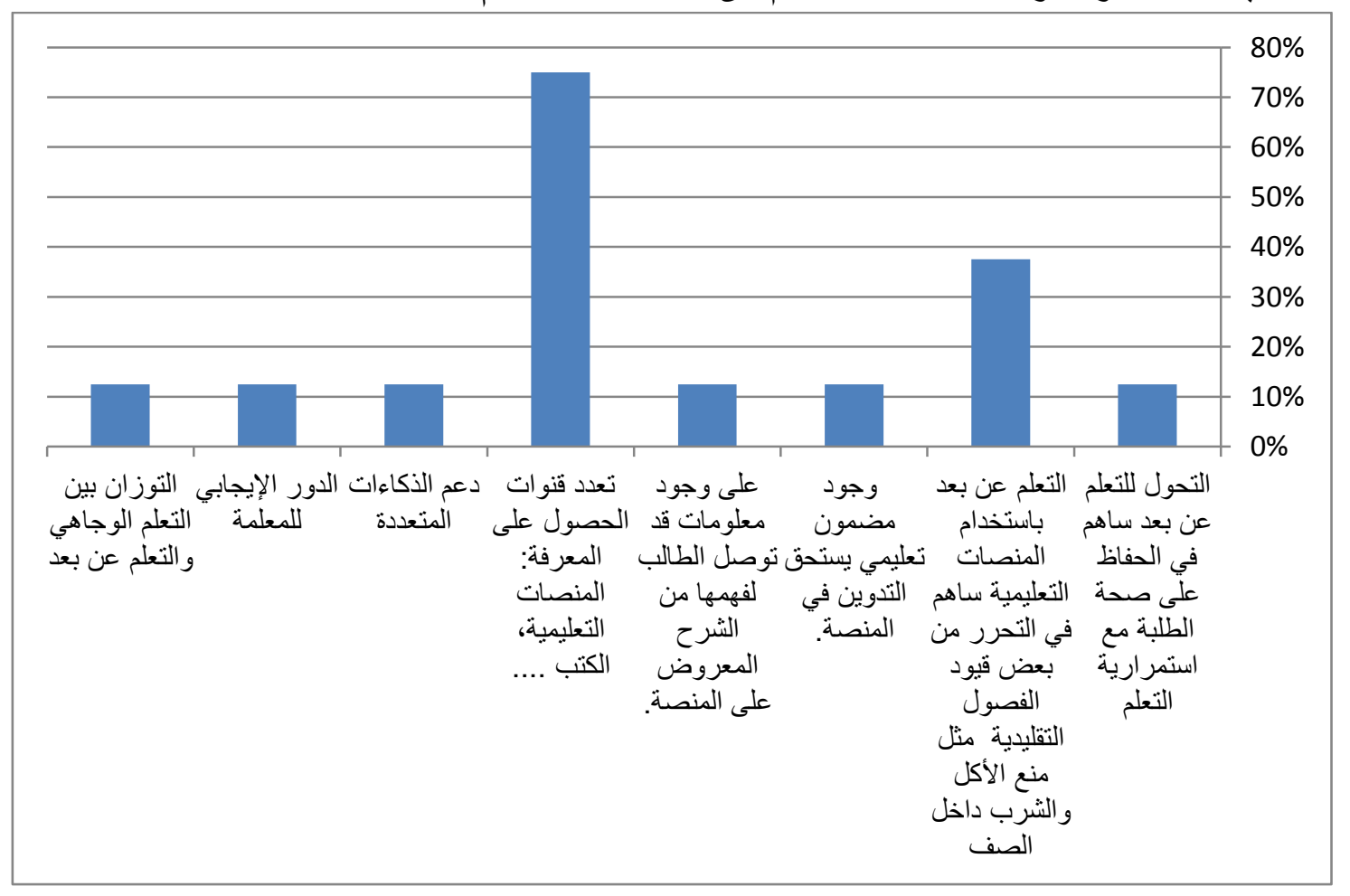

الرسم البياني 2: ظواهر إيجابية مرتبطة بالتعلم عن بعد عن طريق المنصهات التعليمية 


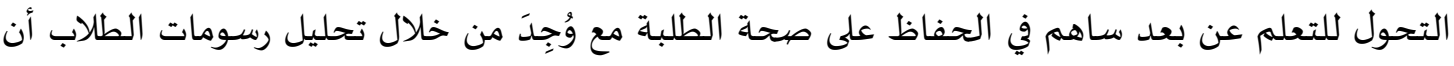

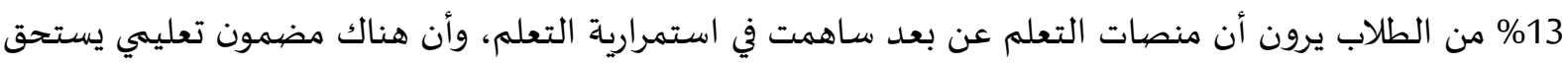
التدوين في المنصاة، وأن هنالك معلومات قد توصل الطالب لفهمها من الشرح المعروض على المات المنصية، وأنها تدعم الذكاءات المتعددة، وأن هناك دور إيجابي للمعلم على المنصات المنات التعليمية، وضرورة التوزان بين التعلم الوجاهي تلوني

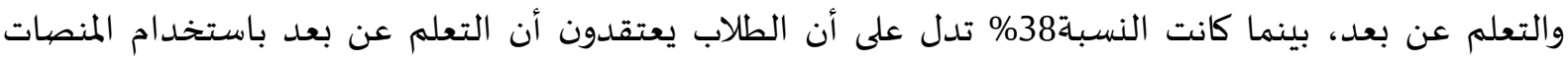

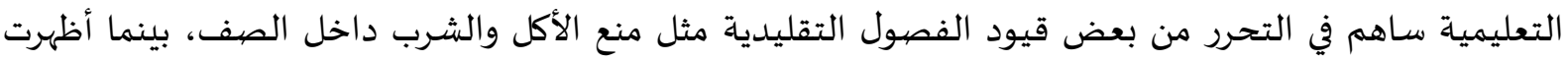
الرسومات التي تم تحليلها أن 75 \% من الطلاب يجدون أن هناك تعدد لقنوات الحصول على المعرفة: المنصات

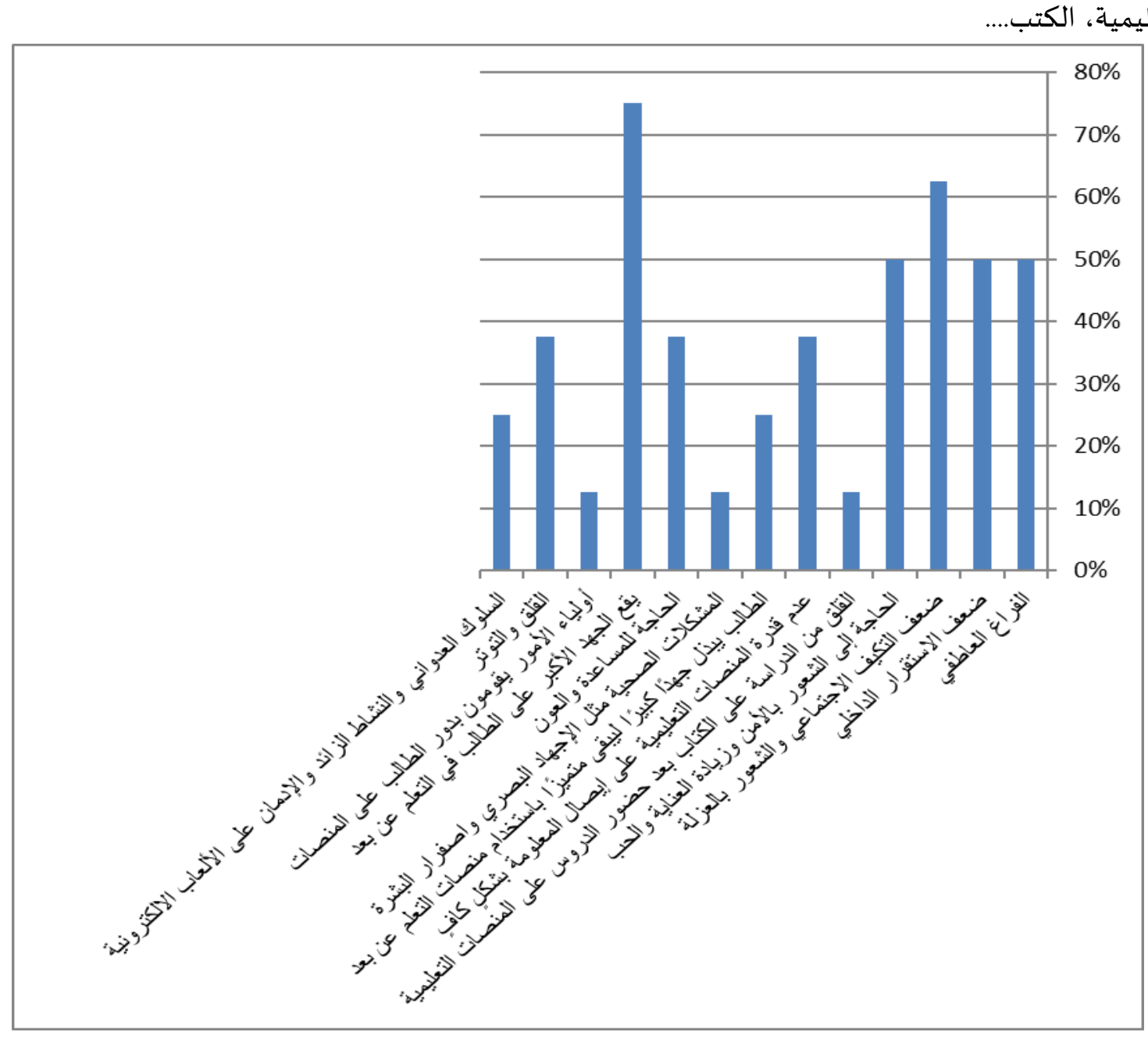

الرسم البياني 3: ظواهر سلبية مرتبطة بالتعلم عن بعد عن طريق المنصيات التعليمية

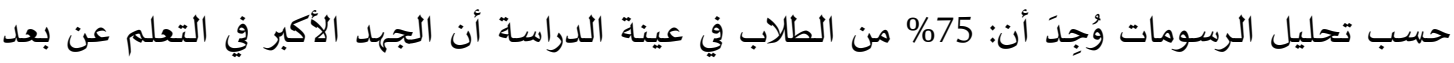
يقع على الطالب، وأن 63 \% أن التعلم عن بعد كان السبب في ضعف أند التكيف الاجتماعي والشعور بالعزلة، وأن 50 والن

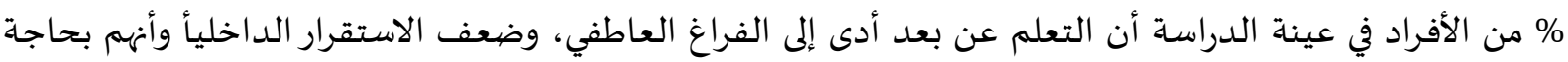

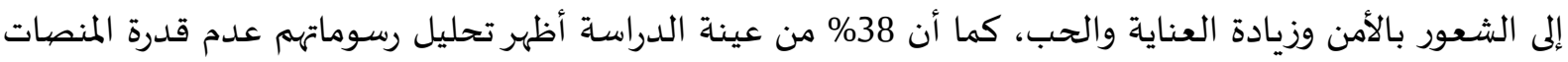

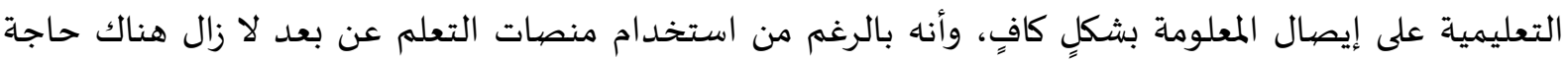

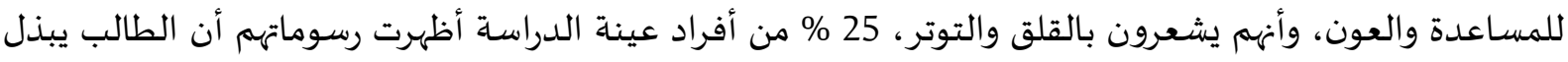

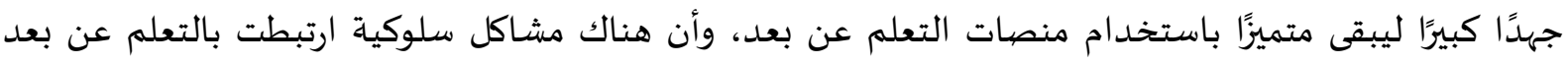


مثل: الطبع العدواني، النشاط الزائد والإدمان على الألعاب الالكترونية، 13 \% من أفراد عينة الدراسة أظهرت رسوماتهم أن القلق من الدراسة على الكتاب بعد حضيور الدروس على المنصات التعليمية، وأن هنالك مشكلات صحية سببتها التقنيات والأجهزة مثل الإجهاد البصري واصفرار البشرة، وأن سلوكيات بعض البه أولياء الأمور خاصية

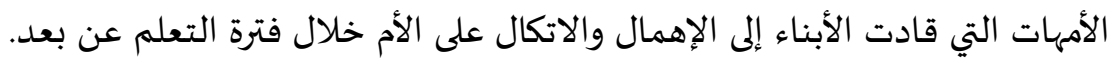

المناقشـة والاستنتاجات:

تم استخلاص تصورات طلاب المرحلة الأساسية في مدارس محافظة المفرق حول استخدام منصات التعلم

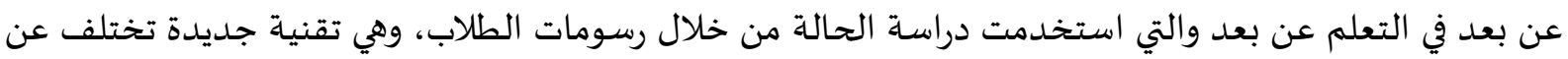

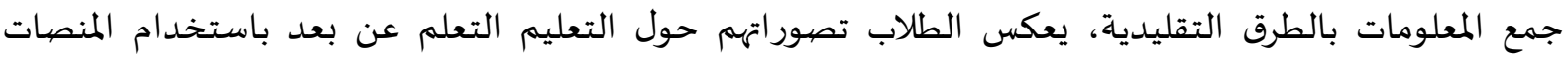

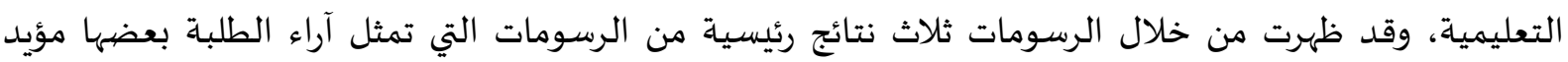
أظهر الإيجابيات، وبعضها معارض أظهر السلبيات، وبعضها محايد تم الإشـارة إليه بعبارة الظواهر العامة المرتبطة بالتعلم عن بعد عن طريق المنصات التعليمية. نتائج سؤال البحث الأول: "ما الظواهر العامة التي ظهرت مصاحبة للتعلم عن بعد من خلال المنصات

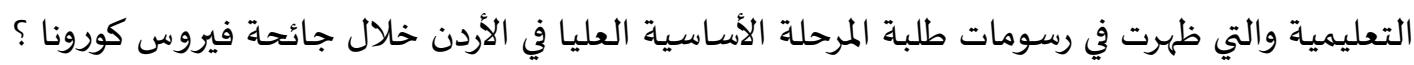

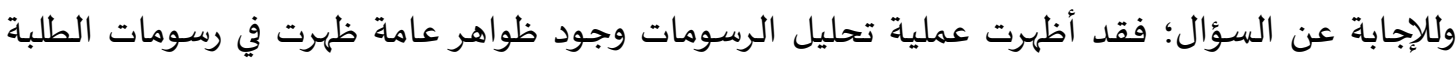
وارتبطت بموضوع التعلم عن بعد وتم تسميتها بظواهر عامة لأهها تقع على الحياد فلا يمكن القول أنها إيجابية

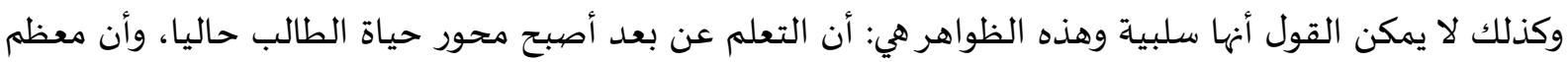

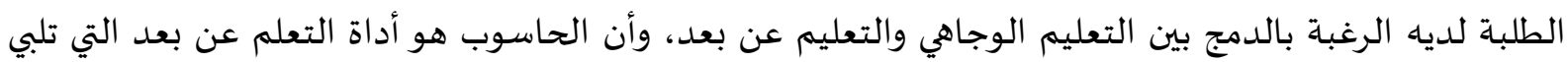

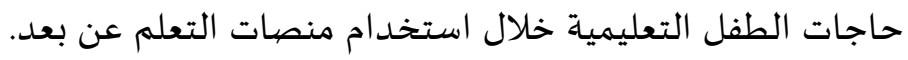
نتائج سؤال البحث الثاني: "ما الأبعاد الإيجابية للتعلم عن بعد من خلال المنصات التعليمية والتي ظهرت في

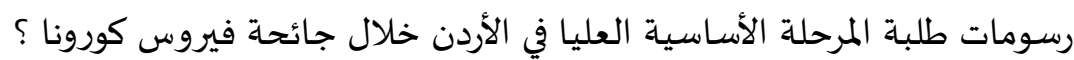
وللإجابة عن السؤال؛ فقد أظهرت عملية تحليل الرسومات وجود أبعاد إيجابية للتعلم عن بعد من خله خلال التهال المنصات التعليمية ظهرت في رسومات الطلبة وارتبطت بموضوع التعلم عن بعد وتم وصفها بأنها إيجابية لأن منافعها تفوق أضرارها وهذه الظواهر هي:

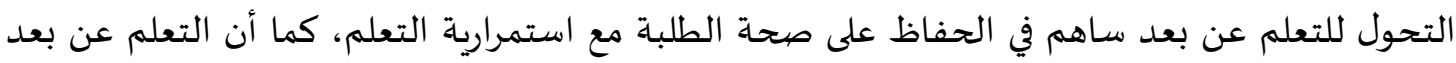

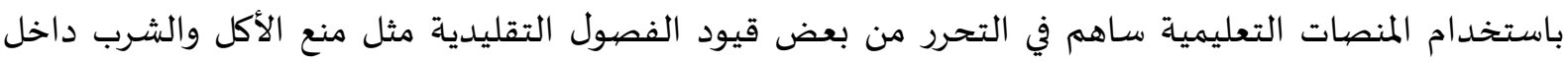

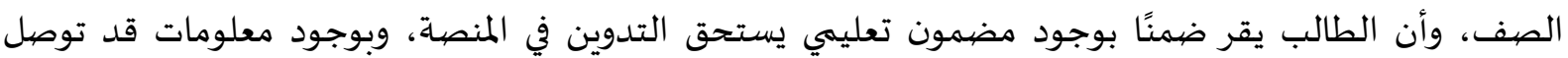

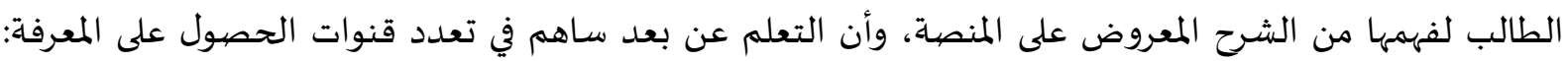

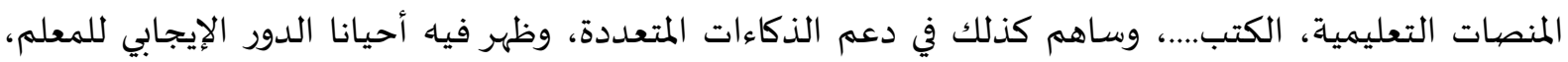
وأن هذه التجربة ستكون واعدة أذا ما تم تحقيق التوزان بين التعلم الوجاهي والتعلم عن بعد.

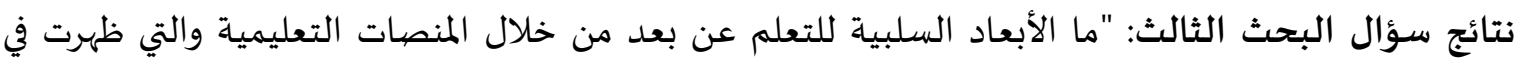

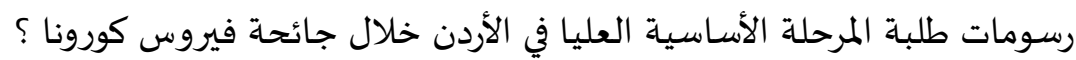
وللإجابة عن السؤال؛ فقد أظهرت عملية تحليل الرسومات وجود أبعاد سلبية للتعلم عن بعد من من خلالال المنصات التعليمية ظهرت في رسومات الطلبة وارتبطت بموضوع التعلم عن بعد وتم وصفها بأهها سلبية لأن أضرارها تفوق منافعها وهذه الظواهر هي: 
مساهمة التعلم عن بعد في ضعف التكيف الاجتماعي والشعور بالعزلة، والفراغ العاطفي، وضعف

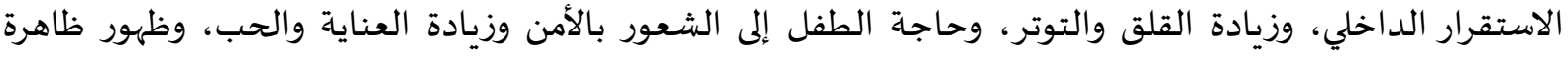

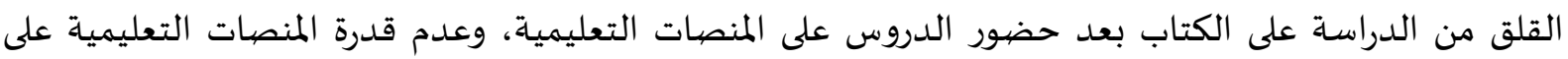

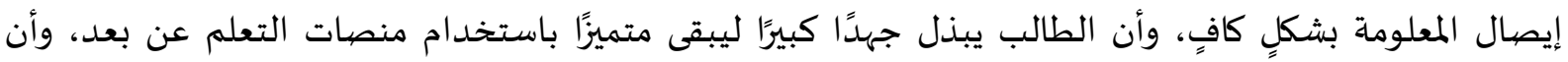

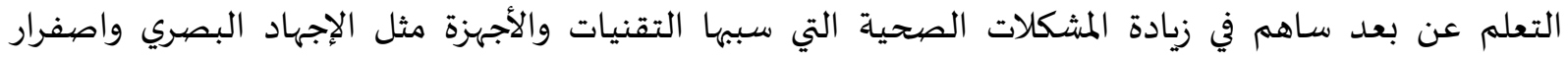

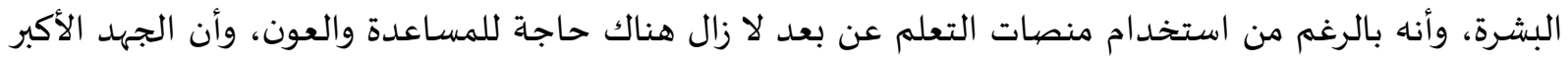

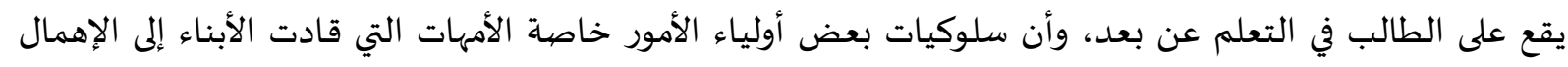

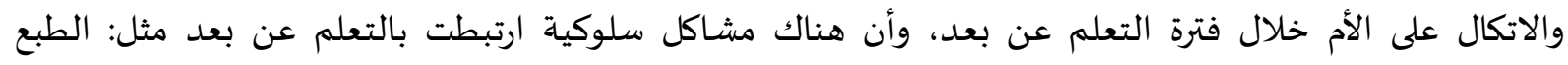

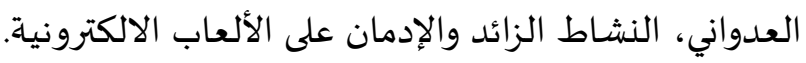

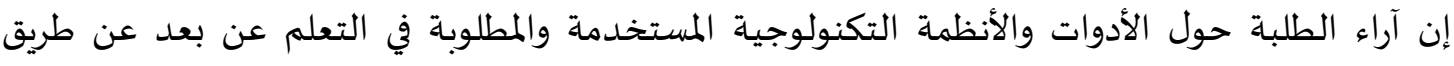

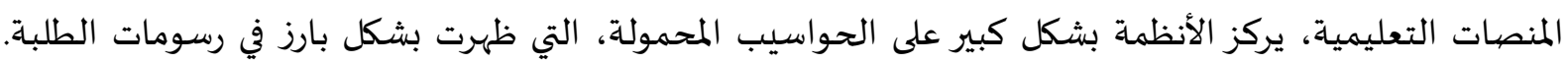

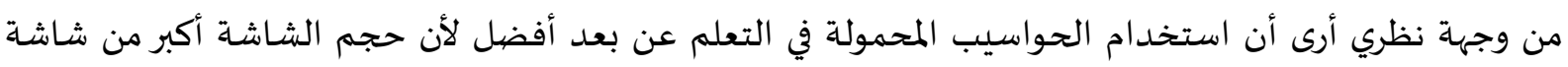
الهواتف المحمولة وبالتالي يقلل من الإجهاد البصرئ البحري.

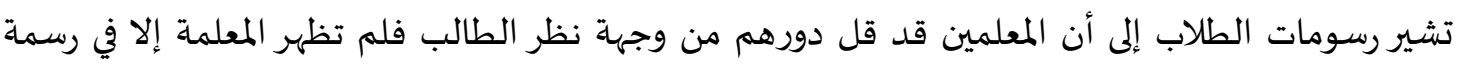

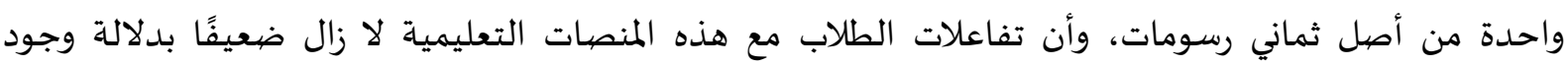

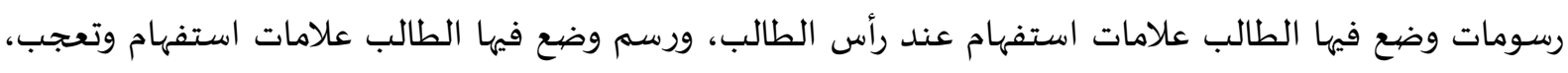

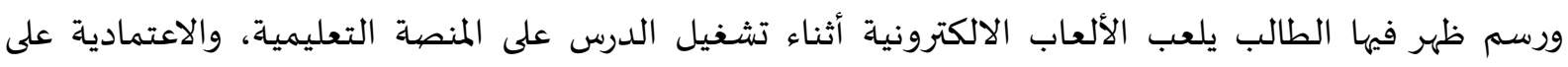

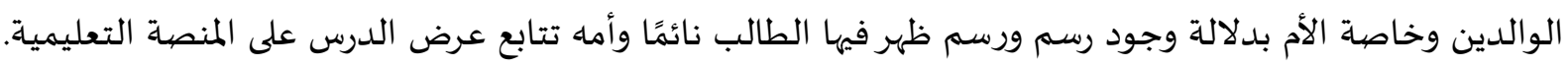

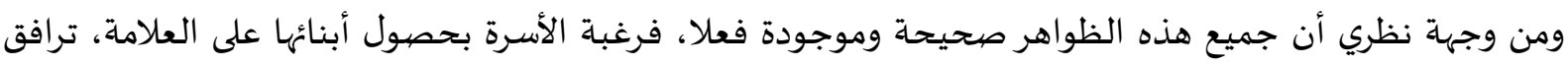

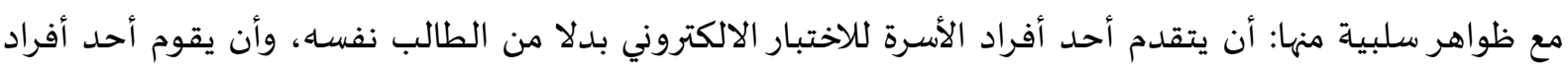

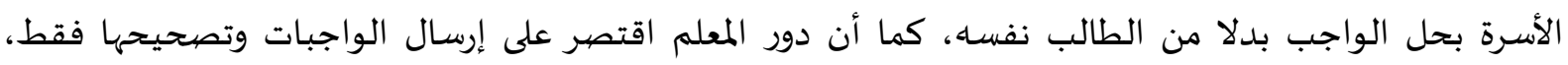

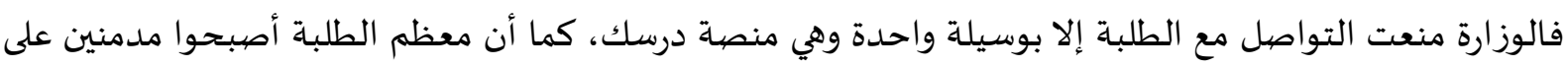

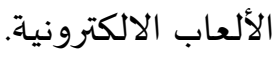

5. التوصيات والمقترحات.

\section{توصيات للقائمين على المنصيات التعليمية:}

1. التعلم عن بعد محور حياة الطالب حاليا، لأنه غير قادر على فهم كل المبادئ العلمية الأساسية لوحداه

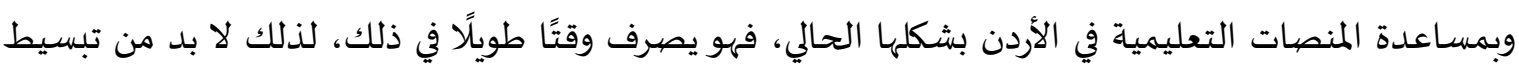

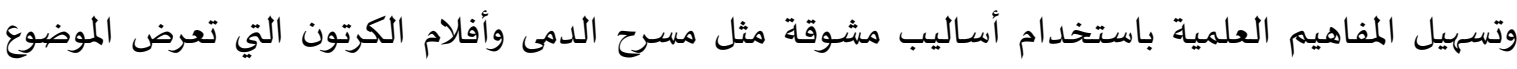

2. ضرورة الدمج بين التعليم الوجاهي والتعليم عن بعد، يكون التعليم الوجاهي لشرح الأساسيات والمفاهيم

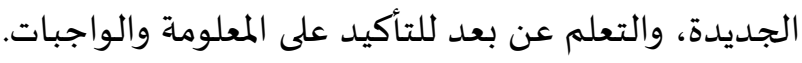
3. الحاسوب هو أداة التعلم عن بعد التي تلبي حاجات الطفل التعليمية خلال استخدام منصات المعات التعلم عن بعد،

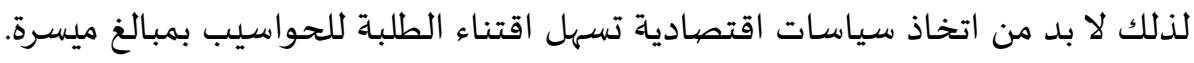


4. يحتاج المعلمون إلى برامج التطوير الممني لفهم كيفية تفعيل دور المعلم بشكل أفضل في التعليم عن بعد

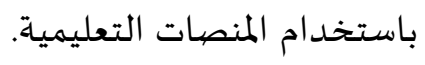

5. إدخال التعلم الالكتروني المتزامن وجيًا لوجها تدريجيا إلى المنصات التعليمية في الأردن.

$$
\text { توصيات للإدارات المدرسية }
$$

1. ت تفعيل الإدارات المدرسية لدور الإرشاد المدرسي والأسري في توجيه الطلبة وأولياء أمورهم إلى أنشطة تقلل من

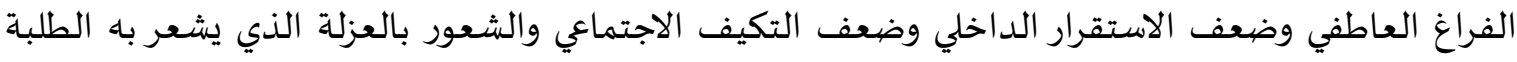
في هذه الفترة بما يتناسب مع الوضع الوبائي.

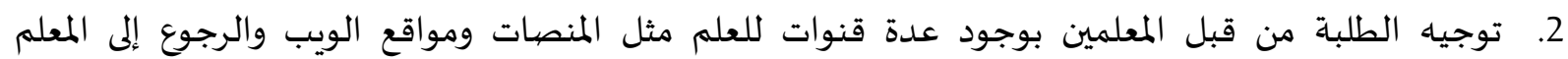
والرجوع إلى أصحاب الاختصاص من أفراد الأسرة. 3. وجود حملات توعية موجهة لأولياء الأمور للحد من سلوكياد الآهرة الأهم التي قادت الأبناء إلى الإهمال والاتكال على الأم

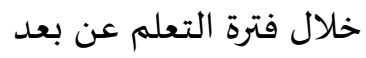

$$
\text { توصيات لأولياء الأمور }
$$

1. بث الشعور بالأمن في نفوس أبنائه، وزيادة العناية والحب المقدم لهم خاصة في هذه المرحلة العمرية الحرجة

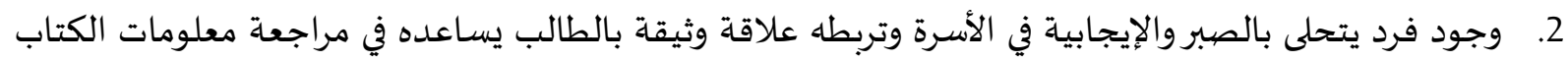

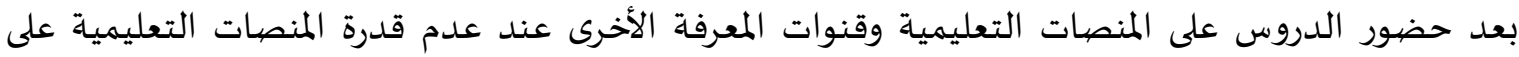

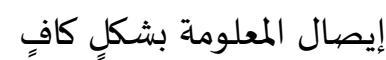
3. استكشاف مهارات الطفل اليدوية وهواياته وتشجيعه على صقلها واستثمارها بالشكل الأمثل، فهواية اليوم قد تكون بوابة لحرفة المستقبل. 4. مساعدة الطالب في تنظيم وقت استخدام التقنيات والأجهزة للحد من المشكلات الصحية المرتبطة بها مثل الإجهاد البصري واصفرار البشرة.

ه في الختام لا بد أن ننوه أنه عند تحليل رسومات الأطفال يجب أن يمتلك الشخرة الشخص المباد المعرفة والميول والإيمان

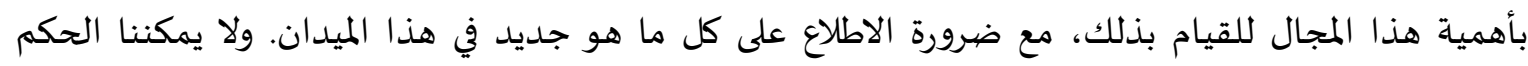

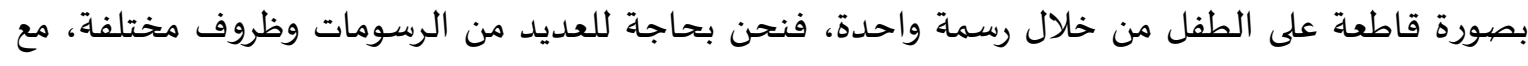
إلمامنا بجوانب من حياة الطفل كالجانب الاجتماعي.

قائمة المراجع.

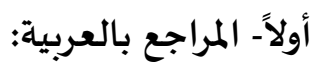

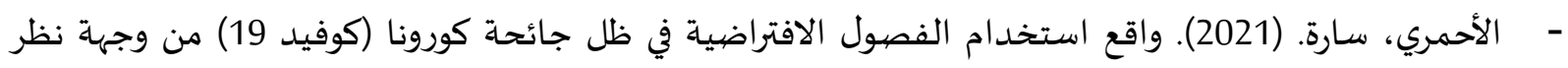

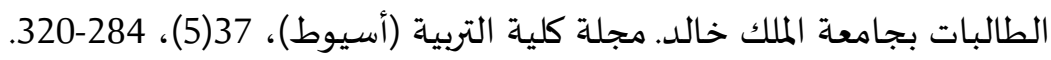

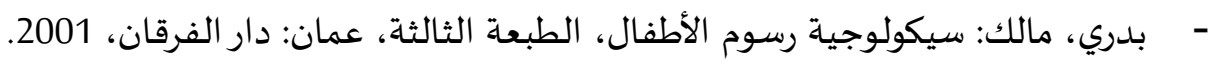
- البسيوني، محمود: تحليل رسومات الأطفال، الطبعة الأولى، مصر: دار المعارف، 1987م. 
تقي، فاطمة. (2015). دراسة مفهوم الذات من خلال الرسم لدى الأطفال الصهم مرتفعي ومنخفضي مفهوم

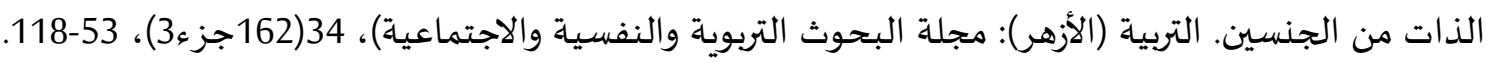

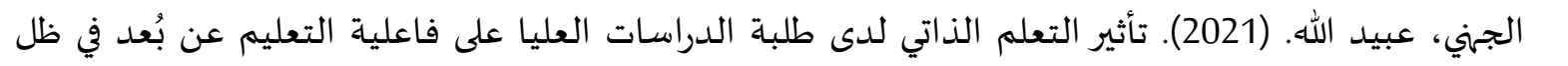

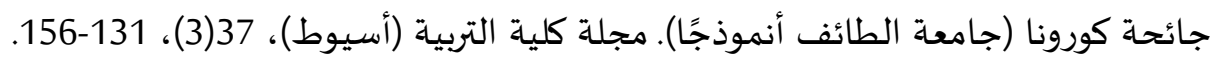
حسن، مصطفى، محمد، نهى، وفراج، عفاف. (2019). دراسة سيكولوجية رسوم الأطفال في ضوء تحوناء تحليل

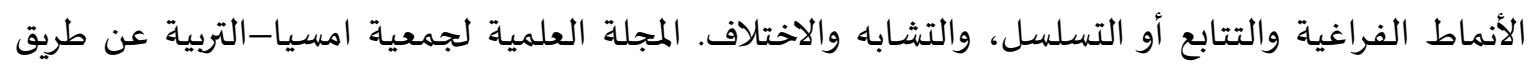
الفن، 5(17)، خايف، سكينة. (2016). الأبعاد النفسية في رسوم أطفال العوائل الفقيرة مادياً. مجلة الدراسات التربوية، (34) 9

الخزرجي، عمار، وبدير، ريان: سيكولوجية رسوم الأطفال، الطبعة الأولى، بيروت: دار الهادي، 2007.

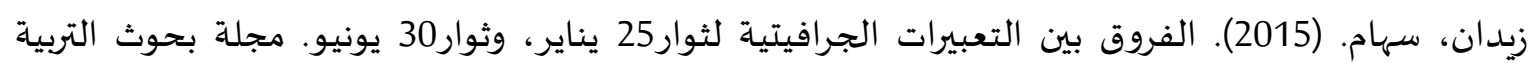

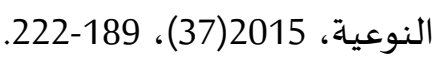

سعدون، جميلة. (2013). تحليل رسوم الأطفال المعتَدَى عليهم جنسيًا بمملكة البحرين دراسة وصفية

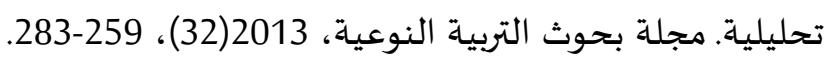
السعدي، محمد (2021). درجة الاستعداد للتعلم الرقمي في الأردن خلال جائحة كورونا من وجهة نظر معلمي

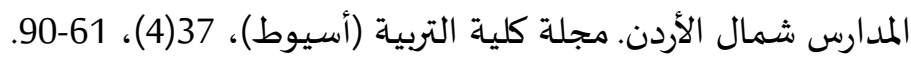

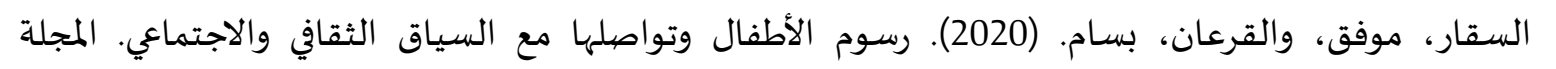

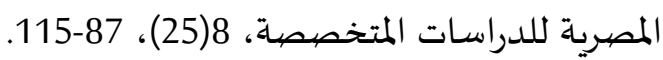
الشطي، يعقوب، وبن جمعة، جاسم. (2017). دراسة واقع الطفل الكويتي مع بيئته من خلال التعبيرات الفنية.

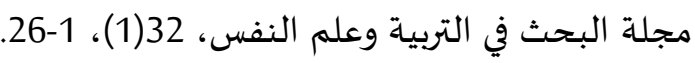

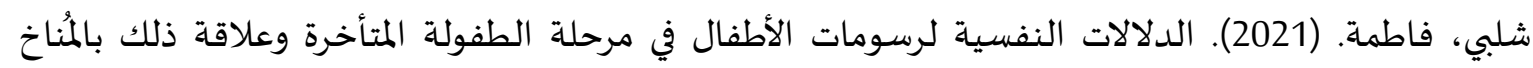
الأسري والتوافق النفس واجتماعي لديهم في محافظة جنين، رسالة دكتوراه، جامعة النجاح الوطنية.

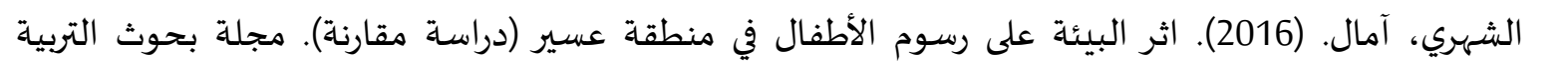
النوعية، 2016(41)، 563-592. الطهراوي، جميل، وأبو دقة، سناء. (2010). الدلالات النفسية لرسومات الأطفال الفلسطينيين" بعد حرب

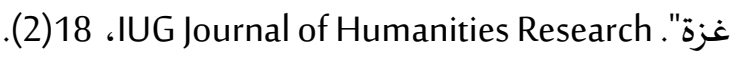
علاق، كريمة. (2012). محاولة تقنين اختبار رسم العائلة باستخدام تقنية رسم العائلة المتخيلة والحقيقية، رسالة دكتور اه، جامعة وهران.

فلفلان، محممد. (2020). التلفزيون وتأثيره على رسوم الأطفال في مرحلة الطفولة المتأخرة (من 9 إلى 12 سنة).

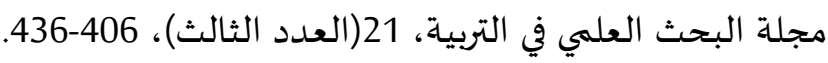

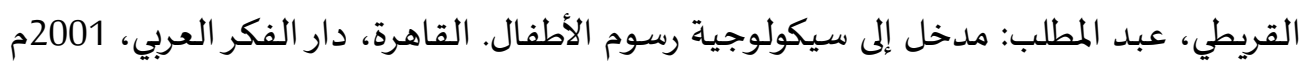

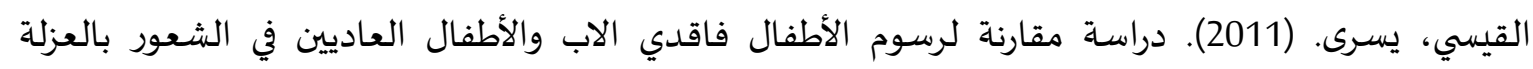
الاجتماعية. Al-Fatih journal، دئسي، 
- المباشر، فاطمة، والياسري، إنصاف. (2013). أثر المسكن الصحراوي في نفسية الطفل البدوي. آداب الكوفة،

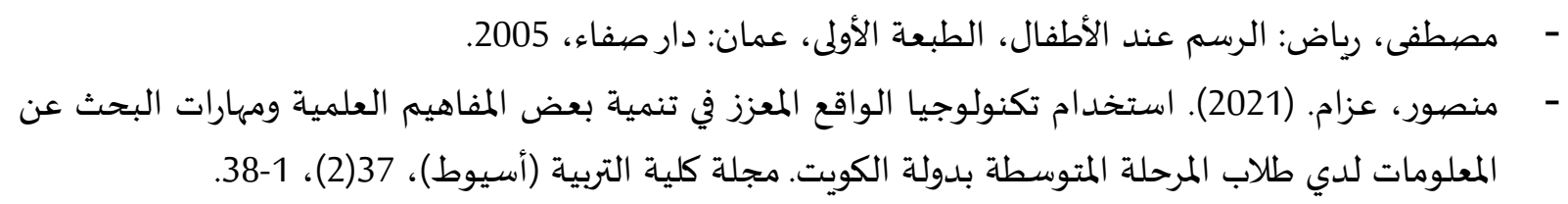

ثانياً - المراجع الأجنبية

- Alabdulkarim, S. O., Khomais, S., Hussain, I. Y., \& Gahwaji, N. (2021). Preschool Children's Drawings: A Reflection on Children's Needs within the Learning Environment Post COVID-19 Pandemic School Closure. Journal of Research in Childhood Education, 1-16.

- Brown, G. \& Wang, Z. (2013). Illustrating assessment: how Hong Kong university students conceive of the purposes of assessment. Studies in Higher Education, 38(7), 1037-1057.

- Caymaz, G. F. Y., Türkdoğdu, H., Edgü, E., \& Karaş, N. (2018). An Analysis of Primary School-Aged Children's Drawings and Their Play Area Preferences. US-China Education Review, 8(5), 221-232.

- Deguara, J. (2019). Young children's drawings: A methodological tool for data analysis. Journal of Early Childhood Research, 17(2), 157-174.

- Funkhouser, B. J. \& Mouza, C. (2013). Drawing on technology: an investigation of preservice teacher beliefs in the context of an introductory educational technology course. Computers \& Education, 62 , 271-285.

- Illhan, G. O., Kaba, G., \& Sin, M. (2021). Usage of Digital Comics in Distance Learning during COVID19. International Journal on Social and Education Sciences, 3(1), 161-179.

- Inaltekin, T. (2020). Examining secondary students' perceptions of the technology-based learning and teaching in science courses. World Journal on Educational Technology: Current Issues. 12(2), 071-083.

- Kumar, V., \& Sharma, D. (2021). E-Learning Theories, Components, and Cloud Computing-Based Learning Platforms.International Journal of Web-Based Learning and Teaching Technologies (IJWLTT), 16(3), 1-16.

- Kuzle, A., \& Gracin, D. G. (2020). Making Sense of Geometry Education Through the Lens of Fundamental Ideas: An Analysis of Children's Drawings. The Mathematics Educator, 29(1)

- Qazi, A., Qazi, J., Naseer, K., Zeeshan, M., Qazi, S., Abayomi-Alli, O.,... \& Haruna, K. (2021). Adaption of distance learning to continue the academic year amid COVID-19 lockdown. Children and Youth Services Review, 126, 106038.

- Shehada, F. H., Khalil, D. M., \& Alrawajfah, F. S. (2021). The Reality of Using Darsak Platform and Its Obstacles By The Teachers of Primary School in Southern Amman Schools in Light of The Corona Pandemic COVID-19. Psychology and Education Journal, 58(1), 4386-4403. 
المجلة العربية للعلوم ونثر الأبحاث ـ مجلة العلوم التربوية والنفسية ـ المجلد الخامس ـ العدد الخمسون ـ ديسمبر 2021م

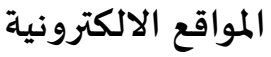

- https://mawdoo3.com-

- http://qattanfoundation.org/si 